\title{
Genetic polymorphisms in some biotransformation enzymes and their impact on head and neck cancer susceptibility
}

Citation for published version (APA):

Lacko, M. (2011). Genetic polymorphisms in some biotransformation enzymes and their impact on head and neck cancer susceptibility. [Doctoral Thesis, Maastricht University]. Datawyse / Universitaire Pers Maastricht. https://doi.org/10.26481/dis.20110623ml

Document status and date:

Published: 01/01/2011

DOI:

10.26481/dis.20110623ml

Document Version:

Publisher's PDF, also known as Version of record

\section{Please check the document version of this publication:}

- A submitted manuscript is the version of the article upon submission and before peer-review. There can be important differences between the submitted version and the official published version of record.

People interested in the research are advised to contact the author for the final version of the publication, or visit the DOI to the publisher's website.

- The final author version and the galley proof are versions of the publication after peer review.

- The final published version features the final layout of the paper including the volume, issue and page numbers.

Link to publication

\footnotetext{
General rights rights.

- You may freely distribute the URL identifying the publication in the public portal. please follow below link for the End User Agreement:

www.umlib.nl/taverne-license

Take down policy

If you believe that this document breaches copyright please contact us at:

repository@maastrichtuniversity.nl

providing details and we will investigate your claim.
}

Copyright and moral rights for the publications made accessible in the public portal are retained by the authors and/or other copyright owners and it is a condition of accessing publications that users recognise and abide by the legal requirements associated with these

- Users may download and print one copy of any publication from the public portal for the purpose of private study or research.

- You may not further distribute the material or use it for any profit-making activity or commercial gain

If the publication is distributed under the terms of Article $25 \mathrm{fa}$ of the Dutch Copyright Act, indicated by the "Taverne" license above, 
Genetic polymorphisms in some biotransformation enzymes and their impact on head and neck cancer susceptibility 
C 2011 M. Lacko, Maastricht, The Netherlands

\section{ISBN 9789461590596}

Production: Datawyse bv | Universitaire Pers Maastricht

Cover painting: Jan Steen (1625-1679), “Soo voer gesongen, soo na gepepen” (c.1665)

Publishing of this thesis was financially supported by:

Dutch sponsors: Atos Medical BV, Glaxo Smith Kline BV, Meditop Medical Products BV, Stallergenes BV Slovak sponsors: NovaMed spol. s r.o., European Club - Slovakia 


\title{
Genetic polymorphisms in some biotransformation enzymes and their impact on head and neck cancer susceptibility
}

\author{
PROEFSCHRIFT \\ Ter verkrijging van de graad van doctor \\ aan de Universiteit Maastricht, \\ op gezag van de Rector Magnificus, \\ Prof. mr. G.P.M.F. Mols.
}

volgens het besluit van het College van Decanen,

in het openbaar te verdedigen

op donderdag 23 juni 2011 om 16.00 uur

door

Martin Lacko

Geboren op 18 april 1966 te Banska Bystrica (Slowakije)

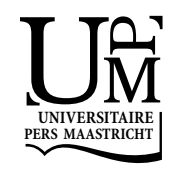




\section{Promotores:}

Prof. dr. J.J. Manni

Prof. dr. B. Kremer

\section{Copromotor:}

Dr. W.H.M. Peters (Universitair Medisch Centrum St. Radboud, Nijmegen)

\section{Beoordelingscommissie:}

Prof. dr. F.C.S. Ramaekers (voorzitter)

Prof. dr. A.J.M. Balm (Nederlands Kanker Instituut-AvL ziekenhuis, Amsterdam)

Prof. dr. M.F. von Meyenfeldt

Prof. dr. F.J. van Schooten 
To my wife Esther, to my children Lukas, Nicolai, Lara and to my parents 



\section{Contents}

\section{Chapter 1}

General introduction and outline of this thesis 9

\section{Chapter 2}

Microsomal epoxide hydrolase genotypes and the risk for head and neck cancer .. 29

\section{Chapter 3}

COX-2 polymorphisms and the risk for head and neck cancer in white patients...... 45

\section{Chapter 4}

Genetic polymorphisms in the tobacco smoke carcinogens detoxifying enzyme UGT1A7 and the risk of head and neck cancer.

\section{Chapter 5}

Genetic polymorphism in the conjugating enzyme UGT1A1 and the risk of head and neck cancer.

\section{Chapter 6}

Combined effect of genetic polymorphisms in phase I and II biotransformation enzymes on head and neck cancer risk

\section{Chapter 7}

Summary, future implications and perspectives of this research 107

Nederlandse samenvatting (Summary in Dutch) .............................................. 115

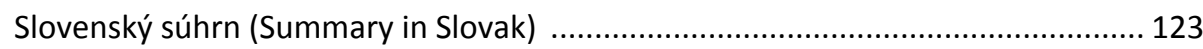

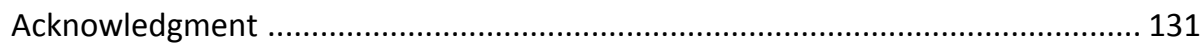

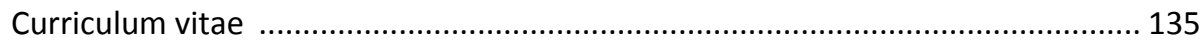





\section{Chapter 1 \\ General introduction and outline of this thesis}

Part of this chapter is published as:

Genetic polymorphisms of smoking-related carcinogen detoxifying enzymes and head and neck cancer susceptibility

Martin Lacko

Michael B. Oude Ophuis

Wilbert H.M. Peters

Johannes J. Manni

Anticancer Research 2009; 29: 753-761. 


\section{Introduction}

Squamous cell carcinoma of the head and neck (SCCHN) including cancer of the oral cavity, pharynx and larynx, worldwide accounts for about 650,000 new cases annually. Recent estimates have indicated that SCCHN is the fifth most common cancer, resulting in approximately 300,000 deaths annually. ${ }^{1}$ The incidence and mortality of SCCHN vary with geographical location, race and gender.

Exposure to tobacco and tobacco smoke, consumption of alcohol and infection by oncogenic serotypes of Human Papilloma Virus (HPV), are considered to be the most important etiological factors for the development of SCCHN. ${ }^{2-6}$ Poor oral hygiene, betel nut or shamma chewing, occupational exposure to carcinogenic chemicals as well as infection with Human Immunodeficiency Virus (HIV) or Ebstein-Barr Virus (EBV) are also associated with an increased risk of head and neck cancer. ${ }^{7-15}$

With 2346 new cases in 2006 in The Netherlands, SCCHN occupied the sixth place in the total cancer incidence ranking for men and the tenth place for women. SCCHN is responsible for $4.1 \%$ of the cancer incidence in this country. ${ }^{16}$

\section{Tobacco smoke induced carcinogenesis and genetic susceptibility}

The incidence of SCCHN in tobacco and alcohol consumers is significantly higher compared to non-consumers. More than 60 carcinogens have been identified in tobacco smoke and at least 16 in unburned tobacco. ${ }^{17}$ Polycyclic aromatic hydrocarbons (PAHs) such as benzo(a)pyrene (BaP) together with tobacco specific nitrosamines and aromatic amines are the most important tobacco related carcinogens. ${ }^{17}$

Although the chance of developing SCCHN increases with the level of tobacco smoking and alcohol consumption, it is obvious that not every (heavy) smoker and/or (excessive) alcohol consumer develops head and neck cancer. Not only the level of smoking, but also whether the (pro)carcinogens in tobacco smoke are activated or detoxified by phase I and phase II biotransformation enzymes present in the epithelial cells of the upper aerodigestive tract (UADT), will influence the extent of exposure of the UADT tract to carcinogens. The risk for an individual to develop SCCHN after exposure to tobacco carcinogens may therefore also depend on alterations in the activity of the biotransformation enzymes, (either increasing or decreasing) 
which may be the result of sequence variations in the genes (genetic polymorphisms) coding for these enzymes. This implies, that not only the exposure to the potential carcinogens, but also other factors such as genetically determined interindividual differences in the metabolism and excretion of tobacco smoke carcinogens as well as variation in the activity of other important enzymes involved in protection against cancer, may play an important role in the development of SCCHN. The presence of genetic susceptibility in the pathogenesis of SCCHN is strongly suggested by the higher incidence of these cancers in first-degree relatives of patients with SCCHN. ${ }^{18}$

Carcinogens and activated procarcinogens in tobacco smoke may react with the DNA of exposed tissues, such as the epithelial cells of the UADT. This can lead to the formation of DNA adducts and subsequently to mutations in crucial genes such as oncogenes or tumor suppressor genes, ultimately resulting in the development of cancer. ${ }^{19}$ However, as mentioned above, these processes may be under the influence of biotransformation or detoxification enzymes, which are essential for the metabolism and subsequent excretion of carcinogens. Detoxification of tobacco smoke (pro)carcinogens, together with DNA repair and apoptotic pathways for cells with deformed DNA, probably are the most important rescue pathways in preventing the development of tobacco induced SCCHN, ${ }^{17,20}$ (see Figure 1).

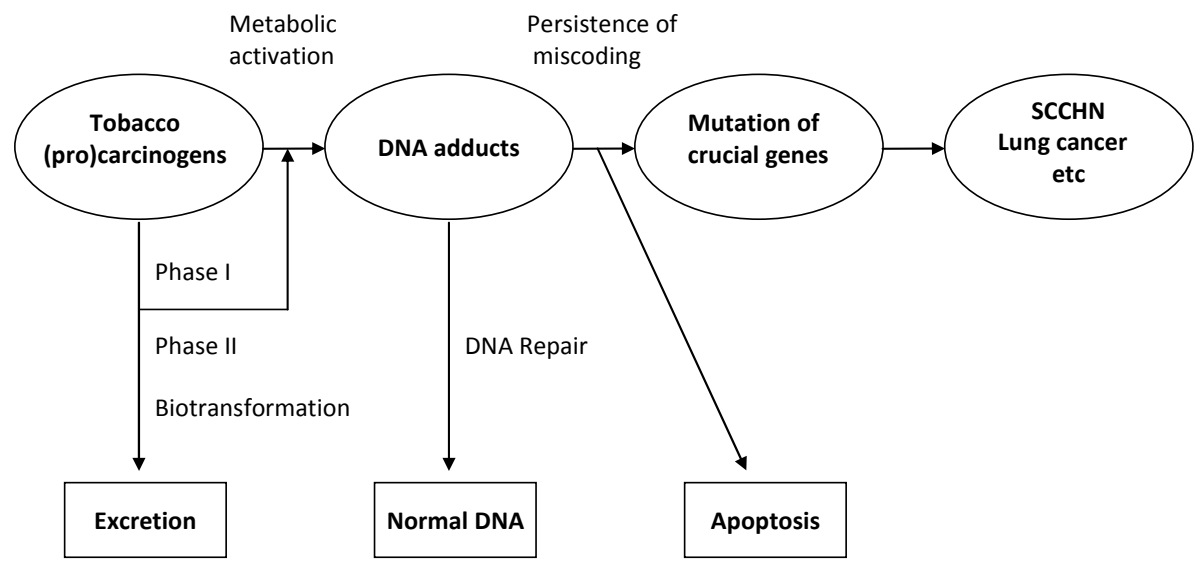

Figure 1. Simplified and modified scheme of tobacco smoke-related carcinogenesis. ${ }^{17}$ 
The biotransformation of many tobacco smoke (pro)carcinogens such as BaP takes place in two phases: transformation of the mostly lipophilic compounds into more polar molecules (phase I), followed by conjugation reactions (phase II). The latter conversion into more water-soluble compounds in general makes them less biologically active and facilitates the excretion of the toxins and carcinogens from the body, which diminishes the exposure of the tissues to these compounds.

However, the phase I reactions, mediated by enzymes such as cytochrome P-450 (CYP) and microsomal epoxide hydrolase $(\mathrm{mEH})$, often result in the formation of phenols, epoxides and other reactive intermediates, that eventually can be transformed into highly carcinogenic electrophilic compounds such as BaP-diolepoxides. ${ }^{21,22}$ These compounds, in the absence of a rapid further intervention by phase II conjugating enzymes such as glutathione S-transferases (GSTs) and uridine 5 '-diphosphate (UDP)-glucuronosyltransferases (UGTs), may form DNA adducts and subsequently initiate carcinogenesis (see Figure 2).

Since the UADT is in direct contact with potentially toxic and/or carcinogenic agents present in tobacco smoke, the mucosa of the UADT acts as a first-line barrier. Enzymes of the phase I and II biotransformation pathways present in the epithelial cells of the UADT therefore play an important role in the metabolism and the excretion of tobacco smoke (pro)carcinogens ${ }^{23}$ and protect this first-line barrier cells against these (pro)carcinogens.

The activity of the enzymes involved in biotransformation may differ between individuals. It is well-known now, that genetic polymorphisms like single nucleotide polymorphisms (SNPs) in the above mentioned enzymes occur, resulting in functional abnormalities, which may be one of the explanations for the differences in inter-individual susceptibility for the development of SCCHN. ${ }^{24-26}$

Genetic polymorphisms in these enzymes, which potentially might modify the susceptibility for head and neck cancer, are discussed below. 


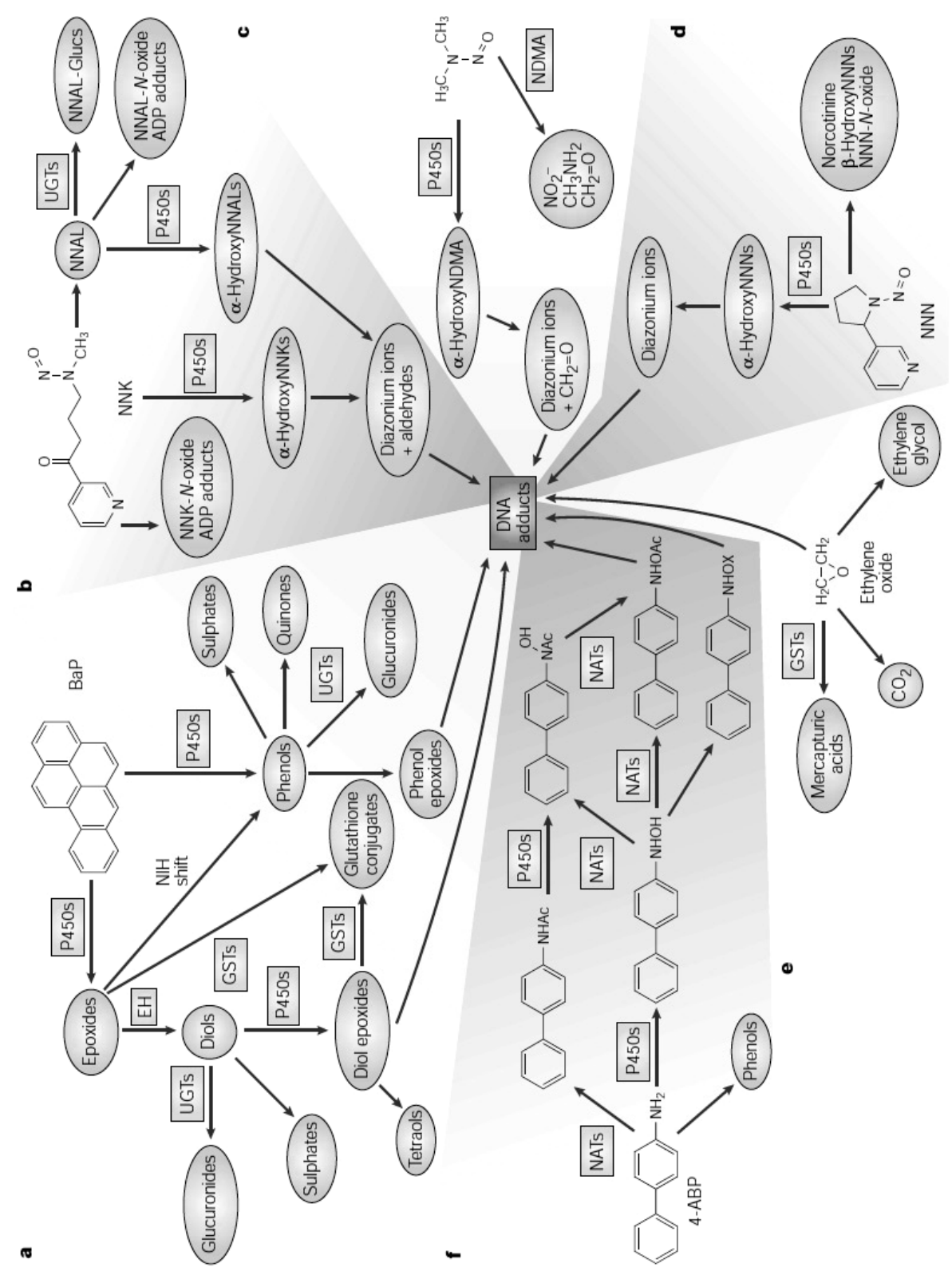

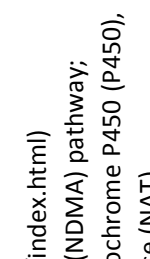

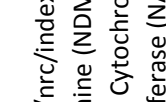
है है

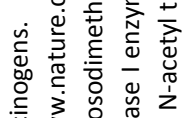

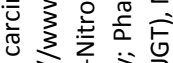

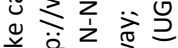

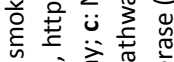
论

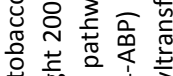

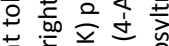
范

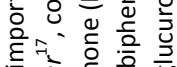

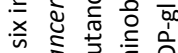

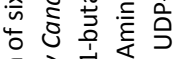

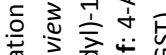

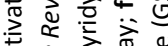

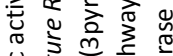

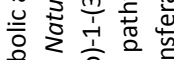

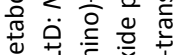

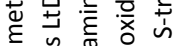
वे एँ

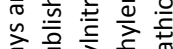

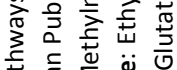
焉焉 을

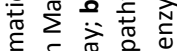

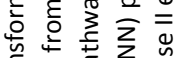

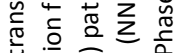

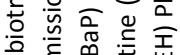

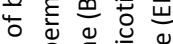

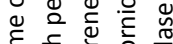
袺考 出要

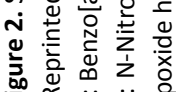




\section{Microsomal epoxide hydrolase (mEH)}

The $\mathrm{mEH}$ is one of the phase I enzymes involved in biotransformation and (de)toxification of potential tobacco smoke (pro)carcinogens. $\mathrm{mEH}$ is present in microsomes derived from the endoplasmatic reticulum and is highly expressed in most tissues, among them also the mucosa of the UADT. ${ }^{27,28}$ This enzyme has a role in both activation and detoxification of environmental (pro)carcinogens. $\mathrm{mEH}$ catalyzes the hydrolysis of reactive epoxide intermediates, in preparation for conjugation reactions (phase II detoxification) and excretion. However, in collaboration with CYP enzymes, $\mathrm{mEH}$ may activate the PAHs present in tobacco smoke, such as BaP, leading to highly reactive carcinogenic diol-epoxides. ${ }^{22,29}$

The gene coding for $\mathrm{mEH}$ (EPHX1) covers nine exons and is located on chromosome 1q42.1. There are two known amino acid-altering polymorphisms in the EPHX1 gene, which may lead to changes in $\mathrm{mEH}$ enzyme activity. The exon 3 polymorphism, with corresponding substitution of histidine for tyrosine at position 113 of the enzyme, is associated with a $40-50 \%$ decrease in $\mathrm{mEH}$ activity. ${ }^{30}$ The exon 4 polymorphism, with substitution of arginine for histidine at position 139 , may increase mEH activity by approximately $25 \%{ }^{30,}{ }^{31}$ According to Benhamou et al. the expected $\mathrm{mEH}$ activity can be classified as low, intermediate or high, depending on the combinations of the exon 3 and exon 4 polymorphisms on the two alleles, ${ }^{32}$ (see Table 2, Chapter 2). Because a higher activity of $\mathrm{mEH}$ can be associated with higher concentrations of carcinogenic diol-epoxides in the mucosa of the UADT, a subpopulation of tobacco smokers with the predicted high activity $\mathrm{mEH}$ polymorphisms, might have a higher risk of SCCHN compared to the subpopulations with intermediate or low $\mathrm{mEH}$ activity polymorphisms.

Several studies have investigated the role of $\mathrm{mEH}$ polymorphisms in head and neck carcinogenesis, $^{26,33-36}$ (see Table 4, Chapter 2). However, only Jourenkova-Mironova et al. found a significant increased risk of oral, pharyngeal and laryngeal cancer in their study population of French Caucasian smokers with predicted high and intermediate $\mathrm{mEH}$ activity polymorphisms, as compared to the predicted low $\mathrm{mEH}$ activity subpopulation. ${ }^{26}$ Park et al. found that the predicted high $\mathrm{mEH}$ activity polymorphisms were significantly associated with an increased risk for oral and laryngeal cancer only in heavy smoking (>35 packyears) Caucasians, but not in AfricanAmerican subjects. ${ }^{33}$ Unfortunately, they did not report on the predicted $\mathrm{mEH}$ activ- 
ity (low, intermediate, high) and oropharyngeal cancer risk in their population. Amador et al. observed a higher incidence of the predicted high activity $\mathrm{mEH}$ Tyr/Tyr genotype in patients with oropharyngeal cancer as compared to a control population. ${ }^{35}$ Wenghoefer et al. found no association between the $\mathrm{mEH}$ polymorphisms with predicted high enzyme activity and an increased risk for SCCHN. ${ }^{34}$ ToFigueras et al. reported an increased risk of laryngeal cancer among a SpanishCaucasian study population with predicted high $\mathrm{mEH}$ activity genotypes in combination with the 105lle/105lle variant of glutathione S-transferase P1 (GSTP1). ${ }^{36}$ However, none of the $\mathrm{mEH}$ polymorphisms alone were associated with an altered risk of laryngeal cancer.

Baxter et $a I^{37}$ recently suggested that the PCR-restriction fragment length polymorphism (PCR-RFLP) assay, which was often used in the exon $3 \mathrm{mEH}$ genotyping research, might be unreliable. Due to the possible presence of an additional polymorphism in codon 119 , the use of a primer adhering to the region containing codon 119 might falsely lead to an apparent $113 \mathrm{His} / \mathrm{His}$ genotype instead of the 113 His/Tyr variant. The methods applied by Jourenkova-Mironova et al., ${ }^{26}$ Park et al. ${ }^{33}$ and Amador et al. ${ }^{35}$ may be inaccurate because of the use of a primer covering codon 119, whereas the methods for estimating the exon 3 polymorphism applied by Wenghoefer et al. $^{34}$ and To-Figueras et al. $^{36}$ were not potentially inaccurate, since no primer adhering to codon 119 was used here.

\section{Glutathione and glutathione S-transferases (GSTs)}

Glutathione (GSH) is an intracellular thiol that neutralizes (pro)carcinogenic and highly reactive electrophilic compounds, a process catalyzed by GSTs. GSTs are a family of cytosolic enzymes, involved in phase II biotransformation. ${ }^{38,39} \mathrm{GSH}$ is produced mainly in the liver (hepatocytes), by coupling of the amino acids glycine, cysteine and glutamic acid. ${ }^{40}$ Hepatic glutathione is transported to most other tissues via the blood. ${ }^{40}$ High levels of glutathione have been demonstrated in mucosal cells of oral/oropharyngeal and laryngeal tissues. ${ }^{41}$ When the GSH production is reduced or GSH is depleted, reactive electrophilic compounds may freely circulate and may cause damage of DNA or other important biomolecules. Since detoxification by GSH is strongly dependent on the GST enzymes, a reduction or deficiency of GST isoforms may also result in more DNA damage. ${ }^{38,40,42}$ Any factor that may disturb the 
process of detoxification can result in increased levels of carcinogens and in a higher cancer risk. In this way GSH and GSTs may regulate the ability of each individual to metabolize environmental (pro)carcinogens, such as those of tobacco smoke.

The cytosolic GST family comprises seven classes and at least 16 different enzymes. The genes corresponding to these enzymes are mapped on different chromosomes. ${ }^{38}$ A limited number of the GSTs have been shown to be expressed in head and neck tissues. GSTA1/A2, GSTM1 or GSTP1 were detected in $91 \%, 64 \%$ and $100 \%$ of normal laryngeal tissues, respectively. ${ }^{41}$ In contrast, in oral and oropharyngeal normal mucosa, GSTP1 was expressed at high levels in all 14 different specimens investigated, whereas GSTM1 and GSTA1/A2 were only expressed at very low levels. ${ }^{41}$ In the corresponding tumor tissues, GSTP1 appeared overexpressed, whereas the expression of GSTM1 and GSTA1/A2 was diminished even further. ${ }^{41}$

Genetic polymorphisms, mostly resulting in a significant reduction of corresponding enzyme activities, have been described in GSTM1, GSTT1, GSTP1 and GSTA1. For GSTM1 and GSTT1, null polymorphisms may be present, resulting in the complete absence of enzyme activity. ${ }^{43,44}$ The fact that GSTM1 and GSTT1 null genotypes in Caucasians are common (approximately 50 and 20\%, respectively), implies that their co-occurrence is also relatively common. Thus approximately $10 \%$ of the individuals are missing both enzymes, which could possibly contribute to the susceptibility of SCCHN. $^{39}$

GSTP1-1, the only member of the GSTP class in humans, appears to be the most widely distributed isoenzyme of all GSTs ${ }^{42}$ and it is probably also the most abundant form in head and neck mucosal tissues. ${ }^{41}$ As reported by Sundberg et al., GSTP1-1 has selective and high activity towards the carcinogenic epoxide of BaP. ${ }^{45} \mathrm{~A}$ functional polymorphism has been described for the GSTP1 gene at codon 105, where an isoleucine to valine substitution may result in considerable loss of the corresponding GSTP1-1 enzyme activity. ${ }^{46,47}$

A promoter polymorphism in GSTA1 is also widespread ${ }^{48}$ and may have significant consequences for the expression of the corresponding enzyme, but it has not been studied yet in patients with head and neck cancer. Since GSTA is highly expressed in laryngeal tissues, ${ }^{41}$ a study on this polymorphism would be highly desirable in patients with laryngeal cancer. 
The studies on GSTM1, GSTT1 and GSTP1 polymorphisms in relation to head and neck cancer have been recently reviewed by Hashibe et al., in a meta-analysis of 31 case-control studies, covering 4635 head and neck cancer patients and 5770 controls. $^{39}$ The results are summarised as follows: the GSTM1 null, GSTT1 null and GSTP1 Ile105Val genotype frequencies were highly variable in the populations of SCCHN cases (range $43-80 \%$ for GSTM1 null, 12-58\% for GSTT1 null and 29-66\% for the GSTP1 Val105 allele frequencies). ${ }^{39}$ However, similar variable frequencies were also seen in the corresponding control populations studied (25-58\% for the GSTM1 null genotype, 8-53\% for GSTT1 null genotype and 24-65\% for the GSTP1 Val105 allele frequencies). When patients were selected according to SCCHN tumor site, a similar variation in GST polymorphism frequencies was reported.

SCCHN susceptibility of individuals with the GSTT1 or GSTM1 null genotype separately, appears to be slightly higher as compared with non-null genotype individuals, with pooled odds ratios of 1.25 (95\% Cl: $1.00-1.57)$ and 1.32 (95\% Cl: 1.07-1.62), respectively, while carrying the GSTP1 Val105 allele does not seem to increase the risk (see Table 1). However, a considerable increased risk of head and neck cancer was observed when the combination of GSTT1 null, GSTM1 null and GSTP1 Val105 was present, with an odds ratio of 2.06 (95\% Cl: 1.11-3.81). ${ }^{39}$

Table 1. Pooled analysis of case-control studies on GSTM1, GSTT1 and GSTP1 genotypes and risk for head and neck cancer. *

\begin{tabular}{|c|c|c|c|}
\hline & GSTM1 (null) & GSTT1 (null) & GSTP1 (any Val105) \\
\hline Number of studies & 11 & 8 & 5 \\
\hline Cases/controls & $2224 / 2517$ & $1929 / 1830$ & $1164 / 982$ \\
\hline Summary OR $(95 \% \mathrm{Cl})$ & 1.32 (1.07-1.62) & $1.25(1.00-1.57)$ & $1.15(0.86-1.53)$ \\
\hline \multicolumn{4}{|l|}{ Oral cancer } \\
\hline OR $(95 \% \mathrm{Cl})$ & 1.20 (0.89-1.63) & $1.34(0.99-1.82)$ & $1.37(0.88-2.14)$ \\
\hline \multicolumn{4}{|l|}{ Pharyngeal cancer } \\
\hline OR $(95 \% \mathrm{Cl})$ & $1.25(0.98-1.61)$ & $1.11(0.66-1.87)$ & $1.10(0.58-2.05)$ \\
\hline \multicolumn{4}{|l|}{ Laryngeal cancer } \\
\hline OR $(95 \% \mathrm{Cl})$ & $1.53(1.17-2.00)$ & 1.10 (0.81-1.49) & $1.08(0.81-1.44)$ \\
\hline \multicolumn{4}{|l|}{ Never smokers } \\
\hline OR $(95 \% \mathrm{Cl})$ & $1.58(1.11-2.23)$ & 1.29 (0.83-1.99) & $1.38(0.46-4.12)$ \\
\hline \multicolumn{4}{|l|}{ Ever smokers } \\
\hline OR $(95 \% \mathrm{Cl})$ & 1.33 (1.01-1.74) & $1.23(0.77-1.94)$ & $1.01(0.76-1.33)$ \\
\hline \multicolumn{4}{|l|}{ Caucasian } \\
\hline OR $(95 \% \mathrm{Cl})$ & $1.19(0.93-1.51)$ & $1.17(0.91-1.50)$ & $1.15(0.86-1.54)$ \\
\hline
\end{tabular}

* Data are from ref. ${ }^{39}$

Abbreviations: GSTM1-gene coding for glutathione S-transferase (GST) M1, GSTT1- gene coding for GSTT1, GSTP1-gene coding for GSTP1, Ile-Isoleucine, Val-Valine, OR- odds ratio, Cl-confidence interval. OR's were adjusted for age, gender and race. 
Three additional studies on GST polymorphisms in association with SCCHN have appeared after the publication of the meta-analysis of Hashibe et al.; two studies dealing with very low numbers of patients, 42 and 83 patients in the studies by Unal et $a .^{49}$ and Konig-Greger et al., ${ }^{50}$ respectively, and one study by our own group, dealing with 185 patients. ${ }^{51}$ However, the findings in these three studies do not alter the general conclusions as described above.

A recent review by Ho et al. ${ }^{52}$ also summarized the results of studies on GST polymorphisms in association with the risk for SCCHN, and again the conclusions were very similar to those presented above.

\section{Uridine 5'-diphosphate (UDP)-glucuronosyltransferases (UGTs)}

UGTs belong to a superfamily of membrane bound phase II enzymes localized in the endoplasmatic reticulum. UGTs catalyze the conjugation of mainly lipophilic substrates with UDP-glucuronic acid (glucuronidation) to form more polar conjugates, that can be easily excreted via the biliary or renal route. Several members of the UGT family are involved in metabolic and detoxification pathways of (pro)carcinogens present in tobacco smoke, such as the glucuronidation of (pro)carcinogenic $\mathrm{BaP}$ metabolites and phenols. Hereby the concentration of such metabolites will be diminished, thus reducing the risk of forming DNA-adducts and cancer. ${ }^{17}$

The genes encoding the various human UGTs have been assigned to four families: UGT1, UGT2, UGT3 and UGT8. ${ }^{53}$ Because, the catalytic and physiological functions of the human UGT3 family enzymes and their distribution in human tissue have not been characterized yet and since the UGT8 enzyme is not involved in detoxification, but has a biosynthetic role (e.g. synthesis of cell-membrane), ${ }^{54}$ the research on UGT genotypes in association with the susceptibility for SCCHN until now has been limited to the genes of UGT1 and UGT2 family. ${ }^{53}$

The UGT1 family enzymes are all derived from a single combined gene, located on chromosome $2 \mathrm{q} 37^{55}$ which encodes for nine functional genes: UGT1A1 and UGT1A3 - UGT1A10. The UGT2 family enzymes are encoded by six separate genes located on chromosome 4q13-q28, resulting in the following enzymes: UGT2B4, UGT2B7, UGT2B10, UGT2B11, UGT2B15 and UGT2B17. 
The expression of the UGT enzymes is tissue specific, but the factors that govern this specificity remain largely unknown. The expression of UGT enzymes in the mucosa of the upper aerodigestive tract has been studied by semiquantitative reverse transcription polymerase chain reaction, which revealed that UGT1A7 and UGT1A10 mRNAs were well expressed in the tongue, tonsil, floor of mouth, larynx and oesophagus, whereas UGT1A8 and UGT1A6 mRNAs were expressed primarily in the larynx. Of the UGT2 family, only UGT2B4 and UGT2B17 exhibited significant mRNA expression levels in tissues of the upper aerodigestive tract. ${ }^{23}$ UGT1A7, UGT1A8, and UGT1A10 were shown to exhibit glucuronidation activity towards metabolites of tobacco smoke (pro)carcinogens such as hydroxylated BaP, whereas UGT1A10 exhibits the highest affinity for this substrate. ${ }^{23,56}$

Three studies on the relationship between UGT1A polymorphisms and head and neck cancer risk have been published until now (see Table 2). The UGT1A7 gene is highly polymorphic and eleven allelic variants in four different codons of this gene have been described so far: UGT1A7 ${ }^{*} 1-11 .{ }^{57}$ Zheng et al. ${ }^{25}$ have found that individuals (Caucasians as well as African-Americans) with any of the predicted lowactivity UGT1A7 genotypes had an increased risk of orolaryngeal cancer, results that were confirmed by Vogel et al. ${ }^{58}$. However, both studies dealt with only a relatively low number of patients (194 patients, Zheng et al.; 76 patients, Vogel et al.).

Considering the UGT1A10 polymorphisms, three functional polymorphisms in codons 139, 240 and 244 have been discovered so far. Elahi et al. found that the allelic prevalence of the codon 240 polymorphism in healthy African-Americans as well as in Caucasians was less than 1\%, whereas the prevalence of the codon 139 and 244 polymorphisms was much higher in African-Americans as compared to Caucasians. None of these polymorphisms were observed in East Asian or Indian individuals. ${ }^{56}$ By studying 115 black African-American patient/control pairs, Elahi et al. observed a decreased risk of oral and laryngeal cancer in individuals with the codon 139 polymorphism of UGT1A10, resulting in a glutamic acid to lysine amino acid change. ${ }^{56}$

The polymorphisms in the two UGT genes (UGT1A7 and UGT1A10) studied until now have both been claimed to modulate individual susceptibility to SCCHN. 
Table 2. Case-control studies on UGT1A7 and UGT1A10 polymorphisms and risk for upper aerodigestive tract cancer.

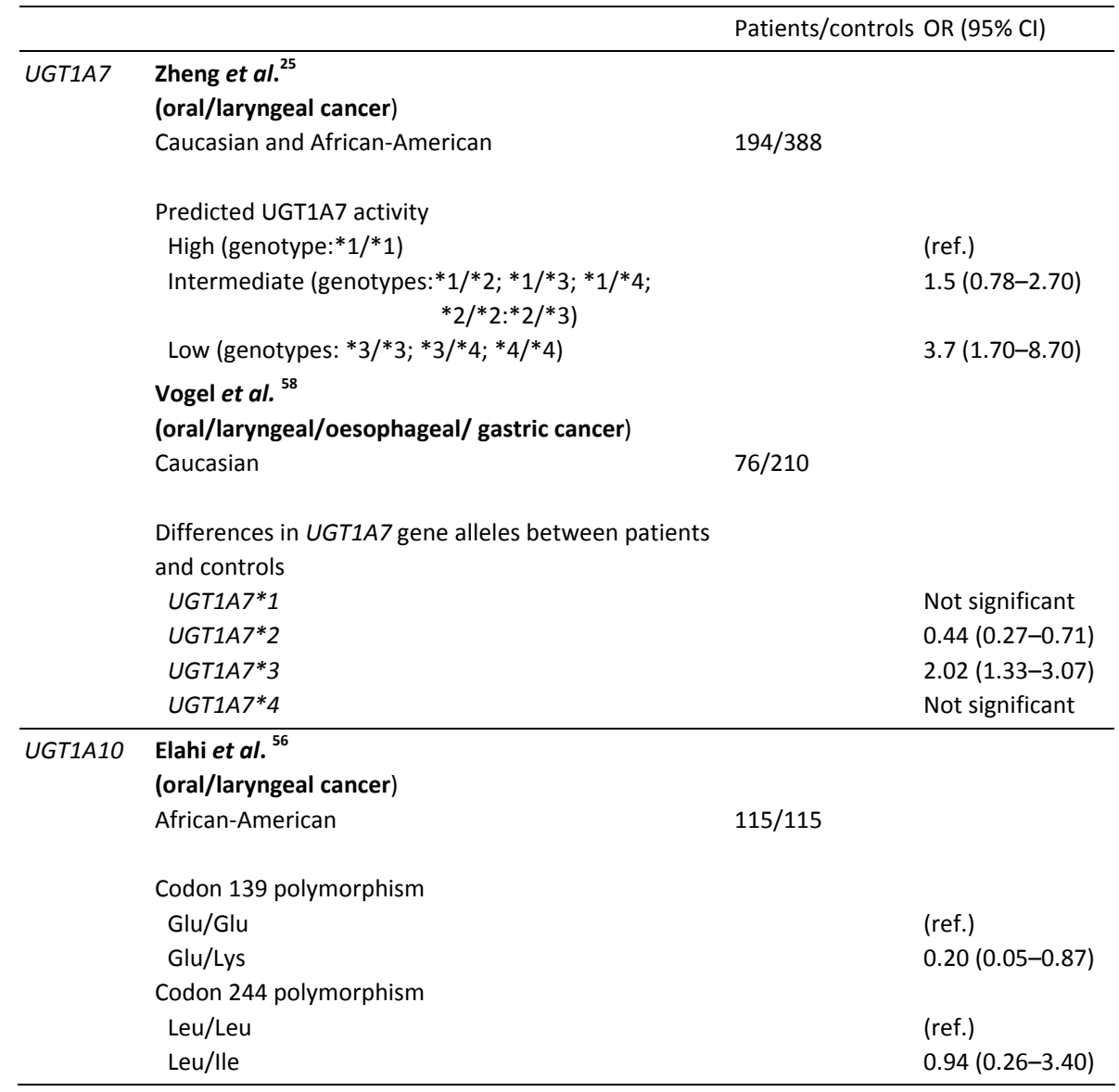

Abbreviations: UGT1A7- gene coding for UDP-glucuronosyltransferase 1A7, UGT1A10- gene coding for UDP-glucuronosyltransferase $1 \mathrm{~A} 10$, OR-odds ratio, $\mathrm{Cl}$-confidence interval.

\section{Cyclooxygenase-2 (COX-2)}

Cyclooxygenases (COXs) or prostaglandin $\mathrm{G}$ and $\mathrm{H}$ synthases are phase I enzymes which are not directly involved in biotransformation and elimination of tobacco smoke (pro)carcinogens. However, COXs catalyse the biosynthesis of prostaglandins (PGs) PGG2 and PGH2, involved in the regulation of many biological reactions and processes like inflammation, pain, fever, cell proliferation, angiogenesis and others. Some of these processes are also important for carcinogenesis. ${ }^{59-63}$ Activation of 
COX-2 gene by the epidermal growth factor receptor (EGFR) pathway probably initiates involvement of COX-2 in these carcinogenic processes. ${ }^{64,65}$

The COX family consist of two main isoenzymes: COX-1 and COX-2. COX-1 is constitutively expressed in most tissue cells and provides PGs required for maintaining of physiological homeostatic functions like haemostasis or gastric cytoprotection. On the other hand, COX-2 is responsible for synthesis of PGs involved in pathophysiological processes like inflammation and carcinogenesis, by stimulation of hyperproliferation, transformation, invasion and metastasis. ${ }^{66,67}$ However, recent data suggest, that this original paradigm considering the functional differences of COX-1 (homeostatic) and COX-2 (pathophysiological) might be partially oversimplified. ${ }^{68}$

Expression of the COX-2 gene is inducible by proinflammatory and mitogenic stimuli like cytokines and growth factors. ${ }^{69}$ Increased expression of $\mathrm{COX}-2$ has been seen in cancers of several organs like skin, stomach, oesophagus, colorectum, lung, breast, urinary tract, but also in head and neck cancer. ${ }^{70-78}$

Interestingly, inhibitors of COX and more specific COX-2, may decrease the risk to develop some of these cancer types. ${ }^{79,80}$ The mechanisms of this anticarinogenic effect of COX inhibitors is not completely revealed yet, but inhibition of angiogenesis or stimulation of apoptosis might be an explanation for this phenomenon. ${ }^{81}$ One can postulate, that certain conditions, like presence of genetic polymorphisms altering the expression of the COX-2 gene (or altering the COX-2 protein configuration) with consequences for the functioning of this enzyme, might have also a risk modifying effect on carcinogenesis.

Although in Caucasians no non-synonymous polymorphisms in the COX-2 gene have been identified yet, ${ }^{80}$ three single nucleotide polymorphisms (SNPs) commonly occur in the promoter region of this gene. ${ }^{82-84}$ Two of these promoter polymorphisms: $-765 G \rightarrow C$ (replacement of Guanine by Cytosine at the base position -765) and $-1195 A \rightarrow G$ (replacement of Adenine by Guanine at base position -1195) did reveal a significantly reduced gene expression when compared to the wild type genotype. However, no significant effect of the third SNP $(-1290 A \rightarrow G)$ on the COX-2 promoter activity was observed. ${ }^{82}$ 
Recent data showed that the above mentioned $-765 G \rightarrow C$ and $-1195 A \rightarrow G$ polymorphisms indeed may play a risk modifying role in oesophageal carcinogenesis in an Asian population. ${ }^{82}$

Despite the fact that COX-2 was shown to be present in head and neck cancer tissue and despite some evidence that this enzyme might be involved in head and neck carcinogenesis, ${ }^{85,86}$ limited data on a possible association between the above mentioned genetic polymorphisms of the COX-2 promoter and head and neck cancer susceptibility are available until now. ${ }^{87}$

\section{Aim of the thesis}

Various genetic polymorphisms (variations in a particular gene) are present in each individual. In most of the cases it considers a substitution of a single nucleotide (single nucleotide polymorphism; SNP), or presence of the so called microsatellites or tandem repeats, consisting of different numbers of repeats of short sequences of 2-8 base pairs (bp), such as dinucleotide thymine-adenine repeats (TATA repeats). Some of these genetic polymorphisms lead to alteration, or even complete absence of the function of the proteins (enzymes) coded by those genes. Polymorphisms present in the genes coding for the phase I and II biotransformation (detoxification) enzymes, which are potentially involved in the process of carcinogenesis, might alter their function and therefore might influence the susceptibility of an individual for head and neck cancer. This phenomenon might explain the differences in the individual risk for this disease.

To detect the risk modifying effect of genetic polymorphisms in selected biotransformation enzymes for head and neck carcinogenesis, we performed case-control studies investigating the differences in the prevalence of genetic polymorphisms in the genes coding for these enzymes between patients with carcinomas of the oral cavity, oropharynx, hypopharynx or larynx and healthy controls.

\section{Outline of the thesis}

Chapter $\mathbf{1}$ is a general introduction for this thesis. This chapter provides a theoretical background about potential risk modifying effects of genetic polymorphisms in several biotransformation enzymes for head and neck carcinogenesis. 
In Chapter 2 the results on the relation between head and neck cancer susceptibility and genetic polymorphisms in $\mathrm{MEH}$ are described.

The COX-2 gene promoter polymorphisms in relation to the head and neck cancer risk is described in Chapter 3.

Chapters $\mathbf{4}$ and $\mathbf{5}$ deal with head and neck cancer susceptibility and genetic polymorphisms in UGT1A7 and UGT1A1, respectively.

Chapter 6 shows the results of the interactive risk modifying effects of polymorphisms in $M E H$ or COX-2, with polymorphisms in genes from the UGT family (UGT1A1, UGT1A6, UGT1A7, UGT1A8, UGT2B4, UGT2B7, UGT2B17) in head and neck carcinogenesis.

Chapter 7 includes a summary, future implications and perspectives of this research.

\section{References}

1. Parkin DM, Bray F, Ferlay J, Pisani P. Global cancer statistics, 2002. CA Cancer J Clin 2005;55:74-108.

2. Maier H, Dietz A, Gewelke U, Heller WD, Weidauer H. Tobacco and alcohol and the risk of head and neck cancer. Clin Investig 1992;70:320-327.

3. Riedel F, Goessler U, Hormann K. Alcohol-related diseases of the mouth and throat. Best Pract Res Clin Gastroenterol 2003;17:543-555.

4. Vidal L, Gillison ML. Human papillomavirus in HNSCC: recognition of a distinct disease type. Hematol Oncol Clin North Am 2008;22:1125-1142, vii.

5. Raitiola HS, Pukander JS. Etiological factors of laryngeal cancer. Acta Otolaryngol Suppl 1997;529:215-217.

6. Rothman KJ. Epidemiology of head and neck cancer. Laryngoscope 1978;88:435-438.

7. Meurman JH, Uittamo J. Oral micro-organisms in the etiology of cancer. Acta Odontol Scand 2008;66:321-326.

8. Lin YS, Jen YM, Wang BB, Lee JC, Kang BH. Epidemiology of oral cavity cancer in taiwan with emphasis on the role of betel nut chewing. ORL J Otorhinolaryngol Relat Spec 2005;67:230-236.

9. Sturgis EM, Pytynia KB. After the smoke clears: environmental and occupational risks for carcinoma of the upper aerodigestive tract. Cancer J 2005;11:96-103.

10. Gustavsson P, Jakobsson R, Johansson H, Lewin F, Norell S, Rutkvist LE. Occupational exposures and squamous cell carcinoma of the oral cavity, pharynx, larynx, and oesophagus: a case-control study in Sweden. Occup Environ Med 1998;55:393-400.

11. Gillison ML. Oropharyngeal cancer: a potential consequence of concomitant HPV and HIV infection. Curr Opin Oncol 2009;21:439-444. 
12. Powles $\mathrm{T}$, Powles J, Nelson $\mathrm{M}$, et al. Head and neck cancer in patients with human immunodeficiency virus-1 infection: incidence, outcome and association with Epstein-Barr virus. J Laryngol Otol 2004;118:207-212.

13. Tumino R, Vicario G. Head and neck cancers: oral cavity, pharynx, and larynx. Epidemiol Prev 2004;28(Suppl):28-33.

14. Abdulamir AS, Hafidh RR, Abdulmuhaimen N, Abubakar F, Abbas KA. The distinctive profile of risk factors of nasopharyngeal carcinoma in comparison with other head and neck cancer types. BMC Public Health 2008;8:400.

15. Al-Rajhi N, Khafaga Y, El-Husseiny J, et al. Early stage carcinoma of oral tongue: prognostic factors for local control and survival. Oral Oncol 2000;36:508-514.

16. Dutch Cancer Registration Database 2009, www.ikcnet.nl

17. Hecht SS. Tobacco carcinogens, their biomarkers and tobacco-induced cancer. Nat Rev Cancer 2003;3:733-744.

18. Foulkes WD, Brunet JS, Sieh W, Black MJ, Shenouda G, Narod SA. Familial risks of squamous cell carcinoma of the head and neck: retrospective case-control study. BMJ 1996;313:716-721.

19. Pfeifer GP, Denissenko MF, Olivier M, Tretyakova N, Hecht SS, Hainaut P. Tobacco smoke carcinogens, DNA damage and p53 mutations in smoking-associated cancers. Oncogene 2002;21:74357451.

20. Hoeijmakers JH. Genome maintenance mechanisms for preventing cancer. Nature 2001;411:366374.

21. Gelboin HV. Benzo[alpha]pyrene metabolism, activation and carcinogenesis: role and regulation of mixed-function oxidases and related enzymes. Physiol Rev 1980;60:1107-66.

22. Pelkonen O, Nebert DW. Metabolism of polycyclic aromatic hydrocarbons: etiologic role in carcinogenesis. Pharmacol Rev 1982;34:189-222.

23. Zheng Z, Fang JL, Lazarus P. Glucuronidation: an important mechanism for detoxification of benzo[a]pyrene metabolites in aerodigestive tract tissues. Drug Metab Dispos 2002;30:397-403.

24. Ye Z, Song H, Guo Y. Glutathione S-transferase M1, T1 status and the risk of head and neck cancer: a meta-analysis. J Med Genet 2004;41:360-365.

25. Zheng Z, Park JY, Guillemette C, Schantz SP, Lazarus P. Tobacco carcinogen-detoxifying enzyme UGT1A7 and its association with orolaryngeal cancer risk. J Natl Cancer Inst 2001;93:1411-1418.

26. Jourenkova-Mironova N, Mitrunen K, Bouchardy C, Dayer P, Benhamou S, Hirvonen A. High-activity microsomal epoxide hydrolase genotypes and the risk of oral, pharynx, and larynx cancers. Cancer Res 2000;60:534-536.

27. Omiecinski CJ, Aicher L, Holubkov R, Checkoway H. Human peripheral lymphocytes as indicators of microsomal epoxide hydrolase activity in liver and lung. Pharmacogenetics 1993;3:150-158.

28. Janot F, Massaad L, Ribrag V, et al. Principal xenobiotic-metabolizing enzyme systems in human head and neck squamous cell carcinoma. Carcinogenesis 1993;14:1279-1283.

29. Conney $\mathrm{AH}$. Induction of microsomal enzymes by foreign chemicals and carcinogenesis by polycyclic aromatic hydrocarbons: G. H. A. Clowes Memorial Lecture. Cancer Res 1982;42:4875-4917.

30. Hassett C, Aicher L, Sidhu JS, Omiecinski CJ. Human microsomal epoxide hydrolase: genetic polymorphism and functional expression in vitro of amino acid variants. Hum Mol Genet 1994;3:421-428.

31. Hassett C, Lin J, Carty CL, Laurenzana EM, Omiecinski CJ. Human hepatic microsomal epoxide hydrolase: comparative analysis of polymorphic expression. Arch Biochem Biophys 1997;337:275-283.

32. Benhamou S, Reinikainen M, Bouchardy C, Dayer P, Hirvonen A. Association between lung cancer and microsomal epoxide hydrolase genotypes. Cancer Res 1998;58:5291-5293.

33. Park JY, Schantz SP, Lazarus P. Epoxide hydrolase genotype and orolaryngeal cancer risk: interaction with GSTM1 genotype. Oral Oncol 2003;39:483-490.

34. Wenghoefer M, Pesch B, Harth V, et al. Association between head and neck cancer and microsomal epoxide hydrolase genotypes. Arch Toxicol 2003;77:37-41.

35. Amador AG, Righi PD, Radpour S, et al. Polymorphisms of xenobiotic metabolizing genes in oropharyngeal carcinoma. Oral Surg Oral Med Oral Pathol Oral Radiol Endod 2002;93:440-445. 
36. To-Figueras J, Gene M, Gomez-Catalan J, et al. Microsomal epoxide hydrolase and glutathione Stransferase polymorphisms in relation to laryngeal carcinoma risk. Cancer Lett 2002;187:95-101.

37. Baxter SW, Choong DY, Campbell IG. Microsomal epoxide hydrolase polymorphism and susceptibility to ovarian cancer. Cancer Lett 2002;177:75-81.

38. Hayes JD, Flanagan JU, Jowsey IR. Glutathione transferases. Annu Rev Pharmacol Toxicol 2005;45:51-88.

39. Hashibe M, Brennan P, Strange RC, et al. Meta- and pooled analyses of GSTM1, GSTT1, GSTP1, and CYP1A1 genotypes and risk of head and neck cancer. Cancer Epidemiol Biomarkers Prev 2003;12:1509-1517.

40. Meister A. Glutathione metabolism and its selective modification. J Biol Chem 1988;263:17205-8.

41. Mulder TP, Manni JJ, Roelofs HM, Peters WH, Wiersma A. Glutathione S-transferases and glutathione in human head and neck cancer. Carcinogenesis 1995;16:619-624.

42. Hayes JD, Pulford DJ. The glutathione S-transferase supergene family: regulation of GST and the contribution of the isoenzymes to cancer chemoprotection and drug resistance. Crit Rev Biochem Mol Biol 1995;30:445-600.

43. Brockmoller J, Kerb R, Drakoulis N, Nitz M, Roots I. Genotype and phenotype of glutathione Stransferase class $\mathrm{mu}$ isoenzymes $\mathrm{mu}$ and psi in lung cancer patients and controls. Cancer Res 1993;53:1004-1011.

44. Pemble S, Schroeder KR, Spencer SR, et al. Human glutathione S-transferase theta (GSTT1): cDNA cloning and the characterization of a genetic polymorphism. Biochem J 1994;300:271-276.

45. Sundberg K, Johansson AS, Stenberg G, et al. Differences in the catalytic efficiencies of allelic variants of glutathione transferase P1-1 towards carcinogenic diol epoxides of polycyclic aromatic hydrocarbons. Carcinogenesis 1998;19:433-436.

46. Watson MA, Stewart RK, Smith GB, Massey TE, Bell DA. Human glutathione S-transferase P1 polymorphisms: relationship to lung tissue enzyme activity and population frequency distribution. Carcinogenesis 1998;19:275-280.

47. van Lieshout EM, Roelofs HM, Dekker S, et al. Polymorphic expression of the glutathione Stransferase P1 gene and its susceptibility to Barrett's esophagus and esophageal carcinoma. Cancer Res 1999;59:586-589.

48. Coles BF, Morel F, Rauch C, et al. Effect of polymorphism in the human glutathione S-transferase A1 promoter on hepatic GSTA1 and GSTA2 expression. Pharmacogenetics 2001;11:663-669.

49. Unal M, Tamer L, Ates NA, et al. Glutathione S-transferase M1, T1, and P1 gene polymorphism in laryngeal squamous cell carcinoma. Am J Otolaryngol 2004;25:318-322.

50. Konig-Greger D, Riechelmann H, Wittich U, Gronau S. Genotype and phenotype of glutathione-Stransferase in patients with head and neck carcinoma. Otolaryngol Head Neck Surg 2004;130:718725 .

51. Oude Ophuis MB, Manni JJ, Peters WH. Glutathione S-transferase T1 null polymorphism and the risk for head and neck cancer. Acta Otolaryngol 2006;126:311-317.

52. Ho T, Wei Q, Sturgis EM. Epidemiology of carcinogen metabolism genes and risk of squamous cell carcinoma of the head and neck. Head Neck 2007;29:682-699.

53. Mackenzie PI, Bock KW, Burchell B, et al. Nomenclature update for the mammalian UDP glycosyltransferase (UGT) gene superfamily. Pharmacogenet Genomics 2005;15:677-685.

54. Stoffel W, Bosio A. Myelin glycolipids and their functions. Curr Opin Neurobiol 1997;7:654-661.

55. Owens IS, Ritter JK. The novel bilirubin/phenol UDP-glucuronosyltransferase UGT1 gene locus: implications for multiple nonhemolytic familial hyperbilirubinemia phenotypes. Pharmacogenetics 1992;2:93-108.

56. Elahi A, Bendaly J, Zheng Z, et al. Detection of UGT1A10 polymorphisms and their association with orolaryngeal carcinoma risk. Cancer 2003;98:872-880.

57. Verlaan M, Drenth JP, Truninger K, et al. Polymorphisms of UDP-glucuronosyltransferase $1 \mathrm{~A} 7$ are not involved in pancreatic diseases. J Med Genet 2005;42:e62. 
58. Vogel A, Ockenga J, Ehmer U, et al. Polymorphisms of the carcinogen detoxifying UDPglucuronosyltransferase UGT1A7 in proximal digestive tract cancer. Z Gastroenterol 2002;40:497502.

59. Williams CS, Mann M, DuBois RN. The role of cyclooxygenases in inflammation, cancer, and development. Oncogene 1999;18:7908-7916.

60. Fosslien E. Molecular pathology of cyclooxygenase-2 in neoplasia. Ann Clin Lab Sci 2000;30:3-21.

61. Trifan OC, Hla T. Cyclooxygenase-2 modulates cellular growth and promotes tumorigenesis. J Cell Mol Med 2003;7:207-222.

62. Gately S. The contributions of cyclooxygenase-2 to tumor angiogenesis. Cancer Metastasis Rev 2000;19:19-27.

63. Leung WK, To KF, Go MY, et al. Cyclooxygenase-2 upregulates vascular endothelial growth factor expression and angiogenesis in human gastric carcinoma. Int J Oncol 2003;23:1317-1322.

64. Lo HW, Cao X, Zhu H, Ali-Osman F. Cyclooxygenase-2 is a novel transcriptional target of the nuclear EGFR-STAT3 and EGFRvIII-STAT3 signaling axes. Mol Cancer Res;8:232-245.

65. Wang SC, Lien HC, Xia W, et al. Binding at and transactivation of the COX-2 promoter by nuclear tyrosine kinase receptor ErbB-2. Cancer Cell 2004;6:251-261.

66. Romano $\mathrm{M}$, Claria J. Cyclooxygenase-2 and 5-lipoxygenase converging functions on cell proliferation and tumor angiogenesis: implications for cancer therapy. Faseb J 2003;17:1986-1995.

67. Murata H, Kawano S, Tsuji S, et al. Cyclooxygenase-2 overexpression enhances lymphatic invasion and metastasis in human gastric carcinoma. Am J Gastroenterol 1999;94:451-455.

68. Rouzer CA, Marnett L. Cyclooxygenases: structural and functional insights. J Lipid Res 2009;50 Suppl:S29-34.

69. Gasparini G, Longo R, Sarmiento R, Morabito A. Inhibitors of cyclo-oxygenase 2: a new class of anticancer agents? Lancet Oncol 2003;4:605-615.

70. Buckman SY, Gresham A, Hale P, et al. COX-2 expression is induced by UVB exposure in human skin: implications for the development of skin cancer. Carcinogenesis 1998;19:723-729.

71. Saukkonen K, Rintahaka J, Sivula A, et al. Cyclooxygenase-2 and gastric carcinogenesis. APMIS 2003;111:915-925.

72. Buskens CJ, Van Rees BP, Sivula A, et al. Prognostic significance of elevated cyclooxygenase 2 expression in patients with adenocarcinoma of the esophagus. Gastroenterology 2002;122:1800-1807.

73. Shamma A, Yamamoto H, Doki Y, et al. Up-regulation of cyclooxygenase-2 in squamous carcinogenesis of the esophagus. Clin Cancer Res 2000;6:1229-1238.

74. Eberhart CE, Coffey RJ, Radhika A, Giardiello FM, Ferrenbach S, DuBois RN. Up-regulation of cyclooxygenase 2 gene expression in human colorectal adenomas and adenocarcinomas. Gastroenterology 1994;107:1183-1188.

75. Wolff H, Saukkonen K, Anttila S, Karjalainen A, Vainio H, Ristimaki A. Expression of cyclooxygenase-2 in human lung carcinoma. Cancer Res 1998;58:4997-5001.

76. Hwang D, Scollard D, Byrne J, Levine E. Expression of cyclooxygenase-1 and cyclooxygenase-2 in human breast cancer. J Natl Cancer Inst 1998;90:455-460.

77. Mohammed SI, Knapp DW, Bostwick DG, et al. Expression of cyclooxygenase-2 (COX-2) in human invasive transitional cell carcinoma (TCC) of the urinary bladder. Cancer Res 1999;59:5647-5650.

78. Chan G, Boyle JO, Yang EK, et al. Cyclooxygenase-2 expression is up-regulated in squamous cell carcinoma of the head and neck. Cancer Res 1999;59:991-994.

79. Gupta RA, Dubois RN. Colorectal cancer prevention and treatment by inhibition of cyclooxygenase- 2 . Nat Rev Cancer 2001;1:11-21.

80. Ulrich CM, Bigler J, Potter JD. Non-steroidal anti-inflammatory drugs for cancer prevention: promise, perils and pharmacogenetics. Nat Rev Cancer 2006;6:130-140.

81. Mohammed SI, Bennett PF, Craig BA, et al. Effects of the cyclooxygenase inhibitor, piroxicam, on tumor response, apoptosis, and angiogenesis in a canine model of human invasive urinary bladder cancer. Cancer Res 2002;62:356-358. 
82. Zhang $X$, Miao X, Tan $W$, et al. Identification of functional genetic variants in cyclooxygenase-2 and their association with risk of esophageal cancer. Gastroenterology 2005;129:565-576.

83. Fritsche E, Baek SJ, King LM, Zeldin DC, Eling TE, Bell DA. Functional characterization of cyclooxygenase-2 polymorphisms. J Pharmacol Exp Ther 2001;299:468-476.

84. Papafili A, Hill MR, Brull DJ, et al. Common promoter variant in cyclooxygenase-2 represses gene expression: evidence of role in acute-phase inflammatory response. Arterioscler Thromb Vasc Biol 2002;22:1631-1636.

85. Saba NF, Choi M, Muller S, et al. Role of cyclooxygenase-2 in tumor progression and survival of head and neck squamous cell carcinoma. Cancer Prev Res (Phila Pa) 2009;2:823-829.

86. Mendes RA, Carvalho JF, Waal I. An overview on the expression of cyclooxygenase-2 in tumors of the head and neck. Oral Oncol 2009;45:e124-128.

87. Lin YC, Huang $\mathrm{HI}$, Wang LH, et al. Polymorphisms of COX-2 -765G>C and p53 codon 72 and risks of oral squamous cell carcinoma in a Taiwan population. Oral Oncol 2008;44:798-804. 



\section{Chapter 2}

\section{Microsomal epoxide hydrolase genotypes and the risk for head and neck cancer}

Martin Lacko

Hennie M.J. Roelofs

Rene H.M. te Morsche

Adri C. Voogd

Michael B. Oude Ophuis

Wilbert H.M. Peters

Johannes J. Manni

Head \& Neck 2008; 30: 836-844. 


\section{Abstract}

Background: Microsomal epoxide hydrolase $(\mathrm{mEH})$ is an enzyme involved in the metabolism of (pro)carcinogens in tobacco smoke. We investigated whether functional genetic polymorphisms in $\mathrm{mEH}$ may have a risk-modifying effect on head and neck carcinogenesis.

Methods: Blood from 429 patients with oral, pharyngeal and laryngeal carcinoma and 419 healthy subjects was investigated for $\mathrm{mEH}$ polymorphisms.

Results: Logistic regression analysis did not show differences in $\mathrm{mEH}$ genotype distributions between patients and controls, when categorized according to predicted $\mathrm{mEH}$ enzyme activity. Also no differences were found when evaluated according to tumor localisation, gender or tobacco consumption. A significantly higher incidence of the 139Arg/Arg variant was found in patients with hypopharyngeal carcinoma, compared with controls (OR: 4.39, 95\% Cl: 1.45-13.35).

Conclusion: In contrast to earlier reports, we could not demonstrate a riskmodifying effect of genetic polymorphisms in $\mathrm{mEH}$ on head and neck carcinogenesis, except for the predicted high activity variant in patients with hypopharyngeal carcinoma. 


\section{Introduction}

Exposure to tobacco smoke and alcohol are considered to be the most important risk factors for the development of squamous cell carcinoma of the head and neck (SCCHN). ${ }^{1-3}$ One of the first steps in the process of carcinogenesis is the binding of reactive tobacco smoke- and alcohol metabolites to the DNA of mucosal cells, which can lead to mutations and malignant transformation.

The human microsomal epoxide hydrolase $(\mathrm{mEH})$ is one of the phase I detoxification enzymes which play a role in biotransformation and detoxification of potential tobacco smoke carcinogens. $\mathrm{mEH}$ is highly expressed in several human tissues including the mucosa of the upper aerodigestive tract. ${ }^{4}$ This enzyme is involved in the biotransformation of electrophilic epoxides, often formed by the action of another phase I enzyme system cytochrome P-450 (CYP), on polycyclic aromatic hydrocarbons ( $\mathrm{PAH}$ 's) such as benzo(a)pyrene (BaP), which are present in high amounts in tobacco smoke. These epoxides subsequently need to be hydrolyzed, mainly by $\mathrm{mEH}$, and after conjugation in a phase II reaction, these conjugates can be excreted. $\mathrm{mEH}$ plays an important role in detoxification of numerous oxide intermediate metabolites; $\mathrm{mEH}$, however, may activate compounds such as the procarcinogen BaP 7,8 oxide, which is transferred to the ultimate carcinogen $\mathrm{BaP} 7,8$ dihydrodiol-9,10epoxide (BPDE) by the combined action of CYP and $\mathrm{mEH}^{5}$ This is an example of a biotransformation process which at first leads to bioactivation of an inert compound which then becomes a carcinogen. As shown by Miyata et al., ${ }^{6}$ an engineered mouse lacking the $\mathrm{mEH}$ gene was resistant to carcinogenicity of another potential bayregion $\mathrm{PAH}$ carcinogen 7,12-dimethylbenz[a]antracene (DMBA), in which $\mathrm{mEH}$ is required for its carcinogenic transformation, similar as for BaP.

The human $\mathrm{mEH}$ gene (EPHX1) is located on chromosome 1q42.1 and is composed of 9 exons. Two amino acid-altering polymorphisms of human EPHX1 with an impact on in vitro enzyme activity have been described. One variant in exon 3 is characterized by substitution of histidine for tyrosine at position 113 (Tyr113 $\rightarrow$ His113) of the $\mathrm{mEH}$ protein. The second variant comprises exon 4, with replacement of arginine for histidine at position 139 (His139 $\rightarrow$ Arg139). ${ }^{7}$ The EPHX1 113His variant is associated with $40 \%$ to $50 \%$ decrease in $\mathrm{mEH}$ activity, while the EPHX1 139Arg variant enhances enzyme activity by approximately $25 \%{ }^{7}$ Because a higher $\mathrm{mEH}$ activity can lead to a higher concentration of reactive compounds (such as BPDE) in the tissues, 
one could expect a higher risk of tobacco-related cancer in a population of smokers with genotypes, associated with high or intermediate activity of $\mathrm{mEH}$, as compared to a population with the low activity $\mathrm{mEH}$ genotypes.

In this study we investigated the role of the above described functional EPHX1 genetic polymorphisms as potential risk-modifying factors for the development of $\mathrm{SCCHN}$, by comparing the distribution of EPHX1 genetic polymorphisms according to predicted $\mathrm{mEH}$ activity in patients with $\mathrm{SCCHN}$, with those of a control population.

\section{Materials and methods}

\section{Patients and controls}

A total of 439 white (Caucasian) patients with newly diagnosed and histologically confirmed SSC of the oral cavity, oropharynx, hypopharynx and larynx have been recruited in the period 1995-2005. All patients admitted to the Department of Otorhinolaryngology, Head and Neck Surgery of the Maastricht University Hospital to undergo diagnostic panendoscopy because of their malignancy were asked to participate in the study. The patients were referred to the Maastricht University Hospital from the southeast region of The Netherlands. Due to failure in isolation of DNA of sufficient quality or failure in genotyping, 10 patients were not eligible for the evaluation and ultimately 429 patients (341 men, 88 women) were included in the study. The patient group consists of 198 patients (46.2\%) with oral/oropharyngeal carcinoma, 176 patients (41.0\%) with laryngeal carcinoma and 55 patients (12.8\%) with hypopharyngeal carcinoma. Mean age of the patient group was 61 years (range 23-93 years; Table 1 ).

The control group consists of 443 healthy white blood donors obtained through the blood bank situated in the referral region of our hospital. Only smokers and pastsmokers were asked to participate in the control group. Due to failure in isolation of DNA of sufficient quality or failure in genotyping, 24 controls were not eligible for further evaluation and ultimately 419 controls (326 men and 93 women) were included in the study. Mean age of this group was 57 years (range 36-91 years; see Table 1). All participants from the control group underwent regular medical checkup before the blood donation. Controls had no malignant disease or history of malignancy. The investigations were approved by the Medical Ethical Review Commit- 
tee of the Maastricht University Hospital and informed consent was obtained from all patients and controls.

Table 1. General characteristics of patients and control subjects.

\begin{tabular}{|c|c|c|c|c|c|}
\hline \multirow[t]{2}{*}{ Characteristic } & \multicolumn{2}{|c|}{ Patients with $\mathrm{SCCHN}^{*}$} & \multicolumn{2}{|l|}{ Controls } & \multirow[t]{2}{*}{$p$-value } \\
\hline & $n=429$ & $\%$ & $n=419$ & $\%$ & \\
\hline \multicolumn{6}{|l|}{ Age (years) } \\
\hline Mean & 61.1 & & 56.7 & & $<0.0001$ \\
\hline Range & $23-93$ & & $36-91$ & & \\
\hline \multicolumn{6}{|l|}{ Sex } \\
\hline Males & 340 & 79.0 & 326 & 77.8 & 0.55 \\
\hline Females & 91 & 21.0 & 93 & 22.2 & \\
\hline \multicolumn{6}{|l|}{ Smoking (pack-years) ${ }^{\#}$} \\
\hline 0 (never smokers) & 29 & 6.8 & 0 & 0 & $<0.0001$ \\
\hline $1-20$ & 48 & 11.1 & 88 & 21.1 & \\
\hline $20-39$ & 162 & 37.8 & 209 & 50.0 & \\
\hline $40-59$ & 144 & 33.6 & 93 & 22.2 & \\
\hline $60+$ & 46 & 10.7 & 28 & 6.7 & \\
\hline \multicolumn{6}{|l|}{ Alcohol (units/day) } \\
\hline 0 & 54 & 12.6 & 71 & 16.9 & $<0.0001$ \\
\hline $1-4$ & 260 & 60.6 & 317 & 75.7 & \\
\hline$>4$ & 115 & 26.8 & 31 & 7.4 & \\
\hline
\end{tabular}

Abbreviations: SCCHN- Squamous Cell Carcinoma of the Head and Neck, n- number.

*Oral cavity/oropharynx ( $n=198)$; larynx $(n=176)$; hypopharynx $(n=55)$.

\#Pack-year is defined as smoking 20 cigarettes per day during one year.

Both patients and controls were asked to fill in a questionnaire with items on demographics, life-long smoking and alcohol consumption. Tobacco use was categorized into amount of pack-years as described by Benhamou et al. ${ }^{8}$ Alcohol consumption was calculated as number of units per day according to the study of Elahi et al. ${ }^{9}$

\section{Blood sampling and assessment of genetic polymorphisms}

Blood samples were collected by vena puncture into EDTA vacutainer tubes which were stored at $-20^{\circ} \mathrm{C}$ immediately after collection until DNA extraction. Genomic DNA was isolated from whole blood using the Puregene ${ }^{\circledR}$ genomic DNA isolation kit, according to the instructions of the manufacturer (Gentra Systems, Minneapolis, MN, USA).

Baxter et $a .^{10}$ recently suggested that the conventional PCR-restriction fragment length polymorphism (PCR-RFLP) assay, which was applied very often in the exon 3 
EPHX1 genotyping research, might be unreliable due to the falsely reported 113 $\mathrm{His} / \mathrm{His}$ genotype instead of the $113 \mathrm{His} / \mathrm{Ty}$ r variant, in cases where a primer covering codon 119 was used. To avoid this inaccuracy in EPHX1 genotyping, we used a dual-colour allele-specific assay for genotyping the exon 3 polymorphism at codon 113 of the $E P H X 1$ gene. EPHX1 exon 3 genotypes were detected using the iCycler iQ Multicolour Real-Time Detection System (Bio-Rad Laboratories) using molecular beacons. PCR was performed with the forward primer 5'-CAA CTC CAA CTA CCT GAA G-3' and the reverse primer 5'-TGA CAT ACA TCC CTC TCT G-3' in the presence of the FAM-labeled wild-type beacon (5'-CGC GAT GAT TCT CAA CAG ATA CCC TCA CTT CAA TCG CG-3') and the HEX-labeled mutant beacon (5'-CGC GAT ATT CTC AAC AGA CAC CCT CAC TTC AAT CGC G-3'). The $25 \mu \mathrm{L}$ microliter reaction mixture contained $200 \mathrm{ng}$ of genomic DNA, $10 \mathrm{mM}$ Tris/ $\mathrm{HCl}(\mathrm{pH} \mathrm{9.0),} 50 \mathrm{mM} \mathrm{KCl}, 0.1 \%$ Triton X-100, 4 $\mathrm{mM} \mathrm{MgCl} 2,0.25 \mathrm{mM}$ dNTPs, 5 pmol of each primer, $200 \mathrm{nM}$ of each beacon and 2.5 $\mathrm{U}$ Taq-DNA-polymerase. The PCR conditions were 3 minutes at $95^{\circ} \mathrm{C}$, then 40 cycles of 30 seconds at $95^{\circ} \mathrm{C}, 30$ seconds at $59^{\circ} \mathrm{C}$ and 30 seconds at $72^{\circ} \mathrm{C}$. Fluorescent signals were measured at $59^{\circ} \mathrm{C}$. Genotypes were assigned using the iCycler iQ Optical System Software version 3.1. At each PCR run (in 96 wells plates) in several wells sterile $\mathrm{H}_{2} \mathrm{O}$ instead of genomic DNA was added as negative controls for amplification.

The EPHX1 exon 4 polymorphism was detected by polymerase chain reaction/restriction fragment length polymorphism (PCR-RFLP) assay according to Harrison et al. ${ }^{11}$ Sigma-Genosys Ltd. (Haverhill, UK) synthesized all primers. Chemicals for PCR were purchased from Promega (Madison, WI, USA).

Pursuant to Benhamou et al., ${ }^{12}$ we classified predicted $\mathrm{mEH}$ activity as low, intermediate or high, as indicated in Table 2.

Table 2. Predicted mEH enzyme activity based on the classification of Benhamou et al. ${ }^{12}$

\begin{tabular}{llll}
\hline $\begin{array}{l}\text { Exon } 4 \\
\text { (His139Arg } \\
\text { polymorphism) }\end{array}$ & \multicolumn{2}{l}{ Exon 3 (Tyr113His polymorphism) } & \\
\hline His/His & Tyr/Tyr & Tyr/His & His/His \\
His/Arg & Intermediate & low & low \\
Arg/Arg & High & intermediate & low \\
\hline
\end{tabular}

Abbreviations: mEH-microsomal epoxide hydrolase, His-Histidine, Arg-Arginine, Tyr-Tyrosine. 


\section{Statistics}

Unconditional logistic regression models were applied to estimate odds ratios (OR) and $95 \%$ confidence intervals $(\mathrm{Cl})$ for the polymorphisms at exons 3 and 4 and of the predicted $\mathrm{mEH}$ enzyme activity, adjusting for age (continuous, per year increase), sex, alcohol consumption ( $0 ; 1-4$ or $>4$ units per day) and smoking behaviour (0;119, 20-39, 40-59 and 60+ pack-years). Stratified regression analyses were performed, according to sex and smoking habits ( $<40$ pack-years, versus $\geq 40$ packyears). Separate regression analyses were also performed for patients with laryngeal cancers, oral/oropharyngeal cancers and those with hypopharyngeal cancer. In all analyses a probability level of 0.05 was used as the criterion of significance. All analyses were performed with the software SPSS for Windows version 13.0 (SPSS Inc., Chicago, IL, USA).

\section{Results}

The exon 3 and exon 4 genotype distributions of EPHX1 as found in patients and controls are given in Table 3. The prevalence of the exon 3 EPHX1 113Tyr and $113 \mathrm{His}$ alleles was $31.0 \%$ and $69.0 \%$ for the patient group and $31.1 \%$ and $68.9 \%$ for the control group, respectively. Distribution of this polymorphism in both patient and control groups fitted the Hardy Weinberg equilibrium ( $p=0.92$ and $p=0.83$, respectively). The prevalence of the exon 4 EPXH1 polymorphism among the patient group was $19.0 \%$ and $81.0 \%$ for $139 \mathrm{His}$ and $139 \mathrm{Arg}$ and $19.7 \%$ and $80.3 \%$ for the control group, respectively. The distribution of this polymorphism in patients and controls fitted the Hardy-Weinberg equilibrium ( $p=0.36$ and $p=0.93$, respectively). Although the exon 3 and exon 4 polymorphisms showed no significant differences in distribution between the whole patient group versus the control group, a significant higher incidence of the $139 \mathrm{Arg} / \mathrm{Arg}$ genotype was found in the subgroup of patients with hypopharyngeal carcinoma, when compared to the control group; (OR: 4.9, 95\% Cl: 1.45-13.35).

Based on the distribution of the exon 3 and exon 4 EPHX1 polymorphisms there were no significant differences in the distribution of putative low, intermediate or high $\mathrm{mEH}$ enzyme activities between the control and patient groups (Table 3). We could not demonstrate an increased risk of SCCHN for the genotypes with a predicted intermediate or high $\mathrm{mEH}$ activity, with the predicted low $\mathrm{mEH}$ activity as 
reference. No significant differences were obtained when in the patient group the predicted $\mathrm{mEH}$ enzyme activity distribution per tumor site (oral/oropharyngeal, hypopharyngeal and laryngeal cancer) was analysed versus the control group. The same analyses were performed for both sexes in the patient versus control group and also for the different smoking habits (moderate smokers with <40 pack-years and heavy smokers with $\geq 40$ pack-years). All these analyses showed no significant differences in the predicted $\mathrm{mEH}$ enzyme activity distribution between the patients versus the control group.

Table 3. EPHX1 genotypes and predicted $\mathrm{mEH}$ activity with odds ratios in SCCHN patients and controls.

\begin{tabular}{|c|c|c|c|c|c|c|}
\hline & \multicolumn{2}{|c|}{ Patients with SCCHN } & \multicolumn{2}{|l|}{ Controls } & \multirow[b]{2}{*}{ OR } & \multirow[b]{2}{*}{$95 \% \mathrm{Cl}$} \\
\hline & $n=429$ & $\%$ & $n=419$ & $\%$ & & \\
\hline \multicolumn{7}{|c|}{ Exon 3 genotypes } \\
\hline Tyr/Tyr & 206 & 48.0 & 196 & 46.8 & 1 (ref.) & \\
\hline Tyr/His & 180 & 42.0 & 185 & 44.2 & 1.01 & $0.75-1.36$ \\
\hline $\mathrm{His} / \mathrm{His}$ & 43 & 10.0 & 38 & 9.1 & 1.20 & $0.73-1.99$ \\
\hline \multicolumn{7}{|c|}{ Exon 4 genotypes } \\
\hline $\mathrm{His} / \mathrm{His}$ & 286 & 66.7 & 269 & 64.2 & 1 (ref.) & \\
\hline His/Arg & 123 & 28.7 & 135 & 32.2 & 0.81 & $0.59-1.10$ \\
\hline Arg/Arg & 20 & 4.7 & 15 & 3.6 & 1.13 & $0.54-2.34$ \\
\hline \multicolumn{7}{|c|}{ Predicted mEH activity } \\
\hline Low & 158 & 36.8 & 158 & 37.7 & 1 (ref.) & \\
\hline Intermediate & 192 & 44.8 & 184 & 43.9 & 0.96 & $0.70-1.32$ \\
\hline High & 79 & 18.4 & 77 & 18.4 & 0.88 & $0.59-1.23$ \\
\hline$p$ for trend & & & & & 0.55 & \\
\hline \multirow[t]{2}{*}{ Subgroup } & \multicolumn{6}{|c|}{$\begin{array}{l}\text { Hypopharyngeal } \\
\text { cancer patients }\end{array}$} \\
\hline & $\mathrm{n}=55$ & $\%$ & $n=419$ & $\%$ & OR & $95 \% \mathrm{Cl}$ \\
\hline \multicolumn{7}{|c|}{ Exon 3 genotypes } \\
\hline Tyr/Tyr & 21 & 38.2 & 196 & 46.8 & 1 (ref.) & \\
\hline Tyr/His & 29 & 52.7 & 185 & 44.2 & 1.79 & $0.95-3.39$ \\
\hline $\mathrm{His} / \mathrm{His}$ & 5 & 9.1 & 38 & 9.1 & 1.53 & $0.52-4.55$ \\
\hline \multicolumn{7}{|c|}{ Exon 4 genotypes } \\
\hline $\mathrm{His} / \mathrm{His}$ & 30 & 54.5 & 269 & 64.2 & 1 (ref.) & \\
\hline His/Arg & 19 & 34.5 & 135 & 32.2 & 1.26 & $0.66-2.41$ \\
\hline Arg/Arg & 6 & 11.0 & 15 & 3.6 & 4.39 & $1.45-13.35$ \\
\hline \multicolumn{7}{|c|}{ Predicted $\mathrm{mEH}$ activity } \\
\hline Low & 21 & 38.2 & 158 & 37.7 & 1 (ref.) & \\
\hline Intermediate & 23 & 41.8 & 184 & 43.9 & 0.93 & $0.48-1.80$ \\
\hline High & 11 & 20.0 & 77 & 18.4 & 0.89 & $0.39-2.06$ \\
\hline
\end{tabular}




\begin{tabular}{|c|c|c|c|c|c|c|}
\hline \multirow{3}{*}{ Subgroup } & \multicolumn{2}{|c|}{ Patients with SCCHN } & \multicolumn{4}{|l|}{ Controls } \\
\hline & \multicolumn{6}{|c|}{$\begin{array}{l}\text { Oral/oropharyngeal } \\
\text { cancer patients }\end{array}$} \\
\hline & $\mathrm{n}=198$ & $\%$ & $n=419$ & $\%$ & OR & $95 \% \mathrm{Cl}$ \\
\hline \multicolumn{7}{|c|}{ Exon 3 genotypes } \\
\hline Tyr/Tyr & 96 & 48.5 & 196 & 46.8 & 1 (ref.) & \\
\hline Tyr/His & 75 & 37.9 & 185 & 44.2 & 0.82 & $0.56-1.21$ \\
\hline $\mathrm{His} / \mathrm{His}$ & 27 & 13.6 & 38 & 9.1 & 1.64 & $0.91-2.96$ \\
\hline \multicolumn{7}{|c|}{ Exon 4 genotypes } \\
\hline His/His & 141 & 71.2 & 269 & 64.2 & 1 (ref.) & \\
\hline His/Arg & 52 & 26.3 & 135 & 32.2 & 0.70 & $0.47-1.05$ \\
\hline Arg/Arg & 5 & 2.5 & 15 & 3.6 & 0.46 & $0.15-1.41$ \\
\hline \multicolumn{7}{|c|}{ Predicted mEH activity } \\
\hline Low & 79 & 39.9 & 158 & 37.7 & 1 (ref.) & \\
\hline Intermediate & 87 & 43.9 & 184 & 43.9 & 0.95 & $0.64-1.41$ \\
\hline High & 32 & 16.2 & 77 & 18.4 & 0.73 & $0.73-1.23$ \\
\hline \multirow[t]{3}{*}{ Subgroup } & \multicolumn{6}{|c|}{ Laryngeal cancer } \\
\hline & \multicolumn{2}{|l|}{ Patients } & & & & \\
\hline & $\mathrm{n}=176$ & $\%$ & $\mathrm{n}=419$ & $\%$ & OR & $95 \% \mathrm{Cl}$ \\
\hline \multicolumn{7}{|c|}{ Exon 3 genotypes } \\
\hline Tyr/Tyr & 89 & 50.6 & 196 & 46.8 & 1 (ref.) & \\
\hline Tyr/His & 76 & 43.2 & 185 & 44.2 & 1.04 & $0.70-1.54$ \\
\hline His/His & 11 & 6.2 & 38 & 9.1 & 0.59 & $0.27-1.28$ \\
\hline \multicolumn{7}{|c|}{ Exon 4 genotypes } \\
\hline His/His & 115 & 65.4 & 269 & 64.2 & 1 (ref.) & \\
\hline His/Arg & 52 & 29.5 & 135 & 32.2 & 0.79 & $0.52-1.21$ \\
\hline Arg/Arg & 9 & 5,1 & 15 & 3.6 & 1.61 & $0.64-4.06$ \\
\hline \multicolumn{7}{|c|}{ Predicted $\mathrm{mEH}$ activity } \\
\hline Low & 58 & 32.9 & 158 & 37.7 & 1 (ref.) & \\
\hline Intermediate & 82 & 46.6 & 184 & 43.9 & 1.11 & $0.72-1.70$ \\
\hline High & 36 & 20.5 & 77 & 18.4 & 1.09 & $0.64-1.86$ \\
\hline
\end{tabular}

Abbreviations: EPHX1- human microsomal epoxide hydrolase gene, $\mathrm{mEH}$-microsomal epoxide hydrolase, OR- Odds ratio, Cl-Confidence interval, SCCHN- Squamous Cell Carcinoma of the Head and Neck, nnumber, Tyr-Tyrosine, His-Histidine, Arg-Arginine.

All OR's were adjusted for age (continuous), sex, smoking (continuous) and alcohol consumption (continuous).

\section{Discussion}

(Pro)carcinogens present in tobacco smoke or alcohol are well known risk factors for SCCHN. Tobacco smoke contains more than 60 known potential carcinogens. Several phase I and II biotransformation enzymes, including $\mathrm{mEH}$, are involved in metabolic pathways of these compounds. Due to genetic polymorphisms commonly present in the genes encoding for these enzymes, corresponding enzyme activity 
may be altered. To assess the individual cancer risk, the identification of these genetic variations and their significance in head and neck carcinogenesis deserves interest.

$\mathrm{mEH}$ plays a pivotal role in the generation of the highly carcinogenic bay-region diol epoxide of the polycyclic aromatic hydrocarbon $\mathrm{BaP}$, which is present in tobacco smoke. This compound can undergo covalent binding with DNA and start the process of carcinogenesis. ${ }^{13}$ Therefore, $\mathrm{mEH}$ may play an important role in modulation of carcinogenesis in tobacco related SCCHN. Compared to other biotransformation enzymes like cytochromes P-450 (CYPs) or glutathione S-transferases (GSTs), only a few studies on the role of $\mathrm{mEH}$ polymorphisms in the onset of SCCHN have been published (Table 4). ${ }^{14-18}$

Table 4. EPHX1 genotypes and predicted $\mathrm{mEH}$ activity with OR's in SCCHN patients and controls in previous studies on Caucasian populations.*

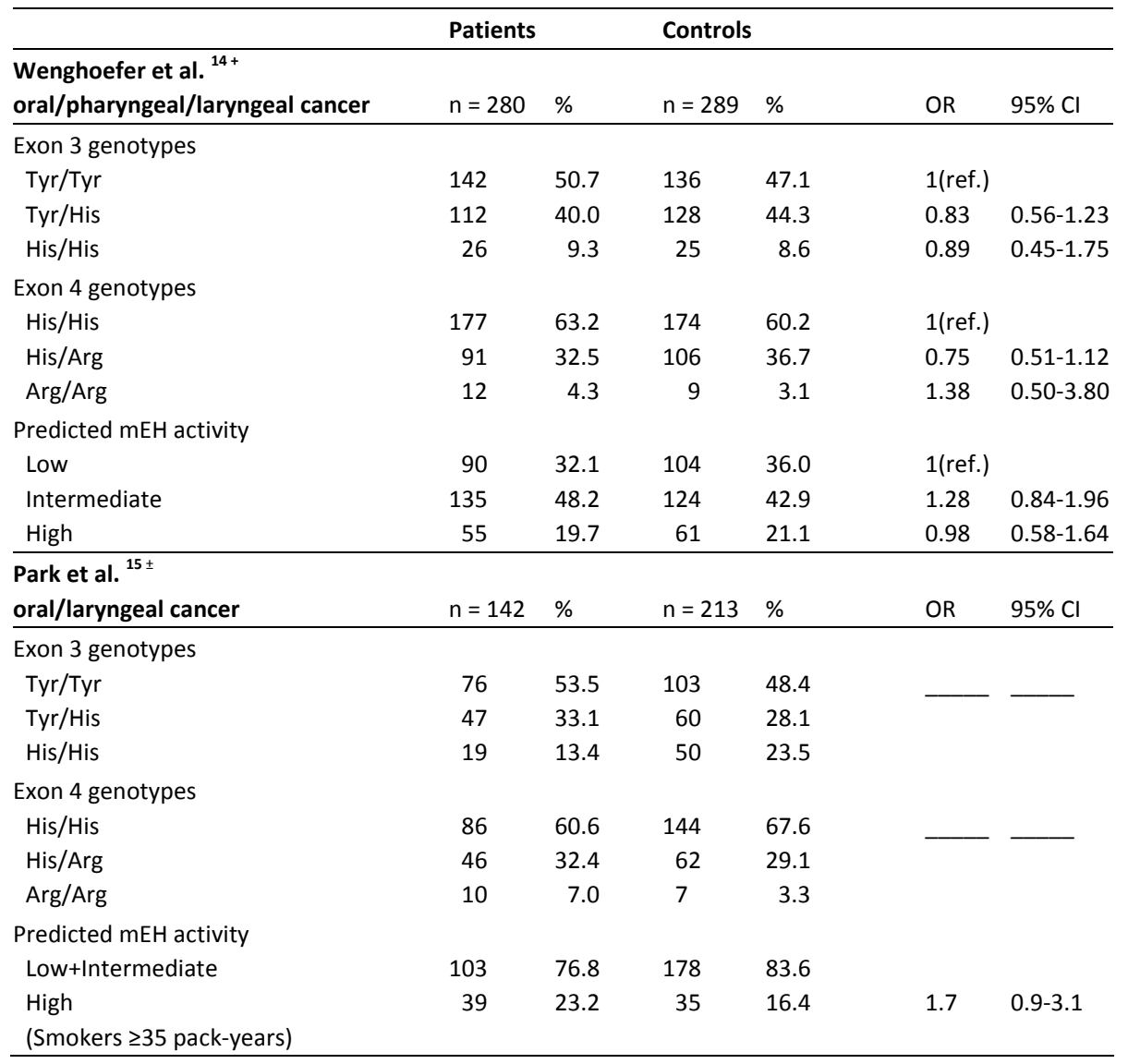




\begin{tabular}{|c|c|c|c|c|c|c|}
\hline & Patients & & Controls & & & \\
\hline Low+Intermediate & 55 & 67.9 & 48 & 87.3 & & \\
\hline High & 26 & 32.1 & 7 & 12.7 & 3.4 & $1.2-9.6$ \\
\hline \multicolumn{7}{|l|}{ To-Figueras et al. ${ }^{16 \S}$} \\
\hline laryngeal cancer & $\mathrm{n}=204$ & $\%$ & $\mathrm{n}=203$ & $\%$ & OR & $95 \% \mathrm{Cl}$ \\
\hline \multicolumn{7}{|l|}{ Exon 3 genotypes } \\
\hline Tyr/Tyr & 106 & 52.0 & 93 & 45.8 & 1 (ref.) & $0.41-1.02$ \\
\hline Tyr/His & 83 & 40.7 & 94 & 46.4 & 0.64 & $0.24-1.47$ \\
\hline $\mathrm{His} / \mathrm{His}$ & 15 & 7.3 & 16 & 7.8 & 0.60 & \\
\hline \multicolumn{7}{|l|}{ Exon 4 genotypes } \\
\hline $\mathrm{His} / \mathrm{His}$ & 145 & 71.0 & 134 & 66.0 & 1 (ref.) & \\
\hline His/Arg & 56 & 27.5 & 62 & 30.5 & 0.95 & $0.58-1.55$ \\
\hline Arg/Arg & 3 & 1.5 & 7 & 3.5 & 0.27 & $0.05-1.43$ \\
\hline \multicolumn{7}{|l|}{ Predicted $\mathrm{mEH}$ activity } \\
\hline Low & 76 & 37.3 & 76 & 37.4 & 1 (ref.) & \\
\hline Intermediate & 91 & 44.6 & 94 & 46.3 & 1.24 & $0.76-2.02$ \\
\hline High & 37 & 18.1 & 33 & 16.3 & 1.32 & $0.69-2.52$ \\
\hline \multirow[t]{2}{*}{$\begin{array}{l}\text { Amador et al. }{ }^{17} * \\
\text { oral/pharyngeal/laryngeal cancer }\end{array}$} & $\begin{array}{l}\text { ever- } \\
\text { smoker }\end{array}$ & $\begin{array}{l}\text { never- } \\
\text { smokers }\end{array}$ & & Fischer test & & \\
\hline & $\mathrm{n}=122$ & $\mathrm{n}=15$ & $\mathrm{n}=99$ & $p$ value & OR & $95 \% \mathrm{Cl}$ \\
\hline Exon 3 genotypes & & & & ever smokers: & & \\
\hline Tyr/Tyr & $41.7 \%$ & $60.0 \%$ & $21.4 \%$ & $P=0.001$ & $\ldots$ & $\ldots$ \\
\hline Tyr/His & $45.0 \%$ & $33.3 \%$ & $46.9 \%$ & never smoker: & & \\
\hline $\mathrm{His} / \mathrm{His}$ & $13.3 \%$ & $6.7 \%$ & $31.6 \%$ & $P=0.006$ & & \\
\hline Exon 4 genotypes & & & & ever smokers: & & \\
\hline His/His & $70.8 \%$ & $86.7 \%$ & $73.7 \%$ & not significant & $\ldots$ & 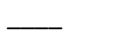 \\
\hline His/Arg & $22.5 \%$ & $0.0 \%$ & $21.2 \%$ & never smoker: & & \\
\hline Arg/Arg & $6.7 \%$ & $13.3 \%$ & $5.1 \%$ & not significant & & \\
\hline \multicolumn{7}{|l|}{ Predicted $\mathrm{mEH}$ activity } \\
\hline \multicolumn{7}{|l|}{$\begin{array}{l}\text { Low } \\
\text { Intermediate }\end{array}$} \\
\hline Intermediate & & & & & & \\
\hline \multicolumn{7}{|l|}{ High } \\
\hline \multicolumn{7}{|l|}{ Jourenkova-Mironova et al. ${ }^{18} \neq$} \\
\hline laryngeal cancer & $\mathrm{n}=129$ & $\%$ & $\mathrm{n}=172$ & $\%$ & OR & $95 \% \mathrm{Cl}$ \\
\hline \multicolumn{7}{|l|}{ Exon 3 genotypes } \\
\hline Tyr/Tyr & 72 & 55.8 & 64 & 37.2 & 1 (ref.) & \\
\hline Tyr/His & 40 & 31.0 & 77 & 44.8 & 0.4 & $0.2-0.7$ \\
\hline $\mathrm{His} / \mathrm{His}$ & 17 & 13.2 & 31 & 18.0 & 0.5 & $0.2-1.1$ \\
\hline \multicolumn{7}{|l|}{ Exon 4 genotypes } \\
\hline His/His & 84 & 65.1 & 121 & 70.3 & 1 (ref.) & \\
\hline His/Arg & 41 & 31.8 & 49 & 28.5 & $1.0^{\|}$ & $0.6-1.8^{\|}$ \\
\hline Arg/Arg & 4 & 3.1 & 2 & 1.2 & & \\
\hline \multicolumn{7}{|l|}{ Predicted $\mathrm{mEH}$ activity } \\
\hline Low & 43 & 33.0 & 85 & 49.4 & 1 (ref.) & \\
\hline Intermediate & 59 & 45.7 & 65 & 37.8 & 1.7 & $1.0-3.1$ \\
\hline High & 27 & 20.9 & 22 & 12.8 & 2.4 & $1.1-5.1$ \\
\hline
\end{tabular}




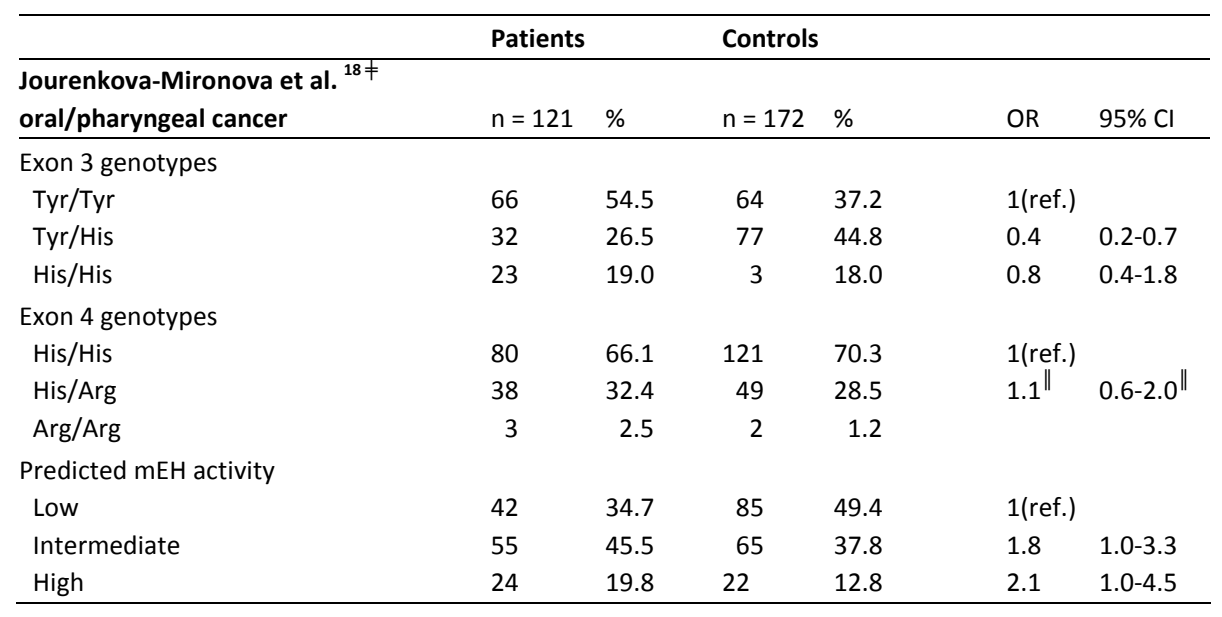

Abbreviations: EPHX1- human microsomal epoxide hydrolase gene, $\mathrm{mEH}$-microsomal epoxide hydrolase, OR- Odds ratio, Cl-Confidence interval, SCCHN- Squamous Cell Carcinoma of the Head and Neck, nnumber, Tyr-Tyrosine, His-Histidine, Arg-Arginine.

* $6.5 \%$ of cases and $9.1 \%$ of controls in the study of Amador et al. ${ }^{17}$ were not white.

${ }^{+}$OR's were adjusted for age and gender.

${ }^{\ddagger}$ OR's were adjusted for age, gender, smoking and alcohol consumption.

${ }^{\S}$ OR's were adjusted for age, gender and smoking.

$\|$ Because of the small number of Arg/Arg genotypes, ORs were calculated for the combined His/Arg and Arg/Arg genotypes.

To investigate the risk-modifying effect of EPHX1 polymorphisms in head and neck carcinogenesis, we compared the exon 3 and exon 4 EPHX1 polymorphisms in 429 SCCHN patients and 419 healthy controls. Our control group findings correspond to figures reported for the Caucasian population by Wenghoefer et al., ${ }^{14}$ but they differed from those reported by Jourenkova-Mironova et al. ${ }^{18}$ for both the exon 3 and exon 4 genotypes and they differed for the exon 3 genotypes only when compared to the reports of Amador et al. ${ }^{17}$ Interestingly, the method for estimating the exon 3 polymorphism applied by Wenghoefer et al. as well as our method are not potentially inaccurate due to a nearby polymorphism at codon 119 as discussed above in the "Material and Methods" section. The methods applied by Jourenkova-Mironova et al. and Amador et al. may be inaccurate because of this codon 119 polymorphism.

Wenghoefer et al. $^{14}$ could not detect a significant correlation between the exon 3 and $4 E P H X 1$ genotypes with predicted low, intermediate or high activity and the risk for oral, pharyngeal and laryngeal cancer in a German population study. However, they reported a significant heterogeneity of the estimated risk for the EPHX1 
genotypes among smokers. Paradoxically, both the putative low $(113 \mathrm{His} / \mathrm{His}$ combined with 139His/Arg) and putative high (113Tyr/Tyr combined with 139His/Arg) enzyme activity genotypes in their study were associated with a significantly lower risk of SCCHN development. This is probably a chance finding by statistical evaluation of subgroups with small numbers of individuals.

Park et al. ${ }^{15}$ found a significant increased risk for oral and laryngeal cancer in heavy smoking (>35 pack-years) subjects of North American white origin with predicted high activity EPHX1 genotype, but not in individuals of African American origin. They also observed a significant positive association between predicted high EPHX1 activity genotypes and orolaryngeal cancer risk in white subjects with the GSTM1 null genotype.

To-Figueras et al. ${ }^{16}$ in their study on the risk of laryngeal cancer among Spanish white patients as compared to a control group of similar origin concluded, that none of the EPHX1 polymorphisms alone were found to be associated with cancer of the larynx. However, they found an increased risk for laryngeal cancer in individuals with both the predicted high activity EPHX1 genotype and the 105Ile/105Ile variant in GSTP1.

Amador et al. ${ }^{17}$ observed an overrepresentation of the high activity EPHX1 genotype (Tyr/Tyr) at codon 113 in a North American patient population with oral, pharyngeal and laryngeal cancer when compared with the control group However, the study population of Amador et al. is relatively small with no data about age, tobacco and alcohol consumption habits, and no information about the presence of SCCHN or any other malignant disease of the control group. Also, the exon $3 E P H X 1$ primers used in this study may have led to inaccuracy in genotyping.

Jourenkova-Mironova et al. ${ }^{18}$ described a significantly higher incidence of oralpharyngeal- and laryngeal cancer, in association with predicted high and intermediate $\mathrm{mEH}$ activity as compared to predicted low $\mathrm{mEH}$ activity in a white French population. They also found a higher risk for larynx cancer when a combination of the high activity-associated EPHX1 genotype and GSTM3 AB or BB genotype was present. However, the primers used for genotyping the exon 3 polymorphism in EPHX1 in their study, may admit some inaccuracy, as outlined. 
Besides the above mentioned potentially inaccurate analysis of the exon 3 EPHX1 genotype, additional potential bias in most of the above quoted studies may be the small study populations or hospital-linked control selections, because $\mathrm{mEH}$ polymorphisms and/or altered activity of this enzyme have been associated not only to SCCHN and other malignancies, but also to non-malignant diseases. ${ }^{19}$ Hospitallinked inclusion of controls may therefore result in potential selection bias in the control groups. To avoid this, we have chosen for a population of healthy smokers or past-smokers, health conditions of which are confirmed by regularly performed medical check-ups. The population of blood donors participating in our study fulfils these criteria. In addition, blood samples were taken during donation of blood and no extra venepuncture had to be performed.

To our best knowledge, this is the largest study published so far on the significance of $\mathrm{mEH}$ polymorphisms in the development of SCCHN. We did not find any significant difference in distribution of EPHX1 polymorphisms related to predicted enzyme activity, between our patient and control groups. Therefore, we can not confirm the findings by other groups that EPHX1 polymorphisms alone can be risk-modifying factors in the development of SCCHN. However, we have found a significantly higher incidence of the predicted high activity 139Arg/Arg variant of the exon 4 polymorphism in patients with hypopharyngeal carcinoma, comparing to the control group (OR: 4.39, 95\% Cl: 1.45-13.35). However, when we combine both the exon 3 and exon 4 polymorphisms in the hypopharyngeal cancer subgroup, with respect to predicted $\mathrm{mEH}$ enzyme activity, there were no significant differences between these patients with hypopharyngeal carcinoma and the control group. This means, that also in this subgroup we can not find a risk-modifying effect of the predicted $\mathrm{mEH}$ enzyme activity on cancer development. Because we do not expect a different pathophysiological role of $\mathrm{mEH}$ in the carcinogenesis of hypoharynx carcinomas as compared to oral, oropharyngeal, of laryngeal carcinomas, results of the exon 4 polymorphism with respect to hypopharyngeal carcinoma could have been a chance finding. However, a larger group of hypopharyngeal carcinoma patients should be studied to confirm this explanation.

As stated by Hosagrahara et al., ${ }^{20}$ the structural differences encoded by the exon 3 and exon 4 polymorphisms in $\mathrm{mEH}$, probably may have only modest impact on the specific activity of the enzyme in vivo In contrast to the $\mathrm{mEH}$ biotransformation activity as measured in vitro, the in vivo $\mathrm{mEH}$ activity and subsequent clearance of 
substrates may probably also be influenced by competing reaction pathways and interactions between genetic polymorphisms of $\mathrm{mEH}$ and other enzymes involved in the biotransformation process, as observed in studies from Park et al. ${ }^{15}$ and ToFigueras et al. ${ }^{16}$

Therefore, more research is needed to also investigate the role of possible interactions between the polymorphic genotypes of the phase I and II enzymes involved in (de)toxification of tobacco smoke carcinogens, like mEH, CYP, GST, UGT, NAT and others, with emphasis on their combined influence on SCCHN carcinogenesis. This may help to understand the role of genetic polymorphisms of these enzymes in the tobacco smoke associated head and neck carcinogenesis and may also help to answer the question whether polymorphisms of these enzymes and their interactions can modulate the individual susceptibility to SCCHN.

\section{References}

1. Rothman KJ. Epidemiology of head and neck cancer. Laryngoscope 1978;88:435-438.

2. Lewin $\mathrm{F}$, Norell SE, Johansson $\mathrm{H}$, et al. Smoking tobacco, oral snuff, and alcohol in the etiology of squamous cell carcinoma of the head and neck: a population-based case-referent study in Sweden. Cancer 1998;82:1367-1375.

3. Maier H, Dietz A, Gewelke U, Heller WD, Weidauer H. Tobacco and alcohol and the risk of head and neck cancer. Clin Investig 1992;70:320-327.

4. Janot F, Massaad L, Ribrag V, et al. Principal xenobiotic-metabolizing enzyme systems in human head and neck squamous cell carcinoma. Carcinogenesis 1993;14:1279-1283.

5. Shimada T. Xenobiotic-metabolizing enzymes involved in activation and detoxification of carcinogenic polycyclic aromatic hydrocarbons. Drug Metab Pharmacokinet 2006;21:257-276.

6. Miyata M, Kudo G, Lee $\mathrm{YH}$, et al. Targeted disruption of the microsomal epoxide hydrolase gene. Microsomal epoxide hydrolase is required for the carcinogenic activity of 7,12-dimethylbenz[a]anthracene. J Biol Chem 1999;274:23963-23968.

7. Hassett C, Aicher L, Sidhu JS, Omiecinski CJ. Human microsomal epoxide hydrolase: genetic polymorphism and functional expression in vitro of amino acid variants. Hum Mol Genet 1994;3:421-428.

8. Benhamou S, Benhamou E, Flamant R. Lung cancer risk associated with cigar and pipe smoking. Int J Cancer 1986;37:825-829.

9. Elahi A, Bendaly J, Zheng Z, et al. Detection of UGT1A10 polymorphisms and their association with orolaryngeal carcinoma risk. Cancer 2003;98:872-880.

10. Baxter SW, Choong DY, Campbell IG. Microsomal epoxide hydrolase polymorphism and susceptibility to ovarian cancer. Cancer Lett 2002;177:75-81.

11. Harrison DJ, Hubbard AL, MacMillan J, Wyllie AH, Smith CA. Microsomal epoxide hydrolase gene polymorphism and susceptibility to colon cancer. Br J Cancer 1999;79:168-171.

12. Benhamou S, Reinikainen M, Bouchardy C, Dayer $P$, Hirvonen A. Association between lung cancer and microsomal epoxide hydrolase genotypes. Cancer Res 1998;58:5291-5291.

13. Dipple A, Khan QA, Page JE, Ponten I, Szeliga J. DNA reactions, mutagenic action and stealth properties of polycyclic aromatic hydrocarbon carcinogens (review). Int J Oncol 1999;14:103-111. 
14. Wenghoefer M, Pesch B, Harth V, et al. Association between head and neck cancer and microsomal epoxide hydrolase genotypes. Arch Toxicol 2003;77:37-41.

15. Park JY, Schantz SP, Lazarus P. Epoxide hydrolase genotype and orolaryngeal cancer risk: interaction with GSTM1 genotype. Oral Oncol 2003;39:483-490.

16. To-Figueras J, Gene M, Gomez-Catalan J, et al. Microsomal epoxide hydrolase and glutathione Stransferase polymorphisms in relation to laryngeal carcinoma risk. Cancer Lett 2002;187:95-101.

17. Amador AG, Righi PD, Radpour S, et al. Polymorphisms of xenobiotic metabolizing genes in oropharyngeal carcinoma. Oral Surg Oral Med Oral Pathol Oral Radiol Endod 2002;93:440-445.

18. Jourenkova-Mironova N, Mitrunen K, Bouchardy C, Dayer P, Benhamou S, Hirvonen A. High-activity microsomal epoxide hydrolase genotypes and the risk of oral, pharynx, and larynx cancers. Cancer Res 2000;60:534-536.

19. Park JY, Chen L, Wadhwa N, Tockman MS. Polymorphisms for microsomal epoxide hydrolase and genetic susceptibility to COPD. Int J Mol Med 2005;15:443-448.

20. Hosagrahara VP, Rettie $A E$, Hassett $C$, Omiecinski CJ. Functional analysis of human microsomal epoxide hydrolase genetic variants. Chem Biol Interact 2004;150:149-159. 


\section{Chapter 3 \\ COX-2 polymorphisms and the risk for head and neck cancer in white patients}

Wilbert H.M. Peters

Martin Lacko

Rene H.M. te Morsche

Adri C. Voogd

Michael B. Oude Ophuis

Johannes J. Manni

Head \& Neck 2009; 31: 938-943. 


\section{Abstract}

Background: Cyclooxygenase-2 (COX-2) is an enzyme involved in the synthesis of prostaglandins and thromboxanes, which are regulators of processes such as inflammation, cell proliferation and angiogenesis, all relevant for cancer development. We investigated whether functional genetic polymorphisms in COX-2 may have a risk-modifying effect on head and neck carcinogenesis.

Methods: Blood from 431 white patients with oral, pharyngeal or laryngeal carcinoma and 438 white healthy controls was investigated for the presence of two functional promoter region polymorphisms $(-1195 A \rightarrow G$ and $-765 G \rightarrow C)$ in COX-2.

Results: Logistic regression analysis did not show differences in COX-2 genotype distributions between patients and controls. Also no differences were found when stratified according to tumor localization, sex or tobacco consumption.

Conclusion: In contrast to earlier reports on the role of these COX-2 polymorphisms in mediating susceptibility to squamous esophageal carcinoma in a Chinese population, we could not demonstrate a risk-modifying effect in head and neck carcinogenesis in whites. 


\section{Introduction}

Cyclooxygenases (COXs) are key enzymes in mediating the conversion of free arachidonic acid into prostaglandin $\mathrm{H}_{2}$, the precursor of prostaglandins and thromboxanes, which are important regulators of many biologic processes such as inflammation, cell proliferation, and angiogenesis, which are all relevant to cancer development and progression. ${ }^{1-4}$ The COX family consists of 2 isozymes; COX-1 which is constitutively expressed in most cell types and this form is involved in the homeostasis of various physiologic functions, and cyclooxygenase-2 (COX-2) which is an inducible form, expression of which can be induced by proinflammatory and mitogenic stimuli such as cytokines and growth factors. ${ }^{5}$ Increased expression of COX-2 was observed in several types of cancers, ${ }^{6-8}$ and overexpression of COX-2 was associated with various steps of cancer development, such as hyperproliferation, transformation, invasion and metastasis. ${ }^{8,9}$ In recent years, several inhibitors of COX-2 have been developed, which potentially could be used in future as a new class of anti-cancer agents. ${ }^{5,10}$

Exposure to tobacco smoke and alcohol are considered to be the most important risk factors for the development of squamous cell carcinoma of the head and neck (SCCHN). ${ }^{11,12}$ One of the first steps in the process of carcinogenesis is the binding of reactive tobacco smoke and alcohol metabolites to the DNA of mucosal cells, which can lead to mutations and malignant transformation. Tobacco smoke extracts have been shown to increase the COX-2 expression in tumor cells, with concomitant increase of cell proliferation and decrease of apoptosis. ${ }^{13}$ Up-regulation of COX-2 has also been shown in head and neck cancer. ${ }^{14,15}$

Sequence variations in the COX-2 gene, including the promoter region, might contribute at least in part to differential COX-2 expression, which subsequently may be responsible for a substantial degree of inter-individual variability in COX-2 levels, ${ }^{16}$ which in turn might explain part of the differences in cancer susceptibility between individuals. Several single nucleotide polymorphisms (SNPs) in COX-2 have been reported previously. ${ }^{17} \mathrm{~A}$ coding polymorphism (Val511Ala) has been linked to a reduced risk of colorectal neoplasia. ${ }^{18}$ 
Recently, two relevant SNPs $(-1195 A \rightarrow G$ and $-765 G \rightarrow C)$ in the COX-2 promoter region have been described. ${ }^{16,19}$ Both the $-765 G \rightarrow C$ and the $-1195 A \rightarrow G$ polymorphism have been shown to display a lower promoter activity. ${ }^{16,19}$

The specific function of COX-2 in the formation of prostaglandins, regulation of cell proliferation, apoptosis and cancer development, makes it a strong candidate for investigating its modulating role in the carcinogenesis of common cancers. Genetic polymorphisms that may alter the level of active enzyme would be anticipated to have an influence on disease activity. In this study, we investigated the possible role of two functional polymorphisms in the promoter region of the human COX-2 gene $(-1195 A \rightarrow G$ and $-765 G \rightarrow C)$ and conducted a case-control study to evaluate the contribution of these polymorphisms to the risk of developing squamous cell carcinoma of the head and neck.

\section{Patients and methods}

\section{Patients and controls}

A total of 439 white patients with newly diagnosed and histologically confirmed SCC of the oral cavity, oropharynx, hypopharynx or larynx have been recruited in the period 1995-2005. All patients admitted to the Department of Otorhinolaryngology, Head and Neck Surgery of the Maastricht University Hospital to undergo diagnostic panendoscopy because of their malignancy were asked to participate in the study. The patients were referred to the Maastricht University Hospital from the southeast region of The Netherlands. Because of the failure in isolation of DNA of sufficient quality or failure in genotyping, some patients were not eligible for the evaluation and ultimately 428 patients (338 males, 90 females) and 431 controls (340 males, 91 females) were included in the study for the COX-2 -765 and COX-2 -1195 polymorphism, respectively. Mean age of the patient group was 61 years (range 2393 years).

The control group consists of 443 healthy white blood donors obtained through the blood bank situated in the referral region of the University Hospital Maastricht. Only smokers and past-smokers were asked to participate in the control group. Because of the failure in isolation of DNA of sufficient quality or failure in genotyping, 10 controls were not eligible for evaluation of the COX-2 -765 polymorphism and 5 
controls were not eligible for evaluation of the COX-2 -1195 polymorphism. Mean age of the control group was 57 years (range 36-91 years). All participants from the control group underwent regular medical check-up before the blood donation. Controls did not suffer from any malignant disease and had no history of malignancy. The investigations were approved by the Medical Ethical Review Committee of the Maastricht University Hospital and informed consent was obtained from all patients and controls.

Both patients and controls were asked to fill in a questionnaire with items on demographics, life-long smoking and alcohol consumption. Tobacco use was categorized into amount of pack-years. Alcohol consumption was calculated as number of units per day. Participants were defined as not drinkers, if they had not consumed alcohol at all, moderate or "social" drinkers if they consumed 1 to 4 units per day ( $\leq 28$ units per week) and heavy drinkers if they consumed more than 4 units per day (>28 units per week).

\section{Blood sampling and assessment of genetic polymorphisms}

Blood samples were collected by vena puncture into EDTA vacutainer tubes, which were stored at $-20^{\circ} \mathrm{C}$ immediately after collection until DNA extraction. Genomic DNA was isolated from whole blood using the Puregene ${ }^{\circledR}$ genomic DNA isolation kit, according to the instructions of the manufacturer (Gentra Systems, Minneapolis, MN, USA).

COX-2 polymorphisms were determined as follows: a dual-color discrimination assay was developed for genotyping the $-765 G \rightarrow C$ polymorphism of the COX-2 gene using the iCycler iQ Multicolour Real-Time Detection System (Bio-Rad Laboratories, Hercules, CA). PCR was performed with the forward primer 5'-GCT TAG GAC CAG TAT TAT GAG G-3' and the reverse primer 5'-AAA TAC TGT TCT CCG TAC CTT C-3' in the presence of the COX-2-765G LNA probe (5'-Fam-tac cTt tCc cGc cTc tc-BHQ1-3') and the Cox-2-765C LNA probe (5'-Hex-tac cTt tCc cCc cTc tc-BHQ1-3'; SigmaProligo, Zwijndrecht, the Netherlands). The $25 \mu$ reaction mixture contained 100 ng of genomic DNA, $10 \mathrm{mM}$ Tris/ $\mathrm{HCl}$ (pH 9.0), $50 \mathrm{mM} \mathrm{KCl,} \mathrm{0.1 \%} \mathrm{Triton} \mathrm{X-100,} 3.75$ $\mathrm{mM} \mathrm{MgCl}$, $0.25 \mathrm{mM}$ dNTPs, $2.5 \mathrm{U}$ Taq-DNA-polymerase, $200 \mathrm{nM}$ of each primer, $225 \mathrm{nM}$ of the COX-2-765G probe and $150 \mathrm{nM}$ COX-2-765C probe. The PCR conditions were 3 minutes at $95^{\circ} \mathrm{C}$, then 40 cycles of 30 seconds at $95^{\circ} \mathrm{C}, 30$ seconds at 
$61.5^{\circ} \mathrm{C}$ and 30 seconds at $72^{\circ} \mathrm{C}$. Fluorescent signals were measured at $61.5^{\circ} \mathrm{C}$. Genotypes were assigned using the iCycler iQ Optical System Software version 3.1.

The $-1195 A \rightarrow G$ polymorphism of the COX-2 gene was detected using the method earlier described by Zhang et al. ${ }^{16}$

\section{Statistics}

Unconditional logistic regression models were applied to estimate odds ratios (OR) and $95 \%$ confidence intervals $(\mathrm{Cl})$ for the polymorphisms at -765 and -1195 and of the predicted COX-2 expression levels, adjusting for age (continuous, per year increase), gender, alcohol consumption ( $0 ; 1-4$ or $>4$ units per day) and smoking behaviour (0; 1-19, 20-39, 40-59 and 60+ pack-years). Stratified regression analyses were performed, according to gender and smoking habits (less than 40 pack-years, versus 40 pack-years or more). Separate regression analyses were also performed for patients with laryngeal cancers, oral/oropharyngeal cancers and those with hypopharyngeal cancer. In all analyses a probability level of 0.05 was used as the criterion of significance. All analyses were performed with the software SPSS for Windows version 13.0 (SPSS Inc., Chicago, IL, USA).

\section{Results}

General characteristics of patients and controls included in this study are given in Table 1.

The -1195 and -765 polymorphism distributions of the COX-2 gene as found in patients and controls are given in Table 2 . The prevalence of the $-1195 \mathrm{~A}$ and $-1195 \mathrm{G}$ alleles was $79.3 \%$ and $20.7 \%$ for the patient group and $78.0 \%$ and $22.0 \%$ for the control group, respectively. Distribution of this polymorphism in both patient and control groups fitted the Hardy Weinberg equilibrium ( $p=0.30$ and $p=0.10$, respectively). The prevalence of the $-765 \mathrm{G}$ and $-765 \mathrm{C}$ alleles was $86.6 \%$ and $13.4 \%$ among the patient group and $85.5 \%$ and $14.5 \%$ for the control group, respectively. The distribution of this polymorphism in patients and controls fitted the HardyWeinberg equilibrium ( $p=0.84$ and $p=0.12$, respectively).

Based on the distribution of these polymorphisms in patients and controls there were no significant differences in the occurrence of putative high $(-765 \mathrm{G} /-765 \mathrm{G})$ 
versus intermediate $(-765 G /-765 C)$ or low $(-765 C /-765 C)$ COX-2 expression genotypes (see Table 2, P-value test for trend $=0.727$ ). We could not demonstrate an altered risk of SCCHN for the genotypes with a predicted high, versus the combined genotypes with expected intermediate and low COX-2 expression taken together (OR: 0.94, 95\% Cl: 0.68-1.31). In addition, when analyzed per tumor site (laryngeal cancer, $n=176$; oral/oropharyngeal cancer, $n=198$; hypopharyngeal cancer, $n=$ 54), sex (males/females) or smoking behaviour (consumption <40 pack-years/consumption $\geq 40$ pack-years) logistic regression analyses of genotypes of patients with a predicted high, versus the combined genotypes with expected intermediate and low COX-2 expression, did reveal no differences at all (data not shown) when compared to the controls.

Table 1. General characteristics of patients and control subjects.

\begin{tabular}{|c|c|c|c|c|c|}
\hline & \multicolumn{2}{|c|}{$\begin{array}{l}\text { Patients } \\
n=431\end{array}$} & \multicolumn{2}{|c|}{$\begin{array}{l}\text { Controls } \\
n=438\end{array}$} & \multirow[t]{2}{*}{$p$-value } \\
\hline \multicolumn{5}{|l|}{ Age (years) } & \\
\hline$<50$ & 65 & $15 \%$ & 46 & $11 \%$ & $<0.0001$ \\
\hline $50-59$ & 134 & $31 \%$ & 243 & $56 \%$ & \\
\hline $60-69$ & 133 & $31 \%$ & 147 & $34 \%$ & \\
\hline $70+$ & 99 & $23 \%$ & 2 & $1 \%$ & \\
\hline Mean (range) & 61 & $(23-93)$ & 57 & $(36-91)$ & \\
\hline \multicolumn{6}{|l|}{ Sex } \\
\hline Male & 340 & $79 \%$ & 343 & $78 \%$ & 0.836 \\
\hline Female & 91 & $21 \%$ & 95 & $22 \%$ & \\
\hline \multicolumn{6}{|c|}{ Smoking (pack-years)* } \\
\hline 0 & 30 & $7 \%$ & 0 & $0 \%$ & $<0.0001$ \\
\hline $1-19$ & 49 & $11 \%$ & 95 & $22 \%$ & \\
\hline 20-39 & 162 & $38 \%$ & 221 & $51 \%$ & \\
\hline $40-59$ & 144 & $33 \%$ & 93 & $21 \%$ & \\
\hline $60+$ & 46 & $11 \%$ & 28 & $6 \%$ & \\
\hline \multicolumn{6}{|c|}{ Alcohol (consumption/day) } \\
\hline 0 & 55 & $13 \%$ & 74 & $17 \%$ & $<0.0001$ \\
\hline $1-4$ & 252 & $58 \%$ & 333 & $76 \%$ & \\
\hline$>4$ & 124 & $29 \%$ & 31 & $7 \%$ & \\
\hline
\end{tabular}

* Pack-year is defined as smoking 20 cigarettes per day during one year.

Also the occurrence of putative high (-1195A/-1195A) versus intermediate (-1195G/$1195 A)$ or low (-1195G/-1195G) COX-2 expression genotypes in patients versus controls was not different (see Table 2, $p$-value test for trend $=0.418$ ). No altered risk of SCCHN was noticed for the genotypes with a predicted high, versus the combined genotypes with expected intermediate and low COX-2 expression taken to- 
gether (OR: $0.83,95 \% \mathrm{Cl}: 0.62-1.11$ ). Similarly as for the -765 polymorphism, when analyzed per tumor site, sex or smoking behaviour, logistic regression analysis of genotypes of patients with a predicted high, versus the combined genotypes with expected intermediate and low COX-2 expression, did reveal no differences at all (data not shown) as compared to the controls.

Table 2. Distribution of the COX-2 -1195 and -765 polymorphisms in patients and controls.

\begin{tabular}{|c|c|c|c|c|c|c|}
\hline & \multicolumn{2}{|c|}{ Patients } & \multicolumn{2}{|c|}{ Controls } & \multirow[b]{2}{*}{ OR } & \multirow[b]{2}{*}{$95 \% \mathrm{Cl}$} \\
\hline & $\mathrm{n}$ & $\%$ & $\mathrm{n}$ & $\%$ & & \\
\hline COX-2 -1195 genotype & \multicolumn{2}{|c|}{$n=431$} & \multicolumn{2}{|c|}{$n=438$} & & \\
\hline$-1195 A /-1195 A$ & 275 & 64 & 260 & 59 & 1 (ref.) & \\
\hline$-1195 G /-1195 A$ & 134 & 31 & 163 & 37 & 0.79 & $0.58-1.07$ \\
\hline$-1195 G /-1195 G$ & 22 & 5 & 15 & 3 & 1.24 & $0.60-2.56$ \\
\hline COX-2 -765 genotype & \multicolumn{2}{|c|}{$n=428$} & \multicolumn{2}{|c|}{$n=433$} & & \\
\hline$-765 G /-765 G$ & 321 & 75 & 321 & 74 & 1 (ref.) & \\
\hline$-765 G /-765 C$ & 99 & 23 & 99 & 23 & 0.99 & $0.71-1.40$ \\
\hline$-765 C /-765 C$ & 8 & 2 & 13 & 3 & 0.59 & $0.23-1.49$ \\
\hline
\end{tabular}

Abbreviations: COX-2, Cyclooxygenase-2; OR, Odds ratios; $\mathrm{Cl}$, confidence interval.

Note: OR's are adjusted for age (continuous), sex, smoking (continuous, 5 levels) and alcohol consumption (continuous, 3 levels).

\section{Discussion}

Recently it has been documented that COX-2 may play a role in the development of various tumors, $^{1-4,6-8}$ most interestingly also cancers of the esophagus, ${ }^{6,16,20}$ which may have similar etiological factors as reported for squamous cell carcinomas of the head and neck (SCCHN).

In a large study on 1026 patients with esophageal squamous cell carcinoma (ESCC) and 1270 controls, Zhang et al. ${ }^{16}$ showed an 1.72-fold (95\% Cl: $\left.1.35-2.20\right)$ and 2.24fold (95\% Cl: 1.59-3.16) risk of developing ESCC for $-1195 A$ A or $-765 C C$ genotype carriers compared with non-carriers, respectively. This seemed to be a controversial result at first sight, since the $-1195 A A$ genotype was associated with a potentially higher COX-2 expression ${ }^{16}$ whereas the $-765 C C$ genotype was reported to be associated with a reduced expression. ${ }^{19}$ However, more recently Szczeklik et al. $^{21}$ described that the production of prostaglandins by monocytes was more than 10 -fold higher in -765CC, as compared to in -765GG homozygote individuals, strongly suggesting that the $-765 \mathrm{C}$ polymorphism may lead to enhanced synthesis of pros- 
taglandins. This could mean that both polymorphisms (-1195A and $-765 C)$ could exert a similar biological effect, both increasing the action of COX-2 and increasing the risk for cancer, as noticed in the ESCC patients studied by Zhang et al. ${ }^{16}$

Since the risk factors for ESCC and SCCHN may be very similar (such as smoking and consumption of alcohol), we hypothesized that the -1195 and -765 COX-2 polymorphisms studied here, in addition to modulating the risk of ESCC, might also modulate the risk for SCCHN. However, no effect at all on SCCHN was noticed here of both polymorphisms.

Explanations for this unexpected findings may be as follows: the etiology of squamous cell carcinoma of the upper areodigestive tract might be different between individuals in China and the Netherlands, due to differences in dietary habits or environmental factors, or otherwise due to differences in sensitivity towards dietary or environmental factors (smoking or consumption of alcohol) due to differences in genetic constitution as a result of the different racial background. Comparison of the genotype distribution of both polymorphisms studied here indeed show large differences between the Chinese and the Dutch study populations: In Chinese controls, percentages of $-1195 A A,-1195 G A$ and $-1195 G G$ genotypes of $24.1 \%, 53.4 \%$ and $22.5 \%$ were found ${ }^{16}$ whereas corresponding values of $59.4 \%, 37.2$ and $3.4 \%$ were found in our Dutch controls. These latter data are in good agreement with the values of $62.5 \%, 32.5 \%$ and $5.0 \%$ obtained for the same genotypes in the study of Moons et al. $^{20}$ on 495 "Dutch controls" with reflux esophagitis and Barrett's esophagus. Similar differences between Chinese and Dutch control individuals are found for the -765 polymorphism: Chinese versus Dutch distribution of -765GG, 765 GC and $-765 C$ genotypes are $95.7 \%$ vs. $74.1 \%, 4.3 \%$ vs. $22.9 \%$ and $0.0 \%$ vs. $3.0 \%$, respectively. ${ }^{16}$

A recent European study on 811 patients with squamous cell carcinoma of the upper aerodigestive tract did reveal no significant association between another polymorphism in the COX-2 gene ( $r$ 5 5275; C8473T) an the risk for this type of cancer. ${ }^{22}$

Overexpression of COX-2 was observed in several types of cancers, ${ }^{6-8}$ including head and neck cancer, ${ }^{14,15}$ and therefore inhibitors of COX-2, such as non steroidal antiinflammatory drugs (NSAIDs) could potentially be used as anti-cancer agents. ${ }^{5,10}$ Recently aspirin, one of the NSAIDs, was shown to be effective in the chemopreven- 
tion of head and neck cancer, although only in moderate consumers of alcohol and tobacco. ${ }^{23}$ To further elucidate the beneficial effects of COX-2 inhibitors, it would be highly valuable in future studies to also collect data on the use of NSAIDs in patients with SCCHN and controls.

Summarizing, in contrast to earlier reports on a role of the COX-2 polymorphisms at -1195 and -765 , in modulating the risk for esophageal squamous cell carcinoma in a Chinese population, we did not find evidence for a similar role of these variations in the COX-2 gene in the risk modulation for squamous cell carcinomas of the head and neck in Dutch whites.

\section{References}

1. Williams CS, Mann M, DuBois RN. The role of cyclooxygenases in inflammation, cancer, and development. Oncogene 1999;18:7908-7916.

2. Fosslien E. Molecular pathology of cyclooxygenase-2 in neoplasias. Ann Clin Lab Sci 2000;30:3-21.

3. Trifan OC, Hla T. Cyclooxygenase-2 modulates cellular growth and promotes tumorigenesis. J Cell Mol Med 2003;7:207-222.

4. Gately S. The contributions of cyclooxygenase-2 to tumor angiogenesis. Cancer Metastasis Rev 2000;19:19-27.

5. Gasparini G, Longo R, Sarminento R, Morabito A. Inhibitors of cyclooxygenase 2: a new class of anticancer agents? Lancet Oncol 2003;4:605-615.

6. Shamma A, Yamamoto H, Doki Y, et al. Upregulation of cyclooxygenase-2 in squamous carcinogenesis of the esophagus. Clin Cancer Res 2000;6:1229-1238.

7. Buskens $C J$, van Rees BP, Sivula A, et al. Prognostic significance of elevated cyclooxygenase 2 expression in patients with adenocarcinoma of the esophagus. Gastroenterology 2002;122:1800-1807.

8. Murata $\mathrm{H}$, Kawano $\mathrm{S}$, Tsuji $\mathrm{S}$, et al. Cyclooxygenase-2 overexpression enhances lymphatic invasion and metastasis in human gastric carcinoma. Am J Gastroenterol 1999;94:451-455.

9. Romano $\mathrm{M}$, Claria J. Cyclooxygenase-2 and 5-lipoxygenase converting functions on cell proliferation and tumor angiogenesis: implications for cancer therapy. FASEB J 2003;17:1986-1995.

10. FitzGerald GA, Patrono C. The coxibs, selective inhibitors of cyclooxygenase-2. N Engl J Med 2001;345:433-442.

11. Lewin $\mathrm{F}$, Norell $\mathrm{SE}$, Johansson $\mathrm{H}$, et al. Smoking tobacco, oral snuff, and alcohol in the etiology of squamous cell carcinoma of the head and neck: a population-based case-referent study in Sweden. Cancer 1998;82:1367-1375.

12. Maier H, Dietz A, Gewelke U, Heller WD, Weidauer H. Tobacco and alcohol and the risk of head and neck cancer. Clin Investig 1992;70:320-327.

13. Liu ES, Shin VY, Ye YN, Luo JC, Wu WK, Cho CH. Cyclooxygenase-2 in cancer cells and macrophages induces colon cancer cell growth by cigarette smoke extract. Eur J Pharmacol. 2005;518:47-55.

14. Chan G, Boyle JO, Yang EK, et al. Cyclooxygenase-2 expression is up-regulated in squamous cell carcinoma of the head and neck. Cancer Res. 1999;59:991-994.

15. Kourelis K, Sotiropoulou-Bonikou G, Vandoros G, Repanti M, Varakis I, Goumas P. Coordinated upregulation of COX-2 and NF-kappaB is a steady feature of laryngeal carcinogenesis. ORL J Otorhinolaryngol Relat Spec. 2007;69:181-189. 
16. Zhang $X$, Miao X, Tan $W$, et al. Identification of functional genetic variants in cyclooxygenase-2 and their association with risk of esophageal cancer. Gastroenterology 2005;129:565-576.

17. Fritsche E, Baek SJ, King LM, Zeldin DC, Eling TE, Bell DA. Functional characterization of cyclooxygenase-2 polymorphisms. J Pharmacol Exp Ther 2001;299:468-476.

18. Lin HJ, Lakkides KM, Keku TO, et al. Prostaglandin H synthase 2 variant (Val511Ala) in African Americans may reduce the risk for colorectal neoplasia. Cancer Epidemiol Biomarkers Prev 2002;11:13051315.

19. Papafili A, Hill MR, Brull DJ, et al. Common promoter variant in cyclooxygenase-2 represses gene expression: evidence of role in acute-phase inflammatory response. Arterioscler Thromb Vasc Biol 2002; 22:1631-1636.

20. Moons LMG, Kuipers EJ, Rygiel AM, et al. COX-2 CA-haplotype is a risk factor for the development of esophageal adenocarcinoma. Am J Gastroenterol. 2007;102:2373-2379.

21. Szczeklik W, Sanak M, Szczeklik A. Functional effects and gender association of COX-2 gene polymorphism G-765C in bronchial asthma. J Allergy Clin Immunol 2004;114:248-253.

22. Campa D, Hashibe $M$, Zaridze $D$, et al. Association of common polymorphisms in inflammatory genes with risk of developing cancers of the upper aerodigestive tract. Cancer Causes Control. 2007;18:449-455.

23. Jayaprakash V, Rigual NR, Moysich KB, et al. Chemoprevention of head and neck cancer with aspirin: a case-control study. Arch Otolaryngol Head Neck Surg. 2006;132:1231-1236. 



\title{
Chapter 4
}

Genetic polymorphisms in the tobacco smoke carcinogens detoxifying enzyme UGT1A7 and the risk of head and neck cancer

\author{
Martin Lacko \\ Hennie M.J. Roelofs \\ Rene H.M. te Morsche \\ Adri C. Voogd \\ Michael B. Oude Ophuis \\ Wilbert H.M. Peters \\ Johannes J. Manni
}

Head \& Neck 2009; 31: 1274-1281. 


\section{Abstract}

Background: UGT1A7 is an enzyme involved in the metabolism of (pro)carcinogens present in tobacco smoke. We investigated whether genetic polymorphisms in UGT1A7, with predicted altered enzyme activity, may have a risk-modifying effect on head and neck carcinogenesis.

Methods: Blood samples from 427 patients with oral, pharyngeal and laryngeal carcinoma and 420 healthy control subjects were investigated for UGT1A7 polymorphisms. Based on these polymorphisms, patients and controls were divided according to predicted enzyme activity (low, intermediate, high).

Results: Logistic regression analysis showed a significant increased distribution of predicted high activity UGT1A7 polymorphisms among the patients (OR: 1.44; 95\% $\mathrm{Cl}$ : 1.07-1.93). Stratified analyses demonstrated that high activity UGT1A7 polymorphisms were even more significantly present in patients with laryngeal cancer, older patients, heavy smokers and heavy drinkers as compared to the control subjects.

Conclusion: Predicted high activity UGT1A7 polymorphisms were significantly associated with an increased risk of head and neck cancer. 


\section{Introduction}

UDP-glucuronosyltransferases (UGTs) are enzymes which catalyze the conjugation and elimination of most environmental toxins and carcinogens, among them also tobacco smoke precarcinogens like benzo(a)pyrene (B[a]P) and 4 (methylnitrosamino)-1-(3-pyridyl)-1-butanone (NNK). ${ }^{1,2}$ These two precarcinogens and their metabolites are considered to play an important role in carcinogenesis of the tobacco smoke related cancers, such as squamous cell carcinoma of the head and neck $(\mathrm{SCCHN}){ }^{3,4}$

The UGTs encoding genes in humans have been assigned to two families: UGT1 and UGT2, encoding for at least fifteen different functional UGT enzymes. ${ }^{5}$ Many of the human UGTs show tissue-specific patterns of expression and there are large individual differences in expression of these enzymes in different organs. ${ }^{6,7}$ The UGT1A7 enzyme belongs to the UGT1 family and plays an important role in the metabolism and elimination of (pre)carcinogens present in tobacco smoke. ${ }^{8}$ UGT1A7 is highly expressed in the human oral, pharyngeal and laryngeal mucosa. ${ }^{9}$ The UGT1A7 gene located on chromosome $2 q 37$ is highly polymorphic and so far 11 allelic variants in four different codons have been described: UGT1A7 *1, *2, *3, *4, *5, *6, *7, *8, *9, $* 10,{ }^{*} 11 .{ }^{10}$ The nomenclature of these variants is based on the chronological order in which they have been discovered. Some of these variants, like UGT1A7*3 and $U G T 1 A 7^{*} 4$, have shown a lower corresponding catalytic activity to several substrates, among them also the $\mathrm{B}[\mathrm{a}] \mathrm{P}$ metabolites, as compared to the wild-type UGT1A7*1 encoding enzyme. ${ }^{11,12}$ These low activity polymorphisms of UGT1A7 may lead to high concentrations of $\mathrm{B}[\mathrm{a}] \mathrm{P}$ metabolites and other tobacco smoke (pro)carcinogens in the mucosa of the proximal aerodigestive tract of smokers. Low enzyme activity due to these polymorphisms at the same time may cause a shift to alternative metabolic pathways, where instead of detoxification even more carcinogenic substrates can be produced. This means that polymorphisms in UGT1A7 may influence the levels of tobacco smoke carcinogens in the mucosa of the upper aerodigestive tract of smokers, and thus might play a role in SCCHN carcinogenesis.

Aim of this study is to investigate whether different UGT1A7 polymorphisms may have a risk modifying effect in head and neck carcinogenesis, which might explain the variability in individual susceptibility to SCCHN among smokers. 


\section{Materials and Methods}

\section{Patients and controls}

A total of 439 white patients with newly diagnosed and histological confirmed squamous cell carcinoma (SSC) of the oral cavity, oropharynx, hypopharynx and larynx have been recruited in the period 1995-2005. All patients admitted to the Department of Otorhinolaryngology, Head and Neck Surgery of the University Medical Center Maastricht, to undergo diagnostic panendoscopy because of their malignancy, were asked to participate in the study. The patients were referred to the University Medical Center Maastricht from the south-east region of The Netherlands, which is the referral region of this hospital. Due to failure in isolation of DNA of sufficient quality or failure in genotyping, 12 patients were not eligible for the evaluation and ultimately 427 patients (339 males, 88 females; $79 \%$ and $21 \%$, respectively) were included in the study. This group consists of 179 patients $(41.9 \%)$ with laryngeal carcinoma, 116 patients (27.2\%) with oropharyngeal carcinoma, 82 patients $(19.2 \%)$ with oral cavity carcinoma and 50 patients $(11.7 \%)$ with hypopharyngeal carcinoma. Median age of the patient group was 61 years (range 36-91 years, see Table 1$)$.

Table 1. General characteristics of the study populations.

\begin{tabular}{|c|c|c|c|c|c|}
\hline & \multicolumn{2}{|c|}{$\begin{array}{l}\text { Patients with SCCHN } \\
\mathrm{n}=427^{*}\end{array}$} & \multicolumn{2}{|c|}{$\begin{array}{l}\text { Controls } \\
n=420\end{array}$} & P-value \\
\hline \multicolumn{6}{|l|}{ Age (years) } \\
\hline Median (range) & \multicolumn{2}{|c|}{$61(36-91)$} & \multicolumn{2}{|c|}{$57(23-93)$} & $<0.001$ \\
\hline \multicolumn{6}{|l|}{ Sex } \\
\hline Male & 339 & $79 \%$ & 329 & $78 \%$ & 0.66 \\
\hline Female & 88 & $21 \%$ & 91 & $22 \%$ & \\
\hline \multicolumn{6}{|c|}{ Smoking (pack-years) ${ }^{\#}$} \\
\hline 0 (never smokers) & 29 & $7 \%$ & 0 & $0 \%$ & $<0.001$ \\
\hline $1-19$ & 48 & $11 \%$ & 91 & $22 \%$ & \\
\hline $20-39$ & 161 & $38 \%$ & 210 & $50 \%$ & \\
\hline $40-59$ & 143 & $34 \%$ & 92 & $22 \%$ & \\
\hline$>59$ & 46 & $11 \%$ & 27 & $6 \%$ & \\
\hline \multicolumn{6}{|l|}{ Alcohol (units/day) } \\
\hline 0 & 53 & $12 \%$ & 70 & $17 \%$ & $<0.001$ \\
\hline $1-4$ & 251 & $59 \%$ & 320 & $76 \%$ & \\
\hline$>4$ & 123 & $29 \%$ & 30 & $7 \%$ & \\
\hline
\end{tabular}

Abbreviations: SCCHN- Squamous Cell Carcinoma of the Head and Neck, n-number.

* Larynx $(n=179)$; oropharynx $(n=116)$; oral cavity $(n=82)$; hypopharynx $(n=50)$.

\# Pack-year is defined as smoking 20 cigarettes per day during one year. 
From the same referral region a control group of 443 whites was recruited. This group consists of healthy blood donors obtained through the blood bank situated in the referral region of our hospital. Only smokers and past-smokers were asked to participate in the control group. Due to failure in isolation of DNA of sufficient quality or failure in genotyping in 22 controls and due to lack of data about exact smoking history in 1 control, ultimately 420 controls (328 males and 92 females; $78 \%$ and $22 \%$, respectively) were included in the study. Median age of this group was 57 years (range 23-93 years, see Table I). All participants from the control group underwent regular medical check-up before the blood donation. Controls did not suffer from any malignant disease and had no history of malignancy. The investigations were approved by the Medical Ethical Review Committee of the University Medical Center Maastricht and informed consent was obtained from all patients and controls.

Both patients and controls were asked to fill in a questionnaire with items on demographics, life-long smoking and alcohol consumption. According to the criteria described by Benhamou et a.l, ${ }^{13}$ we categorized tobacco use into the amount of pack-years: for cigarettes smokers, 1 pack-year = 20 cigarettes per day for 1 year; for cigars smokers, 1 pack-year $=4$ cigars per day for 1 year; and for pipe smokers, 1 pack-year $=5$ pipes per day for 1 year. No other form of tobacco use was found in our study population. In accord with the earlier published study of Elahi et al., ${ }^{14}$ we considered 1 glass wine, 1 glass beer and 1 small-glass hard liquor as roughly equivalent to each other, and alcohol consumption was calculated as the number of consumptions (units) per day. Participants were defined as not drinkers, if they had not consumed alcohol at all, moderate or "social" drinkers if they consumed 1 to 4 units per day ( $\leq 28$ units per week) and heavy drinkers if they consumed more than 4 units per day ( $>28$ units per week).

\section{Blood sampling and assessment of genetic polymorphisms}

Blood samples were collected by vena puncture into EDTA vacutainer tubes which were stored at $-20^{\circ} \mathrm{C}$ immediately after collection. Genomic DNA was isolated from whole blood using the Puregene ${ }^{\circledR}$ genomic DNA isolation kit, according to the instructions of the manufacturer (Gentra Systems, Minneapolis, USA). 
UGT1A7 alleles were genotyped by 1 ) melting curve analysis of the polymorphisms at codon 129 (rs17868323) and 131 (rs17868324) with fluorescence resonance energy transfer (FRET) probes in the iCycler (Biorad Laboratories BV; Hercules CA) and 2) PCR-RFLP for detection of the W208R ( $r$ 11692021) polymorphism. For detection of the polymorphisms at codons 129 and 131 the sensor probe 5'-FAMTTAAGTATTCTACTAATTTTTTGTCCTT-ph and the anchor probe 5'-GGATCGAGAAACACTGCATCAAAACAACTCTCC-TexasRed were used. The sensor probe was complementary to the mutant sequences $(129 \mathrm{~K} / 131 \mathrm{~K})$. During melting curve analysis, the mutant allele forms a more stable duplex than the wild-type allele, resulting in an allele-specific melting curve (N129K/R131K: $58^{\circ} \mathrm{C}$ vs. $47^{\circ} \mathrm{C}$ ).

To detect the W208R alteration, the forward primer $5^{\prime}$-ATGCTCGCTGGACGGCACCATTG-3' and the reverse primer 5'-TGCCGTGACAGGGGTTTGGAGA-3' were used. ${ }^{10}$ After digestion of the PCR product with Rsa I the following fragments can be found: $208 \mathrm{~W} / 208 \mathrm{~W}$ genotype, $440 \mathrm{bp} ; 208 \mathrm{~W} / 208 \mathrm{R}$ genotype, $440+337+103 \mathrm{bp}$; 208R/208R genotype, 337+103 bp.

Allelic variants in the three different codons as determined here were denoted as described earlier. ${ }^{10}$ During each PCR run, sterile $\mathrm{H}_{2} \mathrm{O}$ was added instead of genomic DNA in approximately $2 \%$ of randomly distributed wells of the 96 wells-PCR plate, which served as negative control for amplification. Approximately $4 \%$ of the samples were analyzed twice, with completely identical results. Classification of predicted UGT1A7 enzyme activity as low, intermediate and high, depending on combinations of different UGT1A7 genotypes according to Guillemette et al., ${ }^{11}$ is shown in Table 2.

\section{Statistics}

Unconditional logistic regression models were applied to estimate odds ratios (OR) and $95 \%$ confidence intervals $(95 \% \mathrm{Cl})$ for the polymorphisms with a predicted reduced enzyme activity, adjusting for age (continuous, per year increase), gender, alcohol consumption ( $0 ; 1-4$ or $\geq 4$ units per day) and smoking behaviour $(0 ; 1-19$, 20-39, 40-59 and >59 pack-years). Stratified regression analyses were performed, according to age group ( $\leq 60$ versus $>60$ years), gender, smoking habits ( $<40$ versus $\geq 40$ pack-years) and alcohol consumption ( $\leq 4$ versus $>4$ units/day). Separate regression analyses were also performed for patients with cancer of the larynx, hypophar- 
ynx, oral cavity or oropharynx. In all analyses a probability level of 0.05 was used as the criterion of significance. No adjustment for multiple testing was made. All analyses were performed with the software SPSS for Windows version 15.0 (SPSS Inc., Chicago, IL, USA).

Table 2. UGT1A7 allele frequencies in SCCHN patients and controls and predicted enzyme activity.

\begin{tabular}{|c|c|c|c|c|}
\hline \multirow[b]{2}{*}{ allele } & \multicolumn{2}{|c|}{$\begin{array}{l}\text { Patients } \\
n=427\end{array}$} & \multicolumn{2}{|c|}{$\begin{array}{l}\text { Controls } \\
n=420\end{array}$} \\
\hline & $\mathrm{n}$ & $\%$ & $\mathrm{n}$ & $\%$ \\
\hline UGT1A7*1 $\left(\mathrm{N}^{129} \mathrm{R}^{131} \mathrm{~W}^{208}\right)$ & 340 & 39.8 & 284 & 33.8 \\
\hline UGT1A7*2 $\left(\mathrm{K}^{129} \mathrm{~K}^{131} \mathrm{~W}^{208}\right)$ & 203 & 23.8 & 200 & 23.8 \\
\hline UGT1A7*3 $\left(\mathrm{K}^{129} \mathrm{~K}^{131} \mathrm{R}^{208}\right)$ & 309 & 36.2 & 352 & 41.9 \\
\hline UGT1A7*10 $\left(\mathrm{R}^{129} \mathrm{~K}^{131} \mathrm{R}^{208}\right)$ & 2 & 0.2 & 4 & 0.5 \\
\hline Predicted UGT1A7 enzyme activity ${ }^{(11)}$ & \multicolumn{4}{|c|}{ UGT1A7 genotypes } \\
\hline \multirow[t]{3}{*}{ High } & \multicolumn{4}{|c|}{ UGT1A7*1/UGT1A7*1 } \\
\hline & \multicolumn{4}{|c|}{ UGT1A7*1/UGT1A7*2 } \\
\hline & \multicolumn{4}{|c|}{ UGT1A7*2/UGT1A7*2 } \\
\hline \multirow[t]{3}{*}{ Intermediate } & \multicolumn{4}{|c|}{ UGT1A7*1/UGT1A7*3 } \\
\hline & \multicolumn{4}{|c|}{ UGT1A7*1/UGT1A7*10 ${ }^{\dagger}$} \\
\hline & \multicolumn{4}{|c|}{ UGT1A7*2/UGT1A7*3 } \\
\hline \multirow[t]{2}{*}{ Low } & \multicolumn{4}{|c|}{ UGT1A7*3/UGT1A7*3 } \\
\hline & \multicolumn{4}{|c|}{ UGT1A7*3/UGT1A7*10 ${ }^{\dagger}$} \\
\hline
\end{tabular}

Abbreviations: SCCHN- Squamous Cell Carcinoma of the Head and Neck, n-number, UGT1A7- UDPglucuronosyltransferase $1 A 7, U G T 1 A 7^{*} 1, U G T 1 A 7^{*} 2, U G T 1 A 7^{*} 3, U G T 1 A 7^{*} 10$ - different UDPglucuronosyltransferase $1 A 7$ alleles.

'Predicted activity of the UGT1A7*10 allele can be deduced from data of ref. ${ }^{11}$, since highest activity is associated with the UGT1A7 $\mathrm{W}^{208}$ protein, whereas the $\mathrm{R}^{208}$ form has the lowest activity. Since the $U G T 1 A 7^{*} 10$ allele codes for a protein with $\mathrm{R}^{208}$, it is to be expected that the UGT1A7*10 allele is associated with low enzyme activity.

\section{Results}

The distribution of the UGT1A7 polymorphisms as found in patients and controls is given in Table 2. The distribution of these polymorphisms in both patient and control groups fitted the Hardy Weinberg equilibrium $(p=0.19$ and $p=0.49$, respectively).

The logistic regression analyses showed no significant differences in the distribution of predicted low or intermediate UGT1A7 enzyme activity between the patients and the control subjects. Therefore, the low and intermediate activity categories were combined to one category of low/intermediate activity and set against the predicted high activity category. A significant difference in the distribution of polymor- 
phisms between patients with SCCHN and control subjects was found, with the high activity UGT1A7 polymorphisms being more frequent among the patients than among the control subjects (OR: $1.44 ; 95 \% \mathrm{Cl}$ : 1.07-1.93) (Table 3).

Table 3. Logistic regression analyses of predicted UGT1A7 activity in SCCHN patients according to tumor site and controls.

\begin{tabular}{|c|c|c|c|c|c|c|c|}
\hline \multirow[t]{2}{*}{ Tumor site } & \multirow{2}{*}{$\begin{array}{l}\text { Predicted UGT1A7 } \\
\text { activity }\end{array}$} & \multicolumn{2}{|c|}{ Patients } & \multicolumn{2}{|c|}{ Controls } & \multirow[t]{2}{*}{$\mathrm{OR}^{*}$} & \multirow[t]{2}{*}{$95 \% \mathrm{Cl}$} \\
\hline & & $\mathrm{n}$ & $\%$ & $\mathrm{n}$ & $\%$ & & \\
\hline \multirow[t]{2}{*}{ All sites } & Low/intermediate & 241 & 56 & 275 & 66 & 1 (ref.) & - \\
\hline & High & 186 & 44 & 145 & 35 & 1.44 & $1.07-1.93$ \\
\hline \multirow[t]{2}{*}{ Larynx } & Low/intermediate & 91 & 51 & 275 & 66 & 1 (ref.) & - \\
\hline & High & 88 & 49 & 145 & 35 & 1.90 & $1.30-2.79$ \\
\hline \multirow[t]{2}{*}{ Hypopharynx } & Low/intermediate & 38 & 55 & 275 & 66 & 1 (ref.) & - \\
\hline & High & 22 & 45 & 145 & 35 & 1.58 & $0.84-2.99$ \\
\hline \multirow[t]{2}{*}{ Oral cavity } & Low/intermediate & 51 & 62 & 275 & 66 & 1 (ref.) & - \\
\hline & High & 31 & 38 & 145 & 35 & 1.20 & $0.70-2.03$ \\
\hline \multirow[t]{2}{*}{ Oropharynx } & Low/intermediate & 71 & 61 & 275 & 66 & 1 (ref.) & - \\
\hline & High & 45 & 39 & 145 & 35 & 1.28 & $0.81-2.01$ \\
\hline \multirow[t]{2}{*}{ All sites, except oropharynx } & Low/intermediate & 170 & 55 & 275 & 66 & 1 (ref.) & - \\
\hline & High & 141 & 45 & 145 & 35 & 1.54 & $1.12-2.13$ \\
\hline \multirow{2}{*}{$\begin{array}{l}\text { All sites, except oropharynx, } \\
\text { tonsillar region }\end{array}$} & Low/intermediate & 210 & 55 & 275 & 66 & 1 (ref.) & - \\
\hline & High & 169 & 45 & 145 & 35 & 1.51 & 1.11-2.05 \\
\hline
\end{tabular}

Abbreviations: SCCHN- Squamous Cell Carcinoma of the Head and Neck, n-number, UGT1A7- UDPglucuronosyltransferase 1A7, OR- Odds ratio, $\mathrm{Cl}$-Confidence interval.

*OR's adjusted for age (continuous, per year), sex, smoking (continuous, 5 levels: 0, 1-19, 20-39, 40-59 or $>59$ pack-years) and alcohol consumption (continuous, 3 levels: 0, 1-4 or $>4$ units/day ).

A stratified analysis according to tumor site showed that the odds of having a high activity UGT1A7 polymorphism was only significantly elevated for patients with laryngeal cancer (OR: 1.90; 95\% Cl: 1.30-2.79), but not for patients with cancer of oral cavity, or oropharynx. The estimated OR for patients with cancer of hypopharynx was somewhat lower than for patients with laryngeal cancer (OR: 1.58), and with a larger $95 \% \mathrm{Cl}$, including unity $(95 \% \mathrm{Cl}$ : 0.84-2.99).

Stratified logistic regression analyses according to age, sex, smoking behaviour and alcohol consumption showed, that the higher prevalence of the high activity UGT1A7 polymorphisms was only present in older patients (>60 years) and patients classified as being heavy smokers ( $\geq 40$ pack-years) and heavy drinkers ( $>4$ units/day), as compared to the corresponding control subjects (Table 4). 
Table 4. Logistic regression analyses of predicted UGT1A7 activity in SCCHN patients and controls, according to age, sex, smoking behaviour and alcohol consumption.

\begin{tabular}{|c|c|c|c|c|c|c|c|}
\hline \multirow[t]{2}{*}{ Characteristic } & \multirow[t]{2}{*}{ Predicted UGT1A7 activity } & \multicolumn{2}{|c|}{ Patients } & \multicolumn{2}{|c|}{ Controls } & \multirow[t]{2}{*}{ OR } & \multirow[t]{2}{*}{$95 \% \mathrm{Cl}$} \\
\hline & & $\mathrm{n}$ & $\%$ & $\mathrm{n}$ & $\%$ & & \\
\hline \multicolumn{8}{|l|}{ Age (years)* } \\
\hline \multirow[t]{2}{*}{$\leq 60$} & Low/intermediate & 125 & 60 & 192 & 65 & 1 (ref.) & - \\
\hline & High & 85 & 40 & 103 & 35 & 1.16 & $0.78-1.72$ \\
\hline \multirow[t]{2}{*}{$>60$} & Low/intermediate & 116 & 53 & 83 & 66 & 1 (Ref) & - \\
\hline & High & 101 & 47 & 42 & 34 & 2.15 & $1.27-3.64$ \\
\hline \multicolumn{8}{|l|}{$\operatorname{Sex}^{+}$} \\
\hline \multirow[t]{2}{*}{ Female } & Low/intermediate & 48 & 45 & 59 & 65 & 1 (Ref) & - \\
\hline & High & 40 & 55 & 32 & 35 & 1.33 & $0.69-2.57$ \\
\hline \multirow[t]{2}{*}{ Male } & Low/intermediate & 193 & 57 & 216 & 66 & 1 (Ref) & - \\
\hline & High & 146 & 43 & 113 & 34 & 1.46 & $1.05-2.04$ \\
\hline \multicolumn{8}{|c|}{ Smoking (pack-years) ${ }^{\ddagger}$} \\
\hline \multirow[t]{2}{*}{$<40$} & Low/intermediate & 142 & 60 & 196 & 65 & 1 (Ref) & - \\
\hline & High & 95 & 40 & 105 & 35 & 1.22 & $0.84-1.77$ \\
\hline \multirow[t]{2}{*}{$\geq 40$} & Low/intermediate & 99 & 52 & 79 & 67 & 1 (Ref) & - \\
\hline & High & 90 & 48 & 40 & 33 & 2.00 & $1.20-3.35$ \\
\hline \multicolumn{8}{|c|}{ Alcohol (units/day) ${ }^{\S}$} \\
\hline \multirow[t]{2}{*}{$\leq 4$} & Low/intermediate & 176 & 58 & 250 & 64 & 1 (Ref) & \\
\hline & High & 128 & 42 & 140 & 36 & 1.19 & $0.87-1.66$ \\
\hline \multirow[t]{2}{*}{$>4$} & Low/intermediate & 65 & 53 & 25 & 83 & 1 (Ref) & \\
\hline & High & 58 & 47 & 5 & 17 & 4.70 & $1.66-13.27$ \\
\hline
\end{tabular}

Abbreviations: SCCHN- Squamous Cell Carcinoma of the Head and Neck, n-number, UGT1A7- UDPglucuronosyltransferase $1 \mathrm{~A} 7, \mathrm{OR}$ - Odds ratio, $\mathrm{Cl}$-Confidence interval.

* OR's adjusted for age (continuous, per year), sex, smoking (continuous, 5 levels: 0, 1-19, 20-39, 40-59 or $>59$ pack-years) and alcohol consumption (continuous, 3 levels: 0, 0-4 or $>4$ units/day).

${ }^{\dagger}$ OR's adjusted for age (continuous), smoking (continuous, 5 levels: 0, 1-19, 20-39, 40-59 or >59 packyears) and alcohol consumption (continuous, 3 levels: 0, 1-4 or $>4$ units/day).

${ }^{\ddagger}$ OR's adjusted for age (continuous, per year), sex, smoking (continuous, per packyear) and alcohol consumption (continuous, 3 levels: $0,1-4$ or $>4$ units/day).

${ }^{\S}$ OR's adjusted for age (continuous), sex and smoking (continuous, 5 levels: 0, 1-19, 20-39, 40-59 or >59 pack-years).

\section{Discussion}

SCCHN forms approximately $5 \%$ of the malignancies worldwide. Consumption of alcohol and tobacco smoking are the main etiologic factors in the carcinogenesis of these tumors. ${ }^{15-17} \mathrm{~B}[\mathrm{a}] \mathrm{P}$ is probably one of the most important procarinogens present in tobacco smoke. By cytochrome P-450 mediated oxidation, followed by the epoxide-hydrolase mediated hydrolysis, $\mathrm{B}[\mathrm{a}] \mathrm{P}$ is transformed through $\mathrm{B}[\mathrm{a}] \mathrm{P}$-trans- 
7,8 dihydriol (BPD) into $\mathrm{B}[\mathrm{a}] \mathrm{P}$-trans-7,8 dihydriol-9,10 epoxide (BPDE). ${ }^{18} \mathrm{BPDE}$ is an active carcinogen, highly reactive with DNA and forming DNA-adducts. This can lead to mutation of important genes involved in the carcinogenesis, such as the tumor suppressor gene $p 53$ or the oncogenes RAS or MYC, which might lead to cancer development. $^{19}$

UGT1A7 is one of isoenzymes of the UGT family, expressed in the mucosa of the upper aero-digestive tract, which catalyses the glucuronidation and excretion of BPD, thus preventing the formation of BPDE and thereby potentially decreasing the risk of SCCHN.

So far, only two studies have been published on the relationship between the UGT1A7 polymorphisms and the risk for development of SCCHN. ${ }^{9,20}$ Zheng et al., ${ }^{9}$ studying 194 case subjects (125 whites and 69 African Americans) found that both whites and African-Americans with the predicted low-activity genotypes had significantly increased risk of orolaryngeal cancer compared with whites and AfricanAmericans with the predicted high activity genotype. ${ }^{9}$ Vogel et al. ${ }^{20}$ observed an association between the low activity $U G T 1 A 7^{*} 3$ allelle and a significantly increased risk of proximal aero-digestive tract cancer. ${ }^{20}$ These authors postulated that presence of the $U G T 1 A 7^{*} 3$ allele could be used as a potential marker for proximal aerodigestive tract cancer susceptibility. However, only a relatively small and heterogeneous population of patients (76 patients with oral, laryngeal, oesophageal or gastric cancer) was included in this study.

A recent paper by our group reported, that many UGT1A7 genotyping studies may be flawed by primer dependent genotyping errors. ${ }^{21}$ As discussed in that paper, in the data of Vogel et al., ${ }^{20}$ the UGT1A ${ }^{*} 3$ allele could be under-represented. In addition, since the polymorphic probe used in the study of Zheng et al. ${ }^{9}$ only recognizes the $129 \mathrm{~K} / 131 \mathrm{~K}$ allele and not the more recently discovered $129 \mathrm{R} / 131 \mathrm{~K}$ allele, ${ }^{10,22}$ the classification of the UGTIA7*1, UGT1A7*2 and UGT1A7*4 alleles could be biased to some extent. To what extent this potential bias in genotyping is responsible for the differences in results between the two earlier studies ${ }^{9,20}$ and our study, is difficult to predict. This could be determined only after assaying all samples by using exactly the same methodology. 
In our study, so far the largest number of white patients with SCCHN, all of which are recruited in a small geographic area, were studied with respect to UGT1A7 polymorphisms and the risk of SCCHN. In contrast to both small and heterogeneous studies cited above, ${ }^{9,20}$ we found a small but significant difference in prevalence of high activity associated UGT1A7 polymorphisms between the SCCHN patient and the control subjects. However, when analyzing according to tumor site, this prevalence was only significantly elevated for patients with laryngeal cancer, as compared to the control subjects, and not for those with cancers of the mouth or oropharynx. In subgroup analyses, we also found that a significantly higher number of heavy smoking ( $\geq 40$ pack-years) and heavy drinking ( $>4$ units/day) SCCHN patients, were bearing the predicted high activity UGT1A7 genotypes.

Because a higher UGT1A7 enzyme activity is associated with a higher detoxification capacity towards the tobacco smoke (pro)carcinogens, this is an unexpected finding. However, a similar association between a predicted increased glucuronidation enzyme activity and an increased risk for head and neck carcinogenesis has been recently described by the group of Lazarus and coworkers, ${ }^{23}$ who found higher number of patients with the expected high enzyme activity 139E UGT1A10 allele in the 115 patients with oral and laryngeal cancer. As they stated, there are several possibilities which can explain this finding. One of the most likely explanations is the possible linkage of the 139E UGT1A10 polymorphism to one or more other functional genetic variants within the UGT1A locus, that are important in the risk for SCCHN and which overrule the possible high enzyme activity associated with the 139E UGT1A10 allele.

A similar linkage phenomenon, which could overrule the effect of the high enzyme activity UGT1A7 polymorphisms, might also explain the results of our study. Existence of such linkage between the various UGT1A polymorphisms in association with the risk of tobacco related SCCHN is currently under investigation.

Because the genetic polymorphisms in UGT1A7, as well as genetic polymorphisms in other tobacco smoke (pro)carcinogens detoxifying enzymes, may be potentially involved also in the pathogenesis of other diseases, we have decided to avoid a hospital-linked selection of our control group, to exclude the potential selection bias in this group. Instead of a hospital-linked control group we have chosen for a population of healthy smokers or past-smokers, which health conditions are confirmed 
by regularly performed medical check-ups. The population of blood donors participating in our study fulfils these criteria.

Because the aim of our study was to elucidate the role of the different polymorphisms of the tobacco smoke (pro)carcinogens detoxifying enzyme UGT1A7 in SCCHN carcinogenesis, only smokers and past-smokers, both patients and controls, should be considered as an ideal study population. However, we decided not to exclude the small sub-group of non-smokers among our cases, since these might be individuals with high genetic susceptibility to cancer, which even after low exposure to tobacco smoke carcinogens, due to passive smoking, did develop a SCCHN. Therefore, 29 patients (6.7\% from our patient population) are non-smokers, whereas our control group consists only of smokers or past-smokers. However, results of our statistical analysis were adjusted for smoking behaviour. In addition, a stratified analysis was performed according to the amount of pack-years with 40 pack-years as a cut-off point. Therefore, we do not expect that discrepancy in smoking behaviour between the patients and controls might significantly influence the results of our study.

One of the other potential shortcomings of this study is the lack of data on the human papilloma virus (HPV) involvement in head and neck carcinogenesis in our patient group. This might influence the results of this study. To exclude this potential bias, we performed a sub-analysis comparing the distribution of UGT1A7 polymorphisms between controls and all cases except those with oropharynx cancer, which is strongly associated with HPV infection. The same sub-analysis was performed with exclusion of the tonsil cancer patients. However, these analyses did not significantly change the outcome, compared to analysis of the whole study population.

In summary, in contrast to the results of Zheng et al. ${ }^{9}$ and Vogel et al., ${ }^{20}$ in our study on a much larger patient population we could not demonstrate a modulating effect of the predicted low activity UGT1A7 genotypes in SCCHN. Instead, we found a significantly increased prevalence of the predicted high activity UGT1A7 genotypes in our patient group, compared to the control subjects. Moreover, the predicted high enzyme activity genotypes were more common in patients with larynx cancer, older patients and the subgroups of heavy smokers and heavy drinkers. 


\section{References}

1. Zheng Z, Fang JL, Lazarus P. Glucuronidation: an important mechanism for detoxification of benzo[a]pyrene metabolites in aerodigestive tract tissues. Drug Metab Dispos 2002;30:397-403.

2. Ren Q, Murphy SE, Zheng Z, Lazarus P. O-Glucuronidation of the lung carcinogen 4(methylnitrosamino)-1- (3-pyridyl)-1-butanol (NNAL) by human UDP-glucuronosyltransferases $2 \mathrm{~B} 7$ and 1A9. Drug Metab Dispos 2000;28:1352-1360.

3. Pfeifer GP, Denissenko MF, Olivier M, Tretyakova N, Hecht SS, Hainaut P. Tobacco smoke carcinogens, DNA damage and p53 mutations in smoking-associated cancers. Oncogene 2002;21:74357451.

4. Hecht SS. Cigarette smoking: cancer risks, carcinogens, and mechanisms. Langenbecks Arch Surg 2006;391:603-613.

5. Mackenzie PI, Bock KW, Burchell B, et al. Nomenclature update for the mammalian UDP glycosyltransferase (UGT) gene superfamily. Pharmacogenet Genomics 2005;15:677-685.

6. Wells PG, Mackenzie PI, Chowdhury JR, et al. Glucuronidation and the UDP-glucuronosyltransferases in health and disease. Drug Metab Dispos 2004;32:281-290.

7. Strassburg CP, Nguyen N, Manns MP, Tukey RH. Polymorphic expression of the UDPglucuronosyltransferase UGT1A gene locus in human gastric epithelium. Mol Pharmacol 1998;54:647-654.

8. Strassburg CP, Strassburg A, Nguyen N, Li Q, Manns MP, Tukey RH. Regulation and function of family 1 and family 2 UDP-glucuronosyltransferase genes (UGT1A, UGT2B) in human oesophagus. Biochem J 1999;338:489-498.

9. Zheng Z, Park JY, Guillemette C, Schantz SP, Lazarus P. Tobacco carcinogen-detoxifying enzyme UGT1A7 and its association with orolaryngeal cancer risk. J Natl Cancer Inst 2001;93:1411-1418.

10. Verlaan M, Drenth JP, Truninger K, et al. Polymorphisms of UDP-glucuronosyltransferase $1 \mathrm{~A} 7$ are not involved in pancreatic diseases. J Med Genet 2005;42:e62.

11. Guillemette C, Ritter JK, Auyeung DJ, Kessler FK, Housman DE. Structural heterogeneity at the UDPglucuronosyltransferase 1 locus: functional consequences of three novel missense mutations in the human UGT1A7 gene. Pharmacogenetics 2000;10:629-644.

12. Strassburg CP, Vogel A, Kneip S, Tukey RH, Manns MP. Polymorphisms of the human UDPglucuronosyltransferase (UGT) 1A7 gene in colorectal cancer. Gut 2002;50:851-856.

13. Benhamou S, Benhamou E, Flamant R. Lung cancer risk associated with cigar and pipe smoking. Int J Cancer 1986;37:825-829.

14. Elahi A, Bendaly J, Zheng Z, et al. Detection of UGT1A10 polymorphisms and their association with orolaryngeal carcinoma risk. Cancer 2003;98:872-880.

15. Lewin $\mathrm{F}$, Norell SE, Johansson $\mathrm{H}$, et al. Smoking tobacco, oral snuff, and alcohol in the etiology of squamous cell carcinoma of the head and neck: a population-based case-referent study in Sweden. Cancer 1998;82:1367-1375.

16. Rothman KJ. Epidemiology of head and neck cancer. Laryngoscope 1978;88:435-438.

17. Maier H, Dietz A, Gewelke U, Heller WD, Weidauer H. Tobacco and alcohol and the risk of head and neck cancer. Clin Investig 1992;70:320-327.

18. Fang JL, Beland FA, Doerge DR, et al. Characterization of benzo(a)pyrene-trans-7,8-dihydrodiol glucuronidation by human tissue microsomes and overexpressed UDP-glucuronosyltransferase enzymes. Cancer Res 2002;62:1978-1986.

19. Hecht SS. Tobacco carcinogens, their biomarkers and tobacco-induced cancer. Nat Rev Cancer 2003;3:733-744.

20. Vogel A, Ockenga J, Ehmer $U$, et al. Polymorphisms of the carcinogen detoxifying UDPglucuronosyltransferase UGT1A7 in proximal digestive tract cancer. Z Gastroenterol 2002;40:497502.

21. te Morsche RH, Drenth JP, Truninger K, et al. UGT1A7 polymorphisms in chronic pancreatitis: an example of genotyping pitfalls. Pharmacogenomics J 2008;8:34-41. 
22. van der Logt EM, Bergevoet SM, Roelofs HM, et al. Genetic polymorphisms in UDP-glucuronosyltransferases and glutathione S-transferases and colorectal cancer risk. Carcinogenesis 2004;25:2407-2415.

23. Dellinger RW, Fang JL, Chen G, Weinberg R, Lazarus P. Importance of UDP-glucuronosyltransferase $1 A 10$ (UGT1A10) in the detoxification of polycyclic aromatic hydrocarbons: decreased glucuronidative activity of the UGT1A10139Lys isoform. Drug Metab Dispos 2006;34:943-949. 


\section{Chapter 5 \\ Genetic polymorphism in the conjugating enzyme UGT1A1 and the risk of head and neck cancer}

Martin Lacko

Hennie M.J. Roelofs

Rene H.M. te Morsche

Adri C. Voogd

Michel B. Oude Ophuis

Wilbert H.M. Peters

Johannes J. Manni

International Journal of Cancer 2010; 127: 2815-2821. 


\section{Abstract}

Backround: UDP-glucuronosyltransferase 1A1 (UGT1A1) is an enzyme which catalyses the glucuronidation of tobacco smoke carcinogens like benzopyrene, but also of the endogenous substrate bilirubin. Bilirubin for a long time was considered to be only a toxic waste product of hemoglobin degradation, but recent findings have shown that bilirubin is a potent antioxidant, which may play a protective role against cancer. We investigated whether a genetic polymorphism in UGT1A1 (UGT1A1*28), associated with a reduced UGT1A1 enzyme activity, may have a riskmodifying effect on head and neck carcinogenesis.

Methods: Blood samples from 421 patients with oral, pharyngeal or laryngeal carcinoma and 417 healthy controls were investigated for the UGT1A1*28 polymorphism. On the basis of the occurrence of this polymorphism, patients and controls were divided according to predicted UGT1A1 enzyme activity (low, intermediate, high).

Results: Logistic regression analysis showed a significant increased distribution of predicted high activity UGT1A1*1 polymorphism among the patients (OR: $1.37 ; 95 \%$ $\mathrm{Cl}$ : 1.02-1.83). Stratified analyses demonstrated, that predicted high activity UGT1A1 polymorphisms were present even more significantly in patients with laryngeal cancer, older patients, heavy smokers and heavy drinkers.

Conclusion: The predicted high activity UGT1A1*1 polymorphism, which results in lower serum levels of the endogenous antioxidant bilirubin, was associated with an increased risk of head and neck cancer. 


\section{Introduction}

Squamous cell carcinoma of the head and neck (SCCHN) takes the fifth place in cancer incidence worldwide. ${ }^{1}$ Tobacco smoking and alcohol consumption are the most important causes in developing of SCCHN. Approximately $57 \%$ of men and $10 \%$ of women worldwide are tobacco smokers. ${ }^{2}$ Because of individual differences in susceptibility to develop a tobacco smoke-related cancer, only a small percentage of them will ultimately suffer from SCCHN. However, the mechanisms which influence this individual risk to develop SCCHN and other tobacco and alcohol consumptionrelated cancers are still not elucidated.

Smoking individuals may be daily exposed to a large variety of harmful or even carcinogenic compounds, present in tobacco smoke. ${ }^{3-5}$ However, this threat of harmful compounds is encountered by the efficient and complex detoxification systems that exist in the epithelial cells lining the areodigestive tract. ${ }^{6}$ This detoxification is the result of a complex interaction between phase I and phase II biotransformation enzymes. UDP-glucuronosyltransferase enzymes (UGTs) are an important class of phase II conjugating enzymes, which catalyze the conjugation with UDP-glucuronic acid of many compounds, which subsequently can be excreted via bile or urine. ${ }^{7,8}$ Two main UGT families have been classified: UGT1A and UGT2B. ${ }^{7}$ UGTs generally are being considered as detoxification enzymes since their glucuronide products are more water soluble and less biologically active as compared to the nonglucuronidated parent compound. UGT1A1 is one of the important UGTs involved in the detoxification of tobacco smoke carcinogens like benzopyrenes, ${ }^{8,9}$ but UGT1A1 seems to be hardly expressed in the epithelial lining of the human areodigestive tract. $^{8}$

However, UGT1A1 is also the only enzyme which catalyses the glucuronidation of bilirubin, as part of the hemoglobin catabolism, and therefore it facilitates the excretion of bilirubin. For a long time, bilirubin was considered to be only a toxic waste product of hemoglobin degradation, but recent findings have revealed that bilirubin is a potent antioxidant, which may play a protective role against common diseases, like cardiovascular diseases and cancer. ${ }^{10-13}$ Because the concentration of serum bilirubin is inversely correlated with the UGT1A1 enzyme activity, ${ }^{14-18}$ genetic polymorphisms in UGT1A1 associated with a decreased enzyme activity, might in- 
crease serum bilirubin levels and subsequently decrease the individual risk of developing SCCHN.

In the promoter region of the UGT1A1 gene a thymine-adenosine (TA) repeat polymorphism exists. ${ }^{15}$ The presence of either six or seven TA dinucleotides in the TATA region of the UGT1A1 gene promoter (UGT1A1*1 or UGT1A1*28 allele, respectively) influences the transcriptional activity of the UGT1A1 gene and may subsequently also influence the UGT1A1 enzyme activity. The transcriptional activity is inversely related to the number of TA repeats. Caucasians with the heterozygous variant $\mathrm{TA}_{6} / \mathrm{TA}_{7}$ genotype (UGT1A1*1/UGT1A1*28) showed an intermediate UGT1A1 enzyme activity, individuals with the $\mathrm{TA}_{7} / \mathrm{TA}_{7}$ genotype (UGT1A1*28/UGT1A1*28) demonstrated the lowest, approximately 3-fold reduced enzyme activity when compared to individuals with the wild type $\mathrm{TA}_{6} / \mathrm{TA}_{6}$ genotype (UGT1A1*1/UGT1A1*1), which is associated with the highest enzyme activity. ${ }^{15-17}$ The UGT1A1*28 polymorphism is found in approximately $55 \%$ of the Caucasians. ${ }^{19}$ Grant et al. have hypothesised, that the UGT1A1*28 polymorphism may influence the susceptibility to oxidative damage and cancer development. ${ }^{20}$

In this study we investigated the relation between the UGT1A1*28 polymorphism in the promoter region of UGT1A1 and the risk of SCCHN.

\section{Materials and methods}

\section{Patients and controls}

A total of 439 Caucasian patients with newly diagnosed and histological confirmed squamous cell carcinoma of the oral cavity, oropharynx, hypopharynx and larynx have been recruited in the period 1995-2005 for a study on the relation between genetic polymorphisms in detoxification enzymes and risk of SCCHN. All patients admitted to the Department of Otorhinolaryngology, Head and Neck Surgery of the Maastricht University Medical Center, to undergo diagnostic panendoscopy because of their malignancy, were asked to participate in the study. The patients were referred to the Maastricht University Medical Center from the south-east region of The Netherlands, which is the referral region of this hospital. Due to failure in isolation of DNA of sufficient quality or failure in genotyping, 18 patients were not eligible for the evaluation and ultimately 421 patients (333 males, 88 females; $79 \%$ and 
$21 \%$, respectively) were included in the study. This group consists of 82 patients (19.5\%) with oral cavity carcinoma, 115 (27.3\%) patients with oropharyngeal carcinoma, 174 patients $(41.3 \%)$ with laryngeal carcinoma and 50 patients (11.9\%) with hypopharyngeal carcinoma. Median age of the patient group was 61 years (range 23-91 years, see Table 1).

Table 1. General characteristics of the study populations.

\begin{tabular}{|c|c|c|c|c|c|}
\hline & \multicolumn{2}{|c|}{$\begin{array}{l}\text { Patients with SCCHN* } \\
n=421\end{array}$} & \multicolumn{2}{|c|}{$\begin{array}{l}\text { Controls } \\
n=417\end{array}$} & $p$-value \\
\hline \multicolumn{6}{|l|}{ Age (years) } \\
\hline Median (range) & \multicolumn{2}{|c|}{$61(23-91)$} & \multicolumn{2}{|c|}{$57(36-91)$} & $<0.001$ \\
\hline \multicolumn{6}{|l|}{ Sex } \\
\hline Male & 333 & $79 \%$ & 323 & $78 \%$ & 0.57 \\
\hline Female & 88 & $21 \%$ & 94 & $22 \%$ & \\
\hline \multicolumn{6}{|c|}{ Smoking (pack-years) } \\
\hline 0 (never smokers) & 28 & $7 \%$ & 0 & $0 \%$ & $<0.001$ \\
\hline $1-19$ & 48 & $11 \%$ & 88 & $21 \%$ & \\
\hline 20-39 & 158 & $38 \%$ & 209 & $50 \%$ & \\
\hline $40-59$ & 142 & $34 \%$ & 92 & $22 \%$ & \\
\hline$>59$ & 45 & $11 \%$ & 28 & $7 \%$ & \\
\hline \multicolumn{6}{|l|}{ Alcohol (units/day) } \\
\hline 0 & 51 & $12 \%$ & 70 & $17 \%$ & $<0.001$ \\
\hline $1-4$ & 249 & $59 \%$ & 317 & $76 \%$ & \\
\hline$>4$ & 121 & $29 \%$ & 30 & $7 \%$ & \\
\hline
\end{tabular}

Abbreviations: SCCHN- Squamous Cell Carcinoma of the Head and Neck, n-number.

* Larynx ( $n=174)$; oropharynx ( $n=115)$; oral cavity $(n=82)$; hypopharynx $(n=50)$.

\# Pack-year is defined as smoking 20 cigarettes per day during one year.

From the same referral region a control group of 443 Caucasians was recruited. This group consists of healthy blood donors obtained through the blood bank situated in the referral region of our hospital. Only smokers and past-smokers were asked to participate in the control group. Due to failure in isolation of DNA of sufficient quality, failure in genotyping or due to lack of data on smoking history, ultimately 417 controls (323 males and 94 females; $78 \%$ and 22\%, respectively) were included in the study. Median age of this group was 57 years (range 36-91 years, see Table 1). All participants from the control group underwent regular medical check-up before the blood donation. Controls did not suffer from any malignant disease and had no history of malignancy. The investigations were approved by the Medical Ethical Review Committee of the Maastricht University Medical Center and informed consent was obtained from all patients and controls. 
Both patients and controls were asked to fill in a questionnaire with items on demographics, life-long smoking and alcohol consumption. According to the criteria described by Benhamou et al., ${ }^{21}$ we categorized tobacco use into the amount of pack-years: for cigarettes smokers, 1 pack-year = 20 cigarettes per day for 1 year; for cigars smokers, 1 pack-year $=4$ cigars per day for 1 year; and for pipe smokers, 1 pack-year $=5$ pipes per day for 1 year. No other form of tobacco use was found in our study population. According to the study of Elahi et al., ${ }^{22}$ we considered 1 glass wine, 1 glass beer and 1 small-glass hard liquor as roughly equivalent to each other, and alcohol consumption was calculated as the number of consumptions (units) per day. Participants were defined as not drinkers, if they had not consumed alcohol at all, moderate or "social" drinkers if they consumed 1 to 4 units per day ( $\leq 28$ units per week) and heavy drinkers if they consumed more than 4 units per day ( $>28$ units per week).

\section{Blood sampling and assessment of genetic polymorphisms}

Whole blood from patients and healthy controls was obtained by venapuncture in sterile vacutainer tubes, anti-coagulated with EDTA and stored at $-20^{\circ} \mathrm{C}$ until use. DNA was isolated from whole blood using the Pure Gene DNA isolation kit, according to the instructions of the manufacturer (Gentra Systems, Minneapolis, Minnesota, USA) and was stored at $4^{\circ} \mathrm{C}$.

The number of TA-repeats in the promoter region of the UGT1A1 gene was analyzed using polymerase chain reaction (PCR) conditions and primers exactly as described by Monaghan et al. ${ }^{16}$ Amplification was confirmed by agarose electrophoresis before fragments were resolved on $12 \%$ polyacrylamide gels (19:1 acrylamide/bisacrylamide; Biorad Laboratories, Veenendaal, The Netherlands) in Trisborate-EDTA buffer. Gels $(20 \times 20 \times 0.075 \mathrm{~cm})$ were run at $400 \mathrm{~V}$ for 3 hours and were stained with ethidium bromide for $30 \mathrm{~min} .{ }^{17}$ Fragments of $98 \mathrm{bp}$ indicate the $\mathrm{TA}_{6}(U G T 1 A 1 * 1)$ allele containing six TA repeats and fragments of 100 bp indicate the $\mathrm{TA}_{7}(U G T 1 A 1 * 28)$ allele, containing seven $\mathrm{TA}$ repeats.

Classification of predicted UGT1A1 enzyme activity as low, intermediate and high depending on combinations of different UGT1A1 genotypes ${ }^{15,17}$ is shown in Table 2. 
Table 2. Logistic regression analysis of predicted UGT1A1 activity in patients with SCCHN and controls, based on different UGT1A1 genotypes.

\begin{tabular}{|c|c|c|c|c|c|c|}
\hline \multirow[t]{2}{*}{ Predicted UGT1A1 activity ${ }^{17}$} & \multicolumn{2}{|c|}{$\begin{array}{l}\text { Patients with SCCHN } \\
n=421\end{array}$} & \multicolumn{2}{|c|}{$\begin{array}{l}\text { Controls } \\
n=417\end{array}$} & \multirow[b]{2}{*}{ OR } & \multirow[b]{2}{*}{$95 \% \mathrm{Cl}$} \\
\hline & $\mathrm{n}$ & $\%$ & $\mathrm{n}$ & $\%$ & & \\
\hline \multicolumn{7}{|l|}{ Low } \\
\hline UGT1A1*28/UGT1A1*28 genotype & 37 & 9 & 50 & 12 & 1 (ref.) & - \\
\hline \multicolumn{7}{|l|}{ Intermediate } \\
\hline UGT1A1*1/UGT1A1*28 genotype & 177 & 42 & 195 & 47 & 1.23 & $0.74-2.02$ \\
\hline \multicolumn{7}{|l|}{ High } \\
\hline UGT1A1*1/UGT1A1*1 genotype & 207 & 49 & 172 & 41 & 1.57 & $0.95-2.58$ \\
\hline
\end{tabular}

Test for trend $p=0.04$

Abbreviations: SCCHN- Squamous Cell Carcinoma of the Head and Neck, n-number, UGT1A1- UDPglucuronosyltransferase $1 \mathrm{~A} 1, U G T 1 A 1 * 1$ and UGT1A1*28- different alleles of UGT1A1, OR- Odds ratio, ClConfidence interval.

OR's adjusted for age (continuous, per year), sex, smoking (continuous, 5 levels: 0, 1-19, 20-39, 40-59 or $>59$ pack-years) and alcohol consumption (continuous, 3 levels: 0, 1-4 or >4 units/day ).

\section{Statistics}

Unconditional logistic regression models were applied to estimate odds ratios (OR) and $95 \%$ confidence intervals $(\mathrm{Cl})$ for the genotypes with a predicted reduced enzyme activity, adjusting for age (continuous, per year increase), gender, alcohol consumption (0,1-4 or $>4$ units per day) and smoking behaviour (0, 1-19, 20-39, 40-59 or >59 pack-years). Stratified regression analyses were performed, according to gender and smoking habits ( $<40$ pack-years, versus $\geq 40$ pack-years). Separate regression analyses were also performed for patients with laryngeal cancer, oral-, oropharyngeal cancer and those with hypopharyngeal cancer. In all analyses, a probability level of 0.05 was used as the criterion of significance. All analyses were performed with the software SPSS for Windows, version 13.0 (SPSS Inc., Chicago, IL, USA).

\section{Results}

The distribution of the UGT1A1 genotypes in our study population is given in Table 2. This distribution fitted the Hardy Weinberg equilibrium in the patient- as well as in the control group ( $p=0.92$ and $p=0.64$, respectively). 
When the individuals with predicted high enzyme activity genotype were compared to the individuals with intermediate and low predicted activity genotypes taken together, a significant difference in the distribution of genotypes between patients with SCCHN and control subjects was found. The predicted high activity $\mathrm{TA}_{6} / \mathrm{TA}_{6}$ genotype being more frequent among the patients with SCCHN than among the controls (OR: 1.37 ; 95\% Cl: 1.02-1.83; see Table 3).

Table 3. Logistic regression analyses of predicted UGT1A1 activity in patients with SCCHN according to tumor site and controls.

\begin{tabular}{|c|c|c|c|c|c|c|c|}
\hline \multirow[t]{2}{*}{ Tumor site } & \multirow[t]{2}{*}{$\begin{array}{l}\text { Predicted UGT1A1 } \\
\text { activity }\end{array}$} & \multicolumn{2}{|c|}{$\begin{array}{l}\text { Patients with } \\
\text { SCCHN }\end{array}$} & \multicolumn{2}{|c|}{ Controls } & \multirow[t]{2}{*}{$\mathrm{OR}^{*}$} & \multirow[t]{2}{*}{$95 \% \mathrm{Cl}$} \\
\hline & & $\mathrm{n}$ & $\%$ & $\mathrm{n}$ & $\%$ & & \\
\hline \multirow[t]{2}{*}{ All sites } & Low/intermediate & 214 & 51 & 245 & 59 & 1 (ref.) & - \\
\hline & High & 207 & 49 & 172 & 41 & 1.37 & $1.02-1.83$ \\
\hline \multirow[t]{2}{*}{ Larynx } & Low/intermediate & 81 & 47 & 245 & 59 & 1 (ref.) & - \\
\hline & High & 93 & 53 & 172 & 41 & 1.68 & $1.14-2.46$ \\
\hline \multirow[t]{2}{*}{ Hypopharynx } & Low/intermediate & 29 & 58 & 245 & 59 & 1 (ref.) & - \\
\hline & High & 21 & 42 & 172 & 41 & 1.09 & $0.58-2.06$ \\
\hline \multirow[t]{2}{*}{ Oral Cavity } & Low/intermediate & 45 & 55 & 245 & 59 & 1 (ref.) & - \\
\hline & High & 37 & 45 & 172 & 41 & 1.15 & $0.69-1.94$ \\
\hline \multirow[t]{2}{*}{ Oropharynx } & Low/intermediate & 59 & 51 & 245 & 59 & 1 (ref.) & - \\
\hline & High & 56 & 49 & 172 & 41 & 1.41 & $0.91-2.18$ \\
\hline \multicolumn{2}{|c|}{ All sites, except all oropharynx Low/intermediate } & 155 & 51 & 245 & 59 & 1 (ref.) & - \\
\hline subsides & High & 151 & 49 & 172 & 41 & 1.36 & $0.99-1.87$ \\
\hline \multirow{2}{*}{$\begin{array}{l}\text { All sites, except oropharynx, } \\
\text { tonsillar region }\end{array}$} & Low/intermediate & 187 & 50 & 245 & 59 & 1 (ref.) & - \\
\hline & High & 186 & 50 & 172 & 41 & 1.39 & $1.03-1.88$ \\
\hline
\end{tabular}

Abbreviations: SCCHN- Squamous Cell Carcinoma of the Head and Neck, n-number, UGT1A1- UDPglucuronosyltransferase $1 \mathrm{~A} 1$, OR- Odds ratio, $\mathrm{Cl}$-Confidence interval.

*OR's adjusted for age (continuous, per year), sex, smoking (continuous, 5 levels: 0, 1-19, 20-39, 40-59 or $>59$ pack-years) and alcohol consumption (continuous, 3 levels: $0,1-4$ or $>4$ units/day).

A stratified analysis according to tumor site showed that a high activity UGT1A1 allele was significantly more often present in patients with laryngeal cancer (OR: 1.68; 95\% Cl: 1.14-2.46), but not in patients with cancer of the oral cavity, oropharynx or hypopharynx. 
Stratified logistic regression analyses according to age, sex, smoking behaviour and alcohol consumption showed that the higher prevalence of the high activity UGT1A1 genotype was significantly more often present in older patients (>60 years) and patients classified as being heavy smokers ( $\geq 40$ pack-years) or heavy drinkers ( $>4$ units/day), as compared to the corresponding control subjects (Table 4).

Table 4. Logistic regression analyses of predicted UGT1A1 activity in patients with SCCHN and controls, according to age, sex, smoking behavior and alcohol consumption.

\begin{tabular}{|c|c|c|c|c|c|c|c|}
\hline \multirow[t]{2}{*}{ Characteristic } & \multirow[t]{2}{*}{ Predicted UGT1A1 activity } & \multicolumn{2}{|c|}{$\begin{array}{l}\text { Patients with } \\
\text { SCCHN }\end{array}$} & \multicolumn{2}{|c|}{ Controls } & \multirow[t]{2}{*}{ OR } & \multirow[t]{2}{*}{$95 \% \mathrm{Cl}$} \\
\hline & & $\mathrm{n}$ & $\%$ & $\mathrm{n}$ & $\%$ & & \\
\hline \multicolumn{8}{|l|}{ Age (years) } \\
\hline \multirow[t]{2}{*}{$\leq 60$} & Low/intermediate & 113 & 55 & 173 & 58 & 1 (ref.) & - \\
\hline & High & 93 & 45 & 123 & 42 & 1.09 & $0.74-1.60$ \\
\hline \multirow[t]{2}{*}{$>60$} & Low/intermediate & 101 & 47 & 72 & 60 & 1 (ref.) & - \\
\hline & High & 114 & 53 & 49 & 41 & 1.84 & $1.10-3.06$ \\
\hline \multicolumn{8}{|l|}{ Sex* } \\
\hline \multirow[t]{2}{*}{ Female } & Low/intermediate & 46 & 52 & 52 & 55 & 1 (ref.) & - \\
\hline & High & 42 & 48 & 42 & 45 & 1.13 & $0.60-2.14$ \\
\hline \multirow[t]{2}{*}{ Male } & Low/intermediate & 168 & 51 & 193 & 60 & 1 (ref.) & - \\
\hline & High & 165 & 50 & 130 & 40 & 1.43 & $1.03-1.99$ \\
\hline \multicolumn{8}{|c|}{ Smoking (pack-years) ${ }^{\S}$} \\
\hline \multirow[t]{2}{*}{$<40$} & Low/intermediate & 127 & 54 & 169 & 57 & 1 (ref.) & - \\
\hline & High & 107 & 46 & 128 & 43 & 1.13 & $0.78-1.62$ \\
\hline \multirow[t]{2}{*}{$\geq 40$} & Low/intermediate & 87 & 47 & 76 & 63 & 1 (ref.) & - \\
\hline & High & 100 & 54 & 44 & 37 & 1.95 & $1.18-3.22$ \\
\hline \multicolumn{8}{|c|}{ Alcohol (units/day) } \\
\hline \multirow[t]{2}{*}{$\leq 4$} & Low/intermediate & 159 & 53 & 224 & 58 & 1 (ref.) & \\
\hline & High & 141 & 47 & 163 & 42 & 1.18 & $0.86-1.63$ \\
\hline \multirow[t]{2}{*}{$>4$} & Low/intermediate & 55 & 46 & 21 & 70 & 1 (ref.) & \\
\hline & High & 66 & 55 & 9 & 30 & 2.86 & $1.20-6.86$ \\
\hline
\end{tabular}

Abbreviations: SCCHN- Squamous Cell Carcinoma of the Head and Neck, n-number, UGT1A1- UDPglucuronosyltransferase $1 \mathrm{~A} 1$, OR- Odds ratio, $\mathrm{Cl}$-Confidence interval.

\# OR's adjusted for age (continuous, per year), sex, smoking (continuous, 5 levels: 0, 1-19, 20-39, 40-59 or $>59$ pack-years) and alcohol consumption (continuous, 3 levels: 0, 0-4 or $>4$ units/day).

* OR's adjusted for age (continuous), smoking (continuous, 5 levels: 0, 1-19, 20-39, 40-59 or >59 packyears) and alcohol consumption (continuous, 3 levels: 0, 0-4 or $>4$ units/day).

${ }^{\S}$ OR's adjusted for age (continuous, per year), sex, smoking (continuous, per packyear) and alcohol consumption (continuous, 3 levels: $0,0-4$ or $>4$ units/day).

" OR's adjusted for age (continuous), sex and smoking (continuous, 5 levels: 0, 1-19, 20-39, 40-59 or >59 pack-years). 


\section{Discussion}

In this first study on the relation between the UGT1A1*28 polymorphism and risk of head and neck cancer, we found a significant association between the prevalence of the predicted high activity genotype and an increased risk of SCCHN. At first sight, this seems an unlogical finding, since UGT1A1 is involved in the detoxification of tobacco smoke carcinogens and one would expect exactly the opposite, namely an increased risk in the predicted low activity genotype group. However, the UGT1A1 enzyme facilitates also the conjugation of bilirubin and the finding of this study might be explained by the protective effect of bilirubin against cancer, which has been postulated in several epidemiological and in vitro studies in the last years. ${ }^{10,11,23,24}$ The exact mechanisms involved in the anti-carcinogenic effects of bilirubin are not completely understood. However, Ollinger et al. ${ }^{25}$ have found that bilirubin can induce a cell cycle arrest in abnormally proliferating cells. They also stated, that bilirubin may play a role in the defence against cancer by interfering with pro-carcinogenic signalling pathways. ${ }^{25}$

It is also not clear whether the serum concentration of total bilirubin (conjugated and unconjugated) or only the unconjugated fraction of bilirubin is important as an anti-carcinogen. Novotny and Vitek in their meta-analysis on the inverse relationship between serum bilirubin and atherosclerosis in humans suggest, that hyperbilirubinaemia due to a concomitant liver disease (increasing of conjugated fraction of bilirubin) may not exert the same protective affect as found by an increased concentration of unconjugated bilirubin. ${ }^{26}$ If the same is true also for the anticarcinogenic effect of bilirubin, is not clear yet.

In the present study we did not measure the serum concentration of bilirubin. However, UGT1A1 is the only enzyme involved in the conjugation of bilirubin and clearance of bilirubin solely depends on the function of this enzyme. An inverse relationship between the UGT1A1 enzyme activity based on the UGT1A1*28 polymorphism, and the blood/serum/plasma concentrations of bilirubin in Caucasians has been firmly established. ${ }^{15-18,27}$ Thus, the UGT1A1 enzyme has a permanent and long-term influence on the blood concentrations of bilirubin in humans.

Because the UGT1A1*28 polymorphism can be involved in the aetiology of different cardiovascular and probably also other non-malignant and malignant diseases, we 
have decided to avoid a hospital linked selection of our control group to exclude the potential selection bias in our study population. ${ }^{27-29}$ Instead of a hospital linked control group, we have chosen for a population of healthy smokers or past-smokers, whose health conditions are confirmed by regularly performed medical check-ups. The population of blood donors participating in our study fulfils these criteria.

Although the association between the UGT1A1*28 polymorphism and risk of SCCHN is significant for the whole patient group when compared to the controls, this association is even more pronounced for the subgroup of patients with larynx carcinoma and is not significant for the patients with cancer of the oral cavity or pharynx. It is unclear whether this is due to potentially different pathomechanisms for laryngeal versus pharyngeal carcinogenesis, since larynx carcinoma is mostly associated with tobacco smoking and alcohol consumption, whereas pharynx carcinoma is often based on infection with carcinogenic serotypes of the human papilloma virus (HPV), with or without additive exposure to tobacco smoke and alcohol. One can argue that the anti-oxidative and anti-carcinogenic effect of bilirubin may influence the pathways in which tobacco smoke and alcohol metabolites are converted into procarcinogens and carcinogens, leading to DNA damage of the mucosa and subsequently to cancer. On the other hand, there are no reasons to believe that bilirubin can influence the incorporation of the carcinogenic HPV in DNA, which may result in unlocking the carcinogenic cascade of the infected cells. In this context, it is plausible that individuals with the highest predicted UGT1A1 enzyme activity, and consequently with the lowest levels of the circulating anti-oxidant bilirubin in their blood, may have the highest cancer risk; especially, when these individuals have a high consumption of cigarettes and alcohol as is the case in the larynx cancer subgroup. One can imagine that in these individuals, the balance between attack (by cigarette smoke carcinogens) and protection (by bilirubin) is disturbed and might lead to cancer development. This could explain why especially the heavy smokers $(\geq 40$ pack-years) and heavy alcohol drinkers (>4units/day) with the predicted high activity UGT1A1 genotype (with concomitant low bilirubin protection) are associated with a higher cancer risk, when compared to the moderate smokers and drinkers. For a better understanding, one has to realize that the UGT1A1 enzyme seems to be hardly expressed in the epithelial lining of the human areodigestive tract, ${ }^{8}$ so that a direct protecting effect of this enzyme may hardly be present in the mucosa of the aerodigestive tract, whereas an indirect effect of bilirubin (distributed by the blood) may be present at all sites and in all tissues. 
Recently, we investigated the effect of the UGT1A7 polymorphisms and the risk of SCCHN. UGT1A7 is another enzyme of the UGT1 family, which is involved in detoxification of tobacco smoke (pro)carcinogens. ${ }^{30}$ Surprisingly, we found an association between an increased risk of SCCHN and the high activity polymorphisms of UGT1A7, instead of the expected low activity polymorphisms. We postulated that one of the most likely explanations of this phenomenon could be the linkage between the UGT1A7 polymorphism and other functional genetic variants of the UGT1A locus, which could overrule the effect of the predicted high enzyme activity UGT1A7 polymorphisms. In our study population, we observed a strong relationship between the predicted enzyme activities of UGT1A1 and UGT1A7 polymorphisms (see Table 5). Eighty-two percent of the individuals with predicted low enzyme activity polymorphism of UGT1A1 were also associated with predicted low activity UGT1A7 polymorphism and $74 \%$ of the individuals with predicted high enzyme activity UGT1A1 polymorphism were also associated with predicted high activity UGT1A7 polymorphism. Similar high level of agreement was observed for cases and controls separately. Comparable linkage between the predicted high activity UGT1A1 and UGT1A7 polymorphisms was described in Caucasians and Egyptians by Kohle et al. ${ }^{31}$ Thus, the noticed low anti-carcinogenic effect of the UGT1A1*1 allele with a high enzyme activity, can probably overrule the expected strong anticarcinogenic effect of high activity UGT1A7 polymorphisms. The opposite (protective) effect on carcinogenesis of SCCHN due to presence of the UGT1A1*28 polymorphism, can probably compensate the less protective effect of the low activity UGT1A7 polymorphisms.

Table 5. Predicted UGT1A1 versus UGT1A7 enzyme activity for the total group.

\begin{tabular}{|c|c|c|c|c|}
\hline & UGT1A1 & & & \\
\hline UGT1A7 & Low & Intermediate & High & Total \\
\hline Low & $71(8.6 \%)$ & $60(7.3 \%)$ & $14(1.7 \%)$ & 145 (17.6\%) \\
\hline Intermediate & $11(1.3 \%)$ & 263 (31.9\%) & $82(10.0 \%)$ & $356(43.2 \%)$ \\
\hline High & $5(0.6 \%)$ & $46(5.6 \%)$ & $272(33.0 \%)$ & $323(39.2 \%)$ \\
\hline Total & 87 (10.6\%) & 369 (44.8\%) & 368 (44.7\%) & $824(100 \%)$ \\
\hline
\end{tabular}

Notes: For 420 cases and 404 controls both the UGT1A1 and UGT1A7 polymorphism data were available. All observations on the diagonal line (Low>High) show that there is $73.5 \%$ correspondence between the UGT1A1 and UGT1A7 polymorphism.

In conclusion, in this study on the relation between the UGT1A1*28 polymorphism and risk of SCCHN we found that the high activity UGT1A1*1/UGT1A1*1 genotype 
is significantly associated with an increased risk of SCCHN. The concomitant decreased blood level of bilirubin, (when compared to genotypes with the UGT1A*28 allele) leading to decreased anti-carcinogenic and anti-oxidant capacity of bilirubin, might explain this phenomenon. Because this UGT1A1*28 polymorphism might potentially modify also the susceptibility for other malignancies, results of this study stresses the need for more research on the impact of UGT1A1 polymorphisms in relation to bilirubin blood levels and cancer risk in general. If such a relation could be confirmed, the therapeutic strategies for reducing cancer risk by increasing the blood concentrations of bilirubin with therapeutics like probenecid, as proposed by Mc Carty, ${ }^{12}$ could be established in the future.

\section{References}

1. Parkin DM, Bray F, Ferlay J, Pisani P. Global cancer statistics, 2002. CA Cancer J Clin 2005;55:74-108.

2. Hecht SS. Cigarette smoking: cancer risks, carcinogens, and mechanisms. Langenbecks Arch Surg 2006;391:603-613.

3. Hecht SS. Tobacco carcinogens, their biomarkers and tobacco-induced cancer. Nat Rev Cancer 2003;3:733-744.

4. Wogan GN, Hecht SS, Felton JS, Conney AH, Loeb LA. Environmental and chemical carcinogenesis. Semin Cancer Biol 2004;14:473-486.

5. Ames BN. Dietary carcinogens and anticarcinogens. Oxygen radicals and degenerative diseases. Science 1983;221:1256-1264.

6. de Waziers I, Cugnenc PH, Yang CS, Leroux JP, Beaune PH. Cytochrome P 450 isoenzymes, epoxide hydrolase and glutathione transferases in rat and human hepatic and extrahepatic tissues. Pharmacol Exp Ther1990;253:387-394.

7. Tukey RH, Strassburg CP. Genetic multiplicity of the human UDP-glucuronosyltransferases and regulation in the gastrointestinal tract. Mol Pharmacol 2001;59:405-414.

8. Zheng Z, Fang JL, Lazarus P. Glucuronidation: an important mechanism for detoxification of benzo[a]pyrene metabolites in aerodigestive tract tissues. Drug Metab Dispos 2002;30:397-403.

9. Fang JL, Beland FA, Doerge DR, Wiener D, Guillemette C, Marques MM, Lazarus P. Characterization of benzo(a)pyrene-trans-7,8-dihydrodiol glucuronidation by human tissue microsomes and overexpressed UDP-glucuronosyltransferase enzymes. Cancer Res 2002;62:1978-1986.

10. Zucker SD, Horn PS, Sherman KE. Serum bilirubin levels in the U.S. population: gender effect and inverse correlation with colorectal cancer. Hepatology 2004;40:827-835.

11. Temme EH, Zhang J, Schouten EG, Kesteloot H. Serum bilirubin and 10-year mortality risk in a Belgian population. Cancer Causes Control 2001;12:887-894.

12. McCarty MF. "latrogenic Gilbert syndrome"-a strategy for reducing vascular and cancer risk by increasing plasma unconjugated bilirubin. Med Hypotheses 2007;69:974-994.

13. Vitek L, Schwertner HA. The heme catabolic pathway and its protective effects on oxidative stressmediated diseases. Adv Clin Chem 2007;43:1-57.

14. Beutler E, Gelbart T, Demina A. Racial variability in the UDP-glucuronosyltransferase 1 (UGT1A1) promoter: a balanced polymorphism for regulation of bilirubin metabolism? Proc Natl Acad Sci U S A 1998;95:8170-8174. 
15. Bosma PJ, Chowdhury JR, Bakker C, Gantla S, de Boer A, Oostra BA, Lindhout D, Tytgat GN, Jansen PL, Oude Elferink RP, et al. The genetic basis of the reduced expression of bilirubin UDPglucuronosyltransferase 1 in Gilbert's syndrome. N Engl J Med 1995;333:1171-1175.

16. Monaghan G, Ryan M, Seddon R, Hume R, Burchell B. Genetic variation in bilirubin UPDglucuronosyltransferase gene promoter and Gilbert's syndrome. Lancet 1996;347:578-581.

17. Raijmakers MT, Jansen PL, Steegers EA, Peters WH. Association of human liver bilirubin UDPglucuronyltransferase activity with a polymorphism in the promoter region of the UGT1A1 gene. J Hepatol 2000;33:348-351.

18. Mercke Odeberg J, Andrade J, Holmberg K, Hoglund P, Malmqvist U, Odeberg J. UGT1A polymorphisms in a Swedish cohort and a human diversity panel, and the relation to bilirubin plasma levels in males and females. Eur J Clin Pharmacol 2006;62:829-837.

19. Strassburg CP. Pharmacogenetics of Gilbert's syndrome. Pharmacogenomics 2008;9:703-715.

20. Grant DJ, Bell DA. Bilirubin UDP-glucuronosyltransferase $1 \mathrm{~A} 1$ gene polymorphisms: susceptibility to oxidative damage and cancer? Mol Carcinog 2000;29:198-204.

21. Benhamou S, Benhamou E, Flamant R. Lung cancer risk associated with cigar and pipe smoking. Int $J$ Cancer 1986;37:825-829.

22. Elahi A, Bendaly J, Zheng Z, Muscat JE, Richie JP, Jr., Schantz SP, Lazarus P. Detection of UGT1A10 polymorphisms and their association with orolaryngeal carcinoma risk. Cancer 2003;98:872-880.

23. Keshavan P, Schwemberger SJ, Smith DL, Babcock GF, Zucker SD. Unconjugated bilirubin induces apoptosis in colon cancer cells by triggering mitochondrial depolarization. Int J Cancer 2004;112:433-445.

24. Ching S, Ingram D, Hahnel R, Beilby J, Rossi E. Serum levels of micronutrients, antioxidants and total antioxidant status predict risk of breast cancer in a case control study. J Nutr 2002;132:303-306.

25. Ollinger R, Kogler P, Troppmair J, Hermann M, Wurm M, Drasche A, Konigsrainer I, Amberger A, Weiss $\mathrm{H}$, Ofner D, Bach $\mathrm{FH}$, Margreiter R. Bilirubin inhibits tumor cell growth via activation of ERK. Cell Cycle 2007;6:3078-3085.

26. Novotny L, Vitek L. Inverse relationship between serum bilirubin and atherosclerosis in men: a metaanalysis of published studies. Exp Biol Med (Maywood)2003;228:568-571.

27. Lin JP, O'Donnell CJ, Schwaiger JP, Cupples LA, Lingenhel A, Hunt SC, Yang S, Kronenberg F. Association between the UGT1A1*28 allele, bilirubin levels, and coronary heart disease in the Framingham Heart Study. Circulation 2006;114:1476-1481.

28. Schwertner HA, Vitek L. Gilbert syndrome, UGT1A1*28 allele, and cardiovascular disease risk: possible protective effects and therapeutic applications of bilirubin. Atherosclerosis 2008;198:1-11.

29. Kitsiou-Tzeli S, Kanavakis E, Tzetis M, Kavazarakis E, Galla A, Tsezou A. Gilbert's syndrome as a predisposing factor for idiopathic cholelithiasis in children. Haematologica 2003;88:1193-1194.

30. Lacko M, Roelofs HM, Te Morsche RH, Voogd AC, Ophuis MB, Peters WH, Manni JJ. Genetic polymorphisms in the tobacco smoke carcinogens detoxifying enzyme UGT1A7 and the risk of head and neck cancer. Head \& Neck 2009; 31:1274-1281.

31. Kohle C, Mohrle B, Munzel PA, Schwab M, Wernet D, Badary OA, Bock KW. Frequent co-occurrence of the TATA box mutation associated with Gilbert's syndrome (UGT1A1*28) with other polymorphisms of the UDP-glucuronosyltransferase-1 locus (UGT1A6*2 and UGT1A7*3) in Caucasians and Egyptians. Biochem Pharmacol 2003;65:1521-1527. 


\section{Chapter 6 \\ Combined effect of genetic polymorphisms in phase I and II biotransformation enzymes on head and neck cancer risk}

Martin Lacko

Adri C. Voogd

Hennie M.J. Roelofs

Rene H.M. te Morsche

Michel B. Oude Ophuis

Wilbert H.M. Peters

Johannes J. Manni 


\section{Abstract}

Background: Combinations of genetic polymorphisms in biotransformation enzymes might modify the individual risk for head and neck cancer.

Methods: Blood samples of 432 patients with cancer of oral cavity, pharynx or larynx and 437 controls were investigated for polymorphisms in genes coding for phase I (COX-2, EPHX1) and phase II (UGT1A1, UGT1A6, UGT1A7, UGT1A8, UGT2B4, UGT2B7, UGT2B17) biotransformation enzymes. Analysis of the combined risk modifying effect for head and neck carcinogenesis was performed by grouping patients according to predicted enzyme activities, based on genetic polymorphisms in the corresponding genes.

Results: Combination of polymorphisms in COX-2 or EPHX1 with high activity polymorphisms in UGT1A1, UGT1A6 or UGT1A7 showed a risk modulating effect in head and neck carcinogenesis, especially among heavy smokers and patients with laryngeal cancer. However, no additional risk modifying effect for the combination of these polymorphisms was discovered, when compared to the impact of polymorphism in UGT1A1, UGT1A6 and UGT1A7 individually.

Conclusion: Predicted high activity polymorphisms in the phase II enzymes UGT1A1, UGT1A6 and UGT1A7 are associated with an increased risk of head and neck cancer and are more common in heavy smoking patients and in patients with laryngeal cancer. This effect is not significantly influenced in combination with polymorphisms in phase I enzymes. 


\section{Introduction}

Tobacco use, alcohol consumption and infection with carcinogenic serotypes of the human papilloma virus (HPV) are the main etiologic factors in carcinogenesis of squamous cell carcinoma of the head and neck (SCCHN), including cancer of the oral cavity, pharynx and larynx. ${ }^{1-5}$ Although the consecutive carcinogenic steps on the chromosomal and cell level, leading to transformation of the normal mucosa of the upper aerodigestive tract, become better elucidated and recognised in the last years, ${ }^{6,7}$ still little is known about the factors which determine whom of the individuals exposed to carcinogens will develop SCCHN .

Genetic factors influencing the individual capability of biotransformation and elimination of (pro)carinogens, as well as genetic factors influencing DNA-repair and apoptotic pathways, could be considered as the potential factors which can explain the differences in individual susceptibility to tobacco smoke introduced cancers like SCCHN. ${ }^{8,9}$ Biotransformation or detoxification of different environmental pollutants, or (pro)carcinogens present in tobacco and tobacco smoke, such as polycyclic aromatic hydrocarbons (PAH), takes place in two phases. Phase I (activation or functionalisation) comprises the transformation of the mostly lipophilic- to more polar compounds, by adding of functional groups to these compounds, which is necessary for completion of phase II reaction. Phase II (conjugation) makes these compounds more water-soluble and less biologically active and increases their elimination from the body. However, often the intermediate metabolites created in phase I of biotransformation are highly carcinogenic. For example, the procarcinogen benzo[a]pyrene (BaP) present in tobacco smoke, becomes activated to the ultimate carcinogen BaP trans-7,8,- dihydrodiol-9,10-epoxide. ${ }^{10}$

Individuals with high exposure to (pro)carcinogens from tobacco and tobacco smoke, in combination with a high activity of the phase I biotransformation enzymes (increased concentration of carcinogenic intermediate metabolites) and low activity of the phase II biotransformation enzymes (decreased deactivation and elimination of carcinogenic metabolites) might be more prone to develop cancer, when compare to individuals with the same exposure to carcinogens, but with a normal or low activity of phase I and a high activity of phase II enzymes. ${ }^{11}$ (See also Figure 1). 


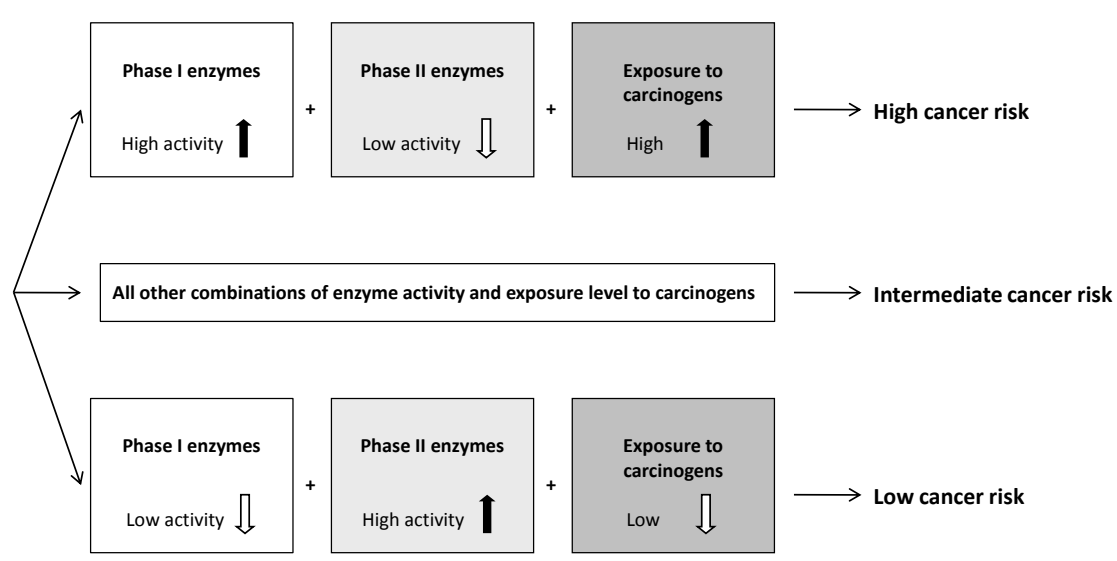

Figure 1. Cancer risk in relation to biotransformation activity and exposure to carcinogens.

Microsomal epoxide hydrolase $(\mathrm{mEH})$ is a phase I enzyme involved in biotransformation of tobacco smoke (pro)carcinogens from the polycyclic aromatic hydrocarbons (PAH) group such as benzo[a]pyrene. ${ }^{10,12}$ However, $\mathrm{mEH}$ also catalyses reactions leading to transformation of tobacco smoke procarcinogens into ultimate carcinogens as described above. ${ }^{10}$

Cyclooxygenase 2 (COX-2) is another phase I biotransformation enzyme. Although not directly involved in detoxification of (pro)carcinogens, COX-2 catalyses the biosynthesis of prostaglandins involved in many steps of carcinogenesis such as angiogenesis, cell proliferation and cell transformation. ${ }^{13,14}$ COX-2 is considered to play a risk modifying role in carcinogenesis of several cancer types.

Both $\mathrm{mEH}$ as well as COX-2 are expressed in most cell types inclusive the mucosal lining of the upper aerodigestive tract (UADT). However, in our previous studies we could not demonstrate a risk-modifying effect of genetic polymorphisms in EPHX1 (the gene coding for $\mathrm{mEH}$ ) or COX-2 gene on head and neck carcinogenesis. ${ }^{15,16}$

The Uridine 5'-diphosphate (UDP)-glucuronosyltransferases (UGTs) are a superfamily of phase II enzymes. UGTs catalyze the conjugation of mainly lipophilic substrates with UDP-glucuronic acid (glucuronidation) to form more polar conjugates, that can be easily excreted via the biliary or renal tract. ${ }^{17}$ Several members of the UGT family are involved in metabolic and detoxification pathways of (pro)carcinogens present in tobacco smoke, such as the glucuronidation of (pro)carcinogenic BaP metabolites and phenols. Hereby the concentration of such 
metabolites will be diminished, thus reducing the risk of forming DNA-adducts and cancer. ${ }^{8}$ The expression of the UGT enzymes is tissue specific: UGT1A7 is well expressed in the tongue, tonsil, floor of mouth, larynx and esophagus, whereas UGT1A8 and UGT1A6 are expressed primarily in the larynx. Also UGT2B4 and UGT2B17 exhibit significant expression levels in the upper aerodigestive tract. ${ }^{18}$

Several functional genetic polymorphisms, like single nucleotide polymorphisms (SNPs), in the genes coding for the above mentioned enzymes involved in phase I and II biotransformation of tobacco smoke (pro)carcinogens are described. These polymorphisms usually comprise several genotypes per coding gene, which may result in an altered functioning of the enzymes coded by these polymorphic genes. These alterations, either increased or decreased enzyme activity, might influence the elimination of (pro)carcinogens and therefore might modulate the individual susceptibility to cancers like SCCHN. Table 1 summarizes important functional genetic polymorphisms in the biotransformation enzymes described above and their predicted effects on the enzyme activities.

In the present study we investigated whether genetic polymorphisms in the phase I enzymes $\mathrm{mEH}$ and COX-2 combined with those in several phase II UGT enzymes, might influence the risk of SCCHN.

Table 1. Investigated genetic polymorphisms in phase I and II biotransformation enzymes and their predicted effects on enzyme activity.

\begin{tabular}{|c|c|}
\hline Genetic polymorphisms & Predicted enzyme activity \\
\hline mEH (SNP/amino acid change in enzyme protein) & Ref. $^{19}$ \\
\hline \multicolumn{2}{|l|}{ exon $3(r s 1051740, T>C)$ exon $4(r s 2234922, A>G)$} \\
\hline \multicolumn{2}{|l|}{ Tyr113His polymorphism His139Arg polymorphism } \\
\hline Tyr/Tyr (a) His/His (A) & High: $a B, a C, b C$ \\
\hline Tyr/His (b) His/Arg (B) & Intermediate : $\mathrm{aA}, \mathrm{bB}, \mathrm{cC}$ \\
\hline $\mathrm{His} / \mathrm{His}(\mathrm{c}) \mathrm{Arg} / \operatorname{Arg}(\mathrm{C})$ & Low: $b A, c A, c B$ \\
\hline COX-2 (SNP in gene promoter) & Ref. $^{20,21}$ \\
\hline \multicolumn{2}{|l|}{ COX-2 -1195 polymorphism (rs689466, A>G) } \\
\hline$-1195 A / A$ & High \\
\hline$-1195 A / G$ & Intermediate \\
\hline$-1195 G / G$ & Low \\
\hline \multicolumn{2}{|l|}{ COX-2 -765 polymorphism (rs20417, G>C) } \\
\hline$-765 G / G$ & High \\
\hline$-765 G / C$ & Intermediate \\
\hline$-765 C / C$ & Low \\
\hline
\end{tabular}




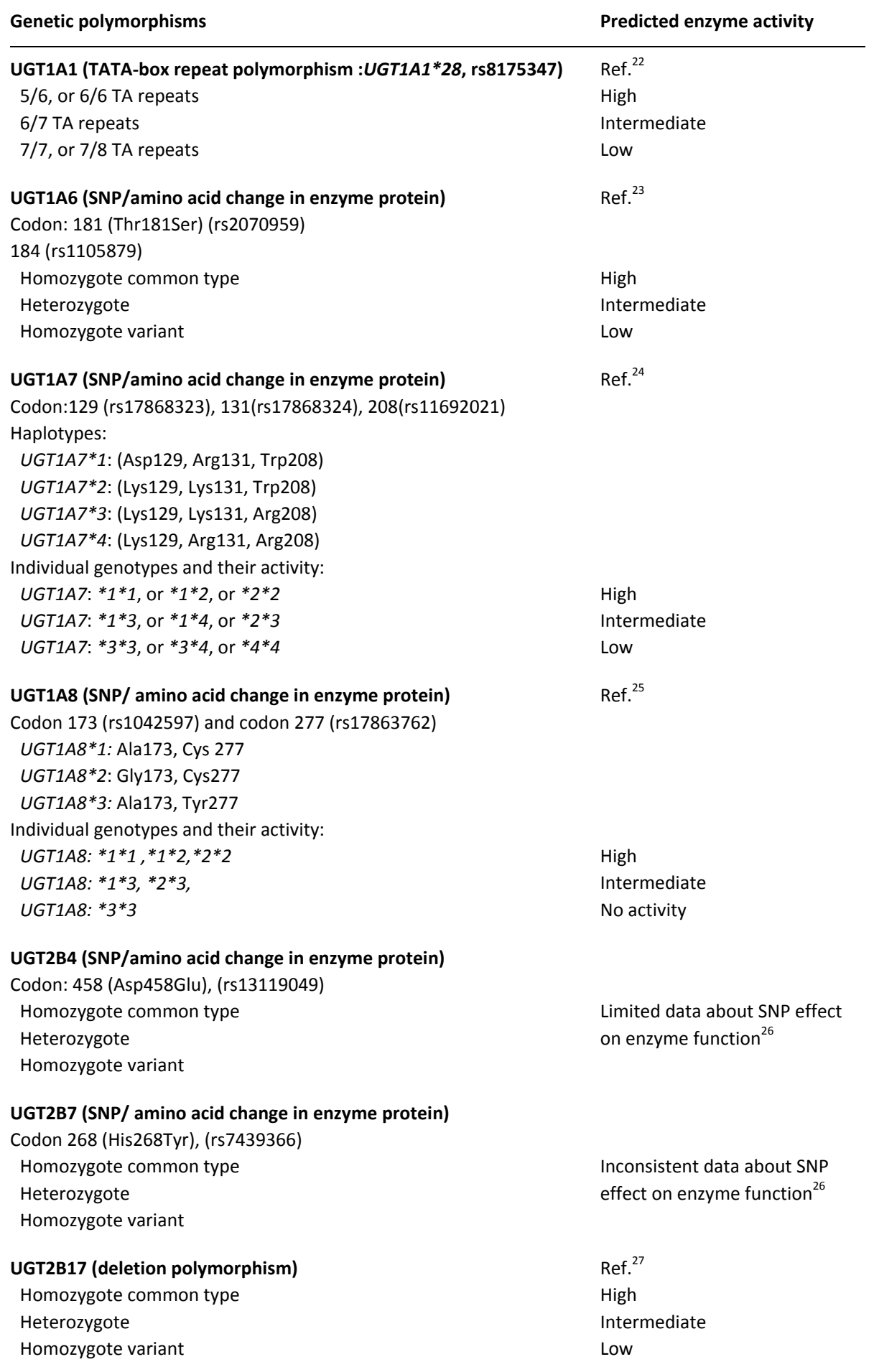




\section{Materials and Methods}

\section{Patients and controls}

A total of 439 Caucasian patients with newly diagnosed and histological confirmed squamous cell carcinoma of the oral cavity, oropharynx, hypopharynx and larynx have been recruited in the period 1995-2005 for a study on the relation between genetic polymorphisms in detoxification enzymes and risk of SCCHN. All patients admitted to the Department of Otorhinolaryngology, Head and Neck Surgery of the Maastricht University Medical Center, to undergo diagnostic panendoscopy because of their malignancy, were asked to participate in the study. The patients were referred to the Maastricht University Medical Center from the south-east region of The Netherlands, which is the referral region of this hospital. Due to failure in isolation of DNA of sufficient quality or failure in genotyping, 7 patients were not eligible for the evaluation and ultimately 432 patients (342 males, 90 females; 79\% and $21 \%$, respectively) were included in the study (see Table 2). This group consists of 83 patients (19\%) with oral cavity carcinoma, $118(27 \%)$ patients with oropharyngeal carcinoma, 181 patients (42\%) with laryngeal carcinoma and 50 patients (12\%) with hypopharyngeal carcinoma. Median age of the patient group was 61 years (range 23-91 years).

Table 2. General characteristics of the study population.

\begin{tabular}{|c|c|c|c|c|c|}
\hline & \multicolumn{2}{|c|}{$\begin{array}{l}\text { Patients with SCCHN* } \\
n=432\end{array}$} & \multicolumn{2}{|c|}{$\begin{array}{l}\text { Controls } \\
n=437\end{array}$} & $p$-value \\
\hline \multicolumn{6}{|l|}{ Age (years) } \\
\hline Median (range) & \multicolumn{2}{|c|}{$61(23-93)$} & \multicolumn{2}{|c|}{$57(36-91)$} & $<0.001$ \\
\hline \multicolumn{6}{|l|}{ Sex } \\
\hline Male & 342 & $79 \%$ & 343 & $78 \%$ & 0.81 \\
\hline Female & 90 & $21 \%$ & 94 & $22 \%$ & \\
\hline \multicolumn{6}{|c|}{ Smoking (pack-years) } \\
\hline 0 (never smokers) & 30 & $7 \%$ & 0 & $0 \%$ & $<0.001$ \\
\hline $1-19$ & 49 & $11 \%$ & 95 & $22 \%$ & \\
\hline 20-39 & 163 & $38 \%$ & 221 & $51 \%$ & \\
\hline $40-59$ & 144 & $33 \%$ & 93 & $21 \%$ & \\
\hline$>59$ & 46 & $11 \%$ & 28 & $6 \%$ & \\
\hline \multicolumn{6}{|l|}{ Alcohol (units/day) } \\
\hline 0 & 55 & $13 \%$ & 74 & $17 \%$ & $<0.001$ \\
\hline $1-4$ & 253 & $59 \%$ & 332 & $76 \%$ & \\
\hline$>4$ & 124 & $29 \%$ & 31 & $7 \%$ & \\
\hline
\end{tabular}

Abbreviations: SCCHN- Squamous Cell Carcinoma of the Head and Neck, n-number.

* Larynx $(n=181)$; oropharynx $(n=118)$; oral cavity $(n=83)$; hypopharynx $(n=50)$.

\# Pack-year is defined as smoking 20 cigarettes per day during one year. 
From the same referral region a control group of 443 Caucasians was recruited. This group consists of healthy blood donors obtained through the blood bank situated in the referral region of our hospital. Only smokers and past-smokers were asked to participate in the control group. Due to failure in isolation of DNA of sufficient quality, failure in genotyping or due to lack of data on smoking history, ultimately 437 controls (343 males and 94 females; $78 \%$ and $22 \%$, respectively) were included in the study. Median age of this group was 57 years (range 36-91 years, see Table 2). All participants from the control group underwent regular medical check-up before the blood donation. Controls did not suffer from any malignant disease and had no history of malignancy. The investigations were approved by the Medical Ethical Review Committee of the Maastricht University Medical Center and informed consent was obtained from all patients and controls.

Both patients and controls were asked to fill in a questionnaire with items on demographics, life-long smoking and alcohol consumption. According to the criteria described by Benhamou et al. ${ }^{28}$ we categorized tobacco use into the amount of pack-years: for cigarettes smokers, 1 pack-year $=20$ cigarettes per day for 1 year; for cigars smokers, 1 pack-year $=4$ cigars per day for 1 year; and for pipe smokers, 1 pack-year $=5$ pipes per day for 1 year. No other form of tobacco use was found in our study population. According to the study of Elahi et al. ${ }^{29}$ we considered 1 glass wine, 1 glass beer and 1 small-glass hard liquor as roughly equivalent to each other, and alcohol consumption was calculated as the number of consumptions (units) per day. Participants were defined as not drinkers, if they had not consumed alcohol at all, moderate or "social" drinkers if they consumed 1 to 4 units per day ( $\leq 28$ units per week) and heavy drinkers if they consumed more than 4 units per day ( $>28$ units per week).

\section{Isolation of DNA and genotyping}

Whole blood from patients and healthy controls was obtained by venapuncture in sterile vacutainer tubes, anti-coagulated with EDTA and stored at $-20^{\circ} \mathrm{C}$ until use. DNA was isolated from whole blood using the Pure Gene DNA isolation kit, according to the instructions of the manufacturer (Gentra Systems, Minneapolis, Minnesota, USA) and DNA was stored at $4^{\circ} \mathrm{C}$. 
EPHX1: A dual-colour allele-specific assay was used for genotyping the exon 3 polymorphism at codon 113 of the EPHX1 gene (rs1051740). The EPHX1 exon 4 polymorphism (rs2234922) was detected by polymerase chain reaction/restriction fragment length polymorphism (PCR/RFLP). Both methods were described by us earlier. $^{15}$

COX-2: The COX-2 -765G $\rightarrow C$ polymorphisms (rs20417) was determined by a dualcolor discrimination assay using the iCycler iQ Multicolour Real-Time Detection System (Bio-Rad Laboratories, Hercules, CA) as described earlier. ${ }^{16}$ The $-1195 \mathrm{~A} \rightarrow G$ polymorphism ( $r$ 689466) was detected essentially as described by Zhang et al. ${ }^{20}$

UGT1A1: The microsatellite polymorphisms of the TATA box in the promoter region of the UGT1A1 gene (UGT1A1*28, rs8175347) has been investigated. The number of TA-repeats was analyzed using polymerase chain reaction (PCR) conditions and primers as described before. $^{30}$

UGT1A6: The T181A (rs2070959) and R184S (rs1105879) polymorphisms in exon 1 of the UGT1A6 gene were studied using polymerase chain reaction followed by restriction fragment length polymorphism analyses. ${ }^{31}$

UGT1A7: UGT1A7 alleles were genotyped for the polymorphisms at codon 129 (rs17868323) and 131 (rs17868324) by melting curve analysis with fluorescence resonance energy transfer (FRET) probes in the iCycler (Biorad Laboratories BV; Hercules CA) and by PCR-RFLP for detection of the W208R (rs11692021) polymorphism, as described elsewhere. ${ }^{32}$

UGT1A8: The polymorphisms UGT1A8*2 (rs1042597) and UGT1A8*3 (rs17863762) were determined using polymerase chain reaction followed by restriction fragment length polymorphism analyses. The primers used for the PCR were UGT1A8*2forward (5'-CAGTTCTCTCATGGCTCGCA-3'), UGT1A8*2-reverse (5'-GTGTGGCTGTAGAGATCATATGCT-3'), UGT1A8*3-forward (5'-TCTTCATTGGTGGTATCAGCT-3') and UGT1A8*3-reverse (5'-AAAATTTGATAACTGATGAGTACATA-3'). The bold $\mathrm{G}$ in the UGT1A8*3-forward primer introduces a Pvull restriction site in the wild type allele. For PCR, the 25 microliter reaction mixture contained $200 \mathrm{ng}$ of genomic DNA, 10 $\mathrm{mM}$ Tris/ $\mathrm{HCl}$ (pH 9.0), $50 \mathrm{mM} \mathrm{KCl}, 0.1 \%$ Triton X-100, $4 \mathrm{mM} \mathrm{MgCl} 2,0.25 \mathrm{mM}$ dNTPs, 5 pmol of each primer, $200 \mathrm{nM}$ of each beacon and $2.5 \mathrm{U}$ Taq-DNA-polymerase. The 
PCR conditions were $4 \mathrm{~min}$ at $95^{\circ} \mathrm{C}$, then 40 cycles of $30 \mathrm{~s}$ at $95^{\circ} \mathrm{C}, 30 \mathrm{~s}$ at $60^{\circ} \mathrm{C}$ for the UGT1A8*2 allele or $30 \mathrm{~s}$ at $48^{\circ} \mathrm{C}$ for the UGT1A8*3 allele and $30 \mathrm{~s}$ at $72^{\circ} \mathrm{C}$ and finally an elongation step at $72^{\circ} \mathrm{C}$ for $7 \mathrm{~min}$. A 750 or $215 \mathrm{bp}$ product was amplified which was subjected to digestion with the restriction enzyme Alul for the UGT1A8*2 allele or Pvull for the UGT1A8*3 allele. Digested samples were run on a $3 \%$ agarose gel (Biozym) and stained with ethidium bromide.

UGT2B4: A dual-colour allele-specific assay was used for genotyping the polymorphism at codon 458 of the UGT2B4 gene (rs13119049). PCR was performed on the iCycler iQ Multicolour Real-Time Detection System (Bio-Rad Laboratories, Hercules, CA) as describe before. ${ }^{33}$ Genotypes were assigned using the iCycler iQ Optical System Software version 3.1. At each PCR run (in 96 wells plates) in several wells sterile $\mathrm{H}_{2} \mathrm{O}$ instead of genomic DNA was added as negative controls for amplification.

UGT2B7: A dual-colour discrimination assay for genotyping the polymorphism at codon 268 of the UGT2B7 gene (rs7439366) was developed in our laboratory as described previously. ${ }^{34}$

UGT2B17: The 150kb deletion in UGT2B17 was detected as described by Wilson et al. ${ }^{35}$

\section{Statistics}

Unconditional logistic regression models were applied to estimate odds ratios (OR) and $95 \%$ confidence intervals $(\mathrm{Cl})$ for the different combination of genotypes with a predicted enzyme activity, adjusting for age (continuous, per year increase), gender, alcohol consumption ( $0 ; 1-4$ or $>4$ units per day) and smoking behaviour $(0 ; 1-19$, 20-39, 40-59 or >59 pack-years). Separate regression analyses were also performed for patients with laryngeal cancer versus controls, all patients but pharynx cancer versus controls and for heavy smokers ( $\geq 40$ pack-years). In all analyses a probability level of 0.05 was used as the criterion of significance. All analyses were performed with the software SPSS for Windows, version 13.0 (SPSS Inc., Chicago, IL, USA). 


\section{Results}

The logistic regression analysis reveals no differences in distribution of genetic polymorphisms between patients and controls in UGT1A8, UGT2B4, UGT2B7 and UGT2B17 separately, neither in combination with the polymorphisms in EPHX1 or COX-2. The same applies also for stratified analyses considering the different tumor sites, age, sex, smoking behaviour and alcohol consumption. Therefore, only the results of genetic polymorphisms in UGT1A1, UGT1A6, UGT1A7 in combination with polymorphisms in EPHX1 (Table 3a) and COX-2 (Tables $3 b$ and $3 c$ ) and the results from the subgroup analyses (Tables $4 a, 4 b, 4 c$ ) are shown.

Table 3a. Logistic regression analyses based on predicted enzyme activities of mEH and UGTs in patients with SCCHN and controls.

\begin{tabular}{|c|c|c|c|c|c|c|}
\hline & \multicolumn{2}{|c|}{ Patients } & \multicolumn{2}{|c|}{ Controls } & \multirow[t]{2}{*}{$O R^{\pi}$} & \multirow[t]{2}{*}{$95 \% \mathrm{Cl}$} \\
\hline & $\mathrm{n}$ & $\%$ & $\mathrm{n}$ & $\%$ & & \\
\hline \multicolumn{7}{|l|}{ EPHX1_UGT1A1 } \\
\hline Low mEH and intermediate/low UGT1A1 & 86 & 21 & 101 & 25 & 1 (ref.) & - \\
\hline Low $\mathrm{mEH}$ and high UGT1A1 & 70 & 17 & 54 & 13 & 1.39 & $0.86-2.26$ \\
\hline Intermediate/high mEH and intermediate/low UGT1A1 & 128 & 31 & 131 & 33 & 0.95 & $0.63-1.42$ \\
\hline Intermediate/high mEH and high UGT1A1 & 136 & 32 & 114 & 28 & 1.24 & $0.82-1.86$ \\
\hline \multicolumn{7}{|l|}{ EPHX1_UGT1A7 } \\
\hline Low $\mathrm{mEH}$ and intermediate/low UGT1A7 & 85 & 20 & 102 & 25 & 1 (ref.) & - \\
\hline Low $\mathrm{mEH}$ and high UGT1A7 & 72 & 17 & 50 & 12 & 1.64 & $1.01-6.67 *$ \\
\hline Intermediate/high mEH and intermediate/low UGT1A7 & 156 & 37 & 161 & 40 & 1.02 & $0.69-1.50$ \\
\hline Intermediate/high mEH and high UGT1A7 & 114 & 27 & 93 & 23 & 1.30 & $0.85-1.98$ \\
\hline \multicolumn{7}{|l|}{$E P H X 1 \_U G T 1 A 6^{\wedge}$} \\
\hline Low mEH and intermediate/low UGT1A6 & 81 & 19 & 97 & 24 & 1 (ref.) & - \\
\hline Low $\mathrm{mEH}$ and high UGT1A6 & 76 & 18 & 59 & 14 & 1.50 & $0.94-2.43$ \\
\hline Intermediate/high mEH and intermediate/low UGT1A6 & 135 & 32 & 147 & 36 & 0.97 & $0.65-1.45$ \\
\hline Intermediate/high mEH and high UGT1A6 & 133 & 31 & 108 & 26 & 1.29 & $0.85-1.96$ \\
\hline
\end{tabular}

Abbreviations: mEH-microsomal epoxide hydrolase; UGT-UDP-glucuronosyltransferase (e.g. UGT1A1, UGT1A6, UGT1A7); SCCHN- Squamous Cell Carcinoma of the Head and Neck; n-number; OR- Odds ratio; $\mathrm{Cl}$-Confidence interval; EPHX1-gen coding for microsomal epoxide hydrolase; UGT1A1, UGT1A6, UGT1A7genes coding for UGT1A1, UGT1A6, UGT1A7.

ๆ OR's adjusted for age (continuous, per year), sex, smoking (continuous, 5 levels: 0, 1-19, 20-39, 40-59 or $>59$ pack-years) and alcohol consumption (continuous, 3 levels: $0,1-4$ or $>4$ units/day).

$* p<.05$;

^Results on UGT1A6_181 and UGT1A6_184 are almost identical due to the linkage of both polymorphisms; therefore, here only results of the UGT1A6_181 polymorphism are shown. 
Table 3b. Logistic regression analyses based on predicted enzyme activities of COX-2 and UGTs in patients with SCCHN and controls.

\begin{tabular}{|c|c|c|c|c|c|c|}
\hline & \multicolumn{2}{|c|}{ Patients } & \multicolumn{2}{|c|}{ Controls } & \multirow[t]{2}{*}{$\mathrm{OR}^{\pi}$} & \multirow[t]{2}{*}{$95 \% \mathrm{Cl}$} \\
\hline & $\mathrm{n}$ & $\%$ & $\mathrm{n}$ & $\%$ & & \\
\hline \multicolumn{7}{|l|}{ COX-2 -765_UGT1A1 } \\
\hline High COX-2 and intermediate/low UGT1A1 & 166 & 39 & 172 & 42 & 1 (ref.) & - \\
\hline High COX-2 and high UGT1A1 & 149 & 35 & 134 & 32 & 1.11 & $0.79-1.56$ \\
\hline Intermediate/low COX-2 and intermediate/low UGT1A1 & 48 & 11 & 70 & 17 & 0.67 & $0.43-1.06$ \\
\hline Intermediate/low COX-2 and high UGT1A1 & 58 & 14 & 38 & 9 & 1.61 & $0.99-2.63$ \\
\hline \multicolumn{7}{|l|}{ COX-2 -765_UGT1A7 } \\
\hline High COX-2 and intermediate/low UGT1A7 & 181 & 43 & 193 & 46 & 1 (ref.) & - \\
\hline High COX-2 and high UGT1A7 & 136 & 32 & 113 & 27 & 1.25 & $0.89-1.76$ \\
\hline Intermediate/low COX-2 and intermediate/low UGT1A7 & 57 & 13 & 79 & 19 & 0.75 & $0.49-1.14$ \\
\hline Intermediate/low COX-2 and high UGT1A7 & 50 & 12 & 31 & 8 & 1.69 & $1.01-2.84^{*}$ \\
\hline \multicolumn{7}{|l|}{ COX-2-765_UGT1A6^ } \\
\hline High COX-2 and intermediate/low UGT1A6 & 167 & 40 & 180 & 43 & 1 (ref.) & - \\
\hline High COX-2 and high UGT1A6 & 149 & 35 & 133 & 32 & 1.18 & $0.84-1.66$ \\
\hline Intermediate/low COX-2 and intermediate/low UGT1A6 & 47 & 11 & 71 & 17 & 0.68 & $0.47-1.07$ \\
\hline Intermediate/low COX-2 and high UGT1A6 & 60 & 14 & 38 & 9 & 1.61 & $0.99-2.63$ \\
\hline
\end{tabular}

Abbreviations: COX-2-Cyclooxygenase-2; UGT-UDP-glucuronosyltransferase; SCCHN- Squamous Cell Carcinoma of the Head and Neck; OR-Odds ratio; $\mathrm{Cl}$-Confidence interval; n-number; COX-2-gene coding for COX-2; UGT1A1, UGT1A6, UGT1A7-genes coding for UGT1A1, UGT1A6, UGT1A7.

ๆ OR's adjusted for age (continuous, per year), sex, smoking (continuous, 5 levels: 0, 1-19, 20-39, 40-59 or $>59$ pack-years) and alcohol consumption (continuous, 3 levels: $0,1-4$ or $>4$ units/day).

$* p<.05$;

$\wedge$ Results on UGT1A6_181 and UGT1A6_184 are almost identical due to the linkage of both polymorphisms; therefore, here only results of the UGT1A6_181 polymorphism are shown.

The distribution of the polymorphisms in EPHX1, COX-2, UGT1A1, UGT1A7, UGT1A6 UGT1A8, UGT2B4 and UGT2B7 in our study population fitted the Hardy Weinberg equilibrium in the control group as well as in the patients. Data on UGT2B17 genotypes however, did not fit the Hardy Weinberg equilibrium in the controls, but in this gene a large deletion of approximately $150 \mathrm{kB}$ is present, which probably is responsible for this deviation. Significant differences between patients and controls were obtained only for the distribution of predicted low activity $\mathrm{mEH}$ genotypes in combination with the predicted high activity UGT1A7 genotypes (Table 3a).

For the combinations of the COX-2 and the UGT polymorphisms, the distributions of the genotypes and their predicted activity between patients and controls were significantly different for the combination of intermediate/low activity COX-2 -765 genotype together with the high activity UGT1A7 genotype (Table $3 \mathrm{~b}$ ) and for the 
combination of a high activity COX-2 -1195 with the high activity UGT1A6 genotype (Table 3c).

Table 3c. Logistic regression analyses based on predicted enzyme activities of COX-2 and UGTs in patients with SCCHN and controls.

\begin{tabular}{|c|c|c|c|c|c|c|}
\hline & \multicolumn{2}{|c|}{ Patients } & \multicolumn{2}{|c|}{ Controls } & \multirow[t]{2}{*}{$\mathrm{OR}^{\pi}$} & \multirow[t]{2}{*}{$95 \% \mathrm{Cl}$} \\
\hline & $\mathrm{n}$ & $\%$ & $\mathrm{n}$ & $\%$ & & \\
\hline \multicolumn{7}{|l|}{ COX-2 -1195_UGT1A1 } \\
\hline High COX-2 and intermediate/low UGT1A1 & 137 & 33 & 150 & 36 & 1 (ref.) & - \\
\hline High COX-2 and high UGT1A1 & 130 & 31 & 97 & 23 & 1.37 & $0.94-1.99$ \\
\hline Intermediate/low COX-2 and intermediate/low UGT1A1 & 77 & 18 & 95 & 23 & 0.83 & $0.55-1.24$ \\
\hline Intermediate/low COX-2 and high UGT1A1 & 77 & 18 & 75 & 18 & 1.15 & $0.76-1.75$ \\
\hline \multicolumn{7}{|l|}{ COX-2 -1195_UGT1A7 } \\
\hline High COX-2 and intermediate/low UGT1A7 & 149 & 35 & 161 & 38 & 1 (ref.) & - \\
\hline High COX-2 and high UGT1A7 & 123 & 29 & 89 & 21 & 1.35 & $0.93-1.97$ \\
\hline Intermediate/low COX-2 and intermediate/low UGT1A7 & 90 & 21 & 114 & 27 & 0.78 & $0.53-1.14$ \\
\hline Intermediate/low COX-2 and high UGT1A7 & 63 & 15 & 56 & 13 & 1.26 & $0.80-1.96$ \\
\hline \multicolumn{7}{|l|}{ COX-2-1195_UGT1A6^ } \\
\hline High COX-2 and intermediate/low UGT1A6 & 133 & 31 & 155 & 36 & 1 (ref.) & - \\
\hline High COX-2 and high UGT1A6 & 139 & 33 & 99 & 23 & 1.50 & $1.03-2.18^{*}$ \\
\hline Intermediate/low COX-2 and intermediate/low UGT1A6 & 82 & 19 & 98 & 23 & 0.90 & $0.60-1.35$ \\
\hline Intermediate/low COX-2 and high UGT1A6 & 70 & 17 & 74 & 17 & 1.14 & $0.75-1.74$ \\
\hline
\end{tabular}

Abbreviations: COX-2-Cyclooxygenase-2; UGT-UDP-glucuronosyltransferase (e.g. UGT1A1, UGT1A6, UGT1A7); SCCHN- Squamous Cell Carcinoma of the Head and Neck; OR-Odds ratio; Cl-Confidence interval; n-number; COX-2- gene coding for COX-2; UGT1A1, UGT1A6, UGT1A7-genes coding for UGT1A1, UGT1A6, UGT1A7.

ๆ OR's adjusted for age (continuous, per year), sex, smoking (continuous, 5 levels: 0, 1-19, 20-39, 40-59 or $>59$ pack-years) and alcohol consumption (continuous, 3 levels: $0,1-4$ or $>4$ units/day).

$* p<.05$;

^Results on UGT1A6_181 and UGT1A6_184 are almost identical due to the linkage of both polymorphisms; therefore, here only results of the UGT1A6_181 polymorphism are shown. 


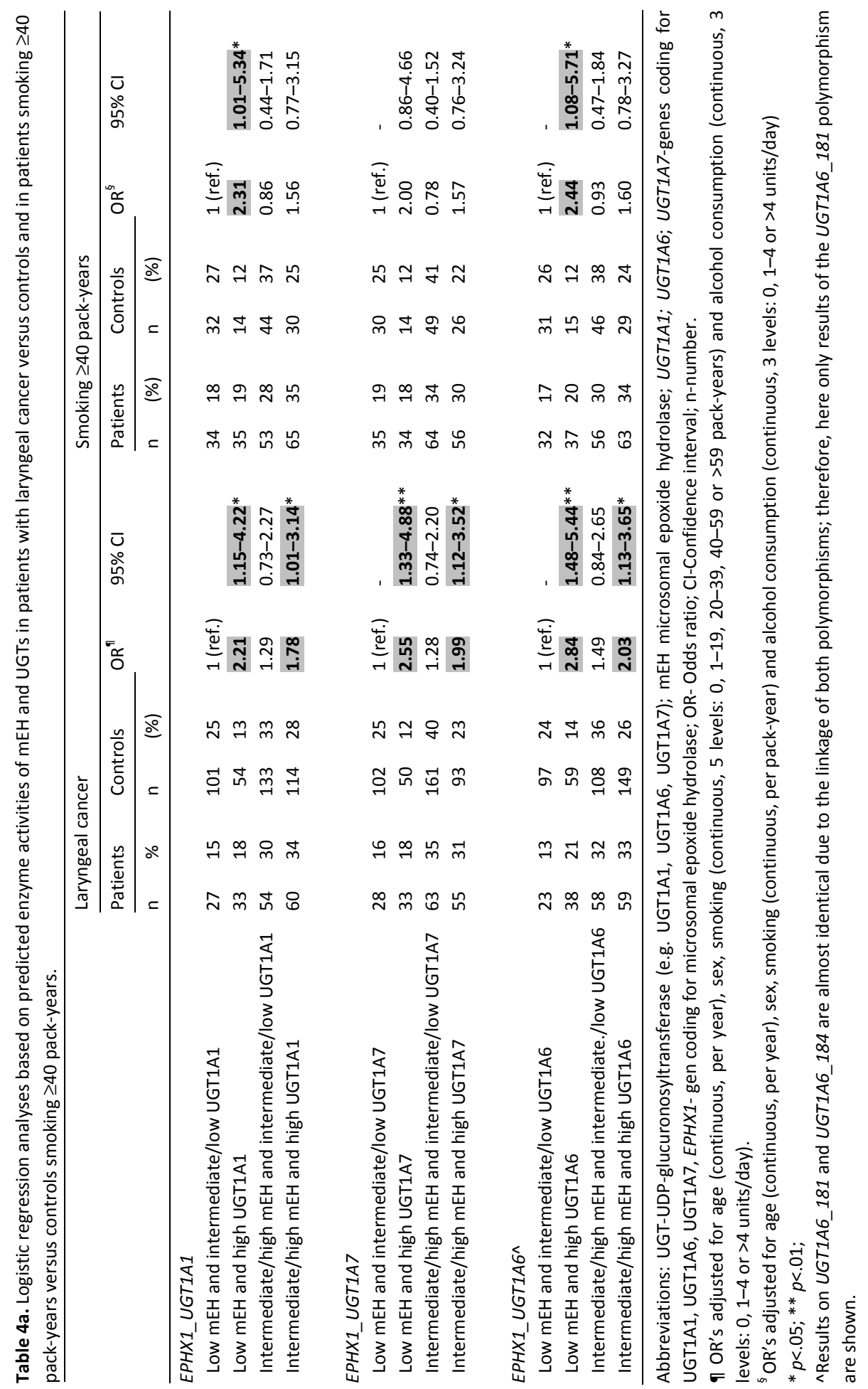




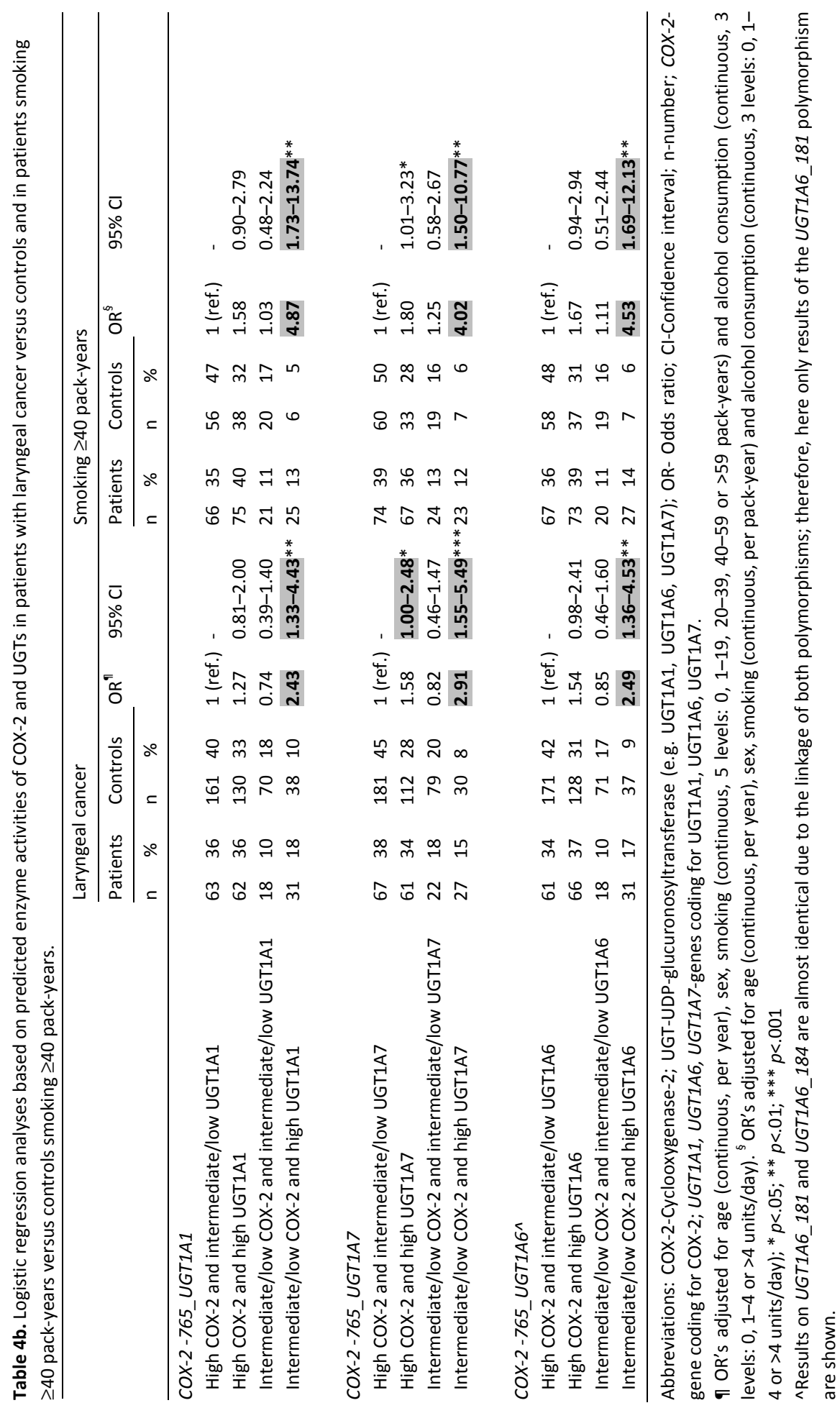




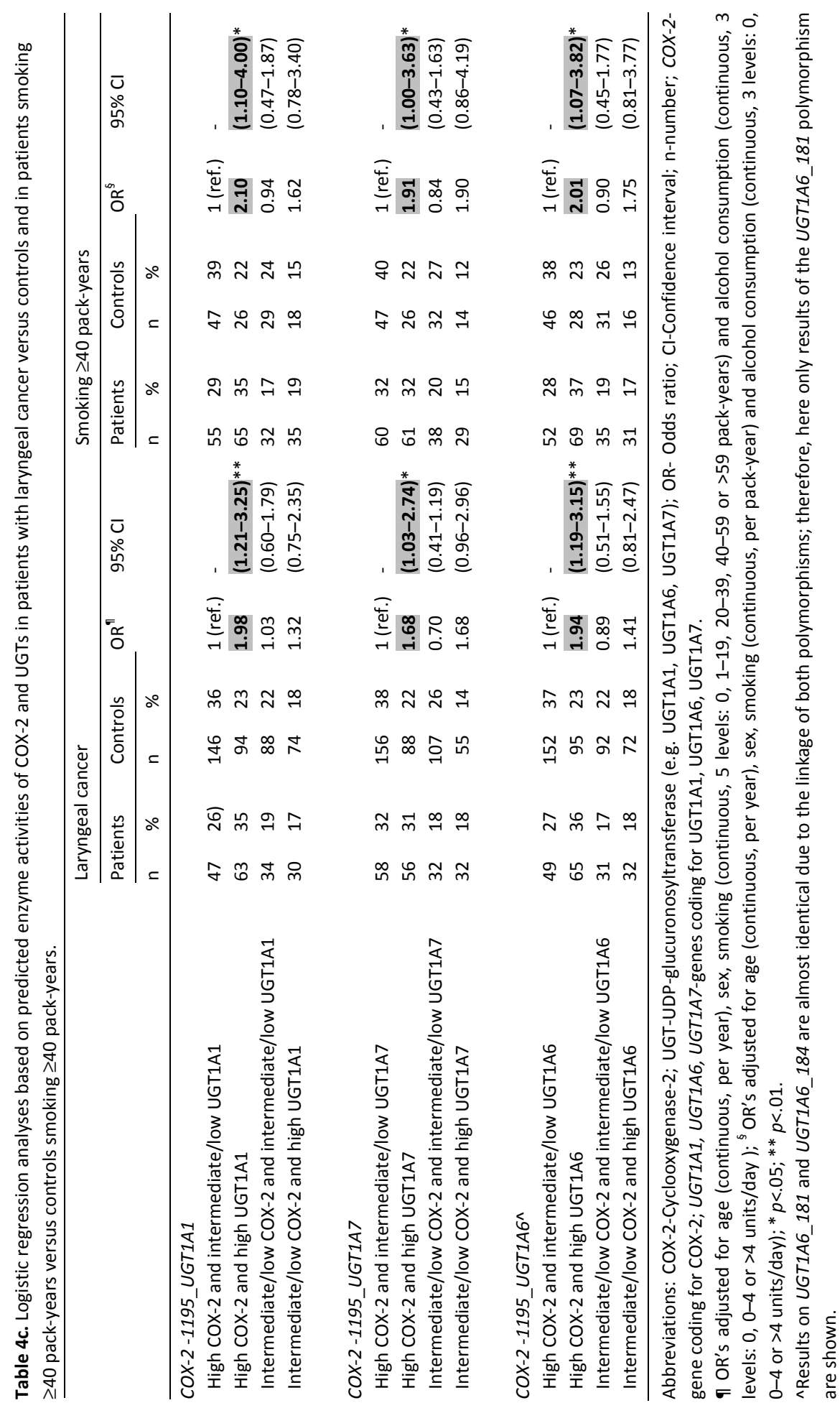


In the subgroup analysis of patients with laryngeal cancer versus controls (Table 4a), a significant difference in the distribution of six combinations of EPHX1 and UGT genotypes with respect to their predicted enzyme activity was found: both low and intermediate/high activity EPHX1 genotypes were significantly more often present in patients in combinations with the high activity UGT1A1, as well as in combination with the high activity UGT1A6 genotypes. In the subgroup of heavy smokers $(\geq 40$ pack-years) two of these combinations of genotypes, low activity EPHX1 together with a high activity UGT1A1 and low activity EPHX1 with high activity UGT1A6 genotypes, were also significantly differently distributed between the patients versus controls (Table 4a).

When analyzing prevalence of genetic polymorphisms in COX-2 -765 and UGTs with respect to their predicted activity in the subgroup of patients with laryngeal cancer versus controls, a significantly different distribution of four combinations of genotypes was found: intermediate/low activity COX-2 with the high activity UGT1A1, the high activity COX-2 with the high activity UGT1A6 and the intermediate/low as well as the high activity COX-2 in combination with the high activity UGT1A7 genotypes. In the subgroup of heavy smokers, exactly the same combinations were also significantly differently distributed between patients versus controls (Table $4 b$ ).

In the prevalence of genetic polymorphisms in COX-2 -1195 and UGTS and their predicted enzyme activity in the subgroup of laryngeal patients versus controls, as well as in the subgroup of heavy smokers, a significant different distribution for three combinations of genotypes was found: the high activity COX-2 with the high activity UGT1A1 genotypes, the high activity COX-2 with the high activity UGT1A6, and the high activity COX-2 and the high activity UGT1A7 (Table 4c).

\section{Discussion}

Genetic polymorphisms in enzymes catalysing biotransformation of (pro)carcinogens, or polymorphisms in enzymes like COX-2 involved in biotransformation of other substrates involved in carcinogenesis, might modify individual susceptibility to cancer such as SCCHN. 
The process of biotransformation comprises a chain of reactions, where a product of the previous reaction becomes a substrate for the next one. This could mean that combinations of polymorphisms in biotransformation enzymes catalysing these consecutive reactions, such as in case of $\mathrm{mEH}$ and UGTs, might have higher impact on cancer susceptibility, when compared to genetic polymorphisms in only one particular enzyme.

In this study, we investigated the combined effects of several different genetic polymorphisms in phase I enzymes ( $\mathrm{mEH}, \mathrm{COX}-2)$ together with phase II UGT family enzymes (UGT1A1, UGT1A6, UGT1A7, UGT1A8, UGT2B4, UGT2B7 and UGT2B17) on head and neck cancer risk. Although COX-2 and UGT1A1 probably do not directly participate in biotransformation and detoxification of tobacco smoke (pro)carcinogens in head and neck tissue, they might influence head and neck carcinogenesis and we therefore decided to involve genetic polymorphisms in these enzymes in our analyses.

For genetic polymorphisms in UGT1A8, UGT2B4, UGT2B7 and UGT2B17 no effect on head and neck cancer risk was observed. This was found for a risk analysis per gene seperately, which was not described before, as well as for a risk analysis of combinations of polymorphisms in COX-2 and EPHX1.

On the other hand, we found three combinations of polymorphisms between the phase I (mEH and COX-2) and phase II (UGT1A1, UGT1A6, UGT1A7) biotransformation enzymes, which might influence the risk for head and neck cancer. However, in the context of our previous results on genetic polymorphisms in these enzymes and head and neck cancer risk, we observed only a slightly modified impact of the combinations of these genetic polymorphisms in comparison to the effect of the polymorphism(s) in these enzymes separately. ${ }^{15,16,30,32}$ In other words, an observed significantly increased risk for head and neck cancer is strictly associated to the high activity genotypes in UGT1A1, UGT1A6 and UGT1A7. Combination with the polymorphisms in COX-2 and EPHX1 does not result in an additional risk modifying effect.

Because a higher exposition to tobacco smoke (pro)carcinogens might reveal (combinations of) genetic polymorphisms with a latent risk modifying effect which are otherwise hidden in case of low exposure to carcinogens, an extra statistical analysis 
for the subgroup of heavy smokers was performed. To exclude HPV induced cancer as a potential confounder, because HPV might be involved in oropharynx and oral cavity carcinogenesis, a separate subgroup analysis was made for the patients with laryngeal carcinoma. Both in heavy smokers as well as in the larynx cancer subgroup, the high activity genotypes of UGT1A1, ${ }^{30} U G T 1 A 6$ and $U G T 1 A 7^{32}$ were overrepresented and this tendency was not further modified by the combination with EPHX1 and COX-2 polymorphisms. Both low as well as intermediated/high activity genotypes in EPHX1 as well as in COX-2 did not further modify the cancer risk of the high activity genotypes of UGT1A1, UGT1A6 and UGT1A7. Therefore, also in the subgroup analysis of heavy smokers and patients with laryngeal cancer no additional effect of the EPHX1 or COX-2 polymorphisms on head and neck carcinogenesis could be revealed.

The question is, why the individuals with a high activity genotype of UGT1A6 and UGT1A7, expressing a high biotransformation (detoxifying) capacity towards tobacco smoke carcinogens, are at higher risk to head and neck cancer when compared to individuals with an intermediate/low activity of these enzymes. This might be explained by a protective effect of UGT1A1 genotypes associated with low enzyme activity, which leads to a higher level of plasma bilirubin. Recent publications showed, that bilirubin is not only a potentially toxic waste product of hemo(globin) degradation, but also a strong anti-carcinogen and anti-oxidant. ${ }^{36-41}$ Elevated, but still not toxic plasma levels of bilirubin might therefore have a protective effect against cancer. Since UGT1A1 is the only enzyme involved in conjugation of bilirubin, which subsequently leads to excretion of bilirubin, there is a strong inverse association between the UGT1A1 enzyme activity and plasma concentration of bilirubin. $^{39,42}$ The protective effect of bilirubin against cancer in individuals with low/intermediate activity UGT1A1 genotypes might overrule the detoxifying effect of the high activity genotypes of UGT1A6 and UGT1A7, which are in linkage disequilibrium with the high activity UGT1A1 genotypes. ${ }^{43}$ We reported this linkage between the UGT1A1 and UGT1A7 genotypes before. ${ }^{30}$

In conclusion, we could not find an additional effect on head and neck carcinogenesis for the combination of polymorphisms in the phase I ( $\mathrm{mEH}, \mathrm{COX}-2)$ and phase II (UGT1A1, UGT1A6, UGT1A7, UGT1A8, UGT2B4, UGT2B7, UGT2B17) biotransformation enzymes. Of the above-mentioned enzymes, only genetic polymorphisms in UGT1A1, UGT1A6 and UGT1A7 were associated with a risk modulating effect in 
head and neck carcinogenesis. Considering the linkage disequilibrium between the polymorphisms in these three enzymes and given their substrate specificity, we presume that only the polymorphism in UGT1A1 is a biological active "true risk modulating factor", whereas the genetic polymorphisms in UGT1A6 and UGT1A7 are probably only the "markers" of this risk-modulation. These findings should be confirmed by larger replication studies on UGT1A1 polymorphism in relation to head and neck cancer, which should eventually be supported also by measurement of serum bilirubin, which was not done in our earlier study. ${ }^{30}$

If the hypothesis about the involvement of UGT1A1 polymorphism in head and neck carcinogenesis could be firmly established, further steps can be made to transform this knowledge in diagnostic and therapeutic use. Primary and secondary prevention of head and neck cancer, by increasing of serum level of anti-oxidants/bilirubin, as already proposed by others in the case of malignant as well as non-malignant diseases, would be an option than. ${ }^{36,39,40}$

\section{References}

1. Maier H, Dietz A, Gewelke U, Heller WD, Weidauer H. Tobacco and alcohol and the risk of head and neck cancer. Clin Investig 1992;70:320-327.

2. Raitiola HS, Pukander JS. Etiological factors of laryngeal cancer. Acta Otolaryngol Suppl 1997;529:215-217.

3. Riedel F, Goessler U, Hormann K. Alcohol-related diseases of the mouth and $t$ hroat. Best Pract Res Clin Gastroenterol 2003;17:543-555.

4. Vidal L, Gillison ML. Human papillomavirus in HNSCC: recognition of a distinct disease type. Hematol Oncol Clin North Am 2008;22:1125-1142, vii.

5. Wogan GN, Hecht SS, Felton JS, Conney AH, Loeb LA. Environmental and chemical carcinogenesis. Semin Cancer Biol 2004;14:473-486.

6. Califano J, van der Riet P, Westra W, et al. Genetic progression model for head and neck cancer: implications for field cancerization. Cancer Res 1996;56:2488-2492.

7. Forastiere A, Koch W, Trotti A, Sidransky D. Head and neck cancer. N Engl J Med 2001;345:18901900.

8. Hecht SS. Tobacco carcinogens, their biomarkers and tobacco-induced cancer. Nat Rev Cancer 2003;3:733-744.

9. Hecht SS. Progress and challenges in selected areas of tobacco carcinogenesis. Chem Res Toxicol 2008;21:160-171.

10. Shimada T. Xenobiotic-metabolizing enzymes involved in activation and detoxification of carcinogenic polycyclic aromatic hydrocarbons. Drug Metab Pharmacokinet 2006;21:257-276.

11. Nebert DW, Dalton TP. The role of cytochrome P450 enzymes in endogenous signalling pathways and environmental carcinogenesis. Nat Rev Cancer 2006;6:947-960.

12. Jiang H, Gelhaus SL, Mangal D, Harvey RG, Blair IA, Penning TM. Metabolism of benzo[a]pyrene in human bronchoalveolar H358 cells using liquid chromatography-mass spectrometry. Chem Res Toxicol 2007;20:1331-1341. 
13. Romano M, Claria J. Cyclooxygenase-2 and 5-lipoxygenase converging functions on cell proliferation and tumor angiogenesis: implications for cancer therapy. Faseb J 2003;17:1986-1995.

14. Murata H, Kawano S, Tsuji S, et al. Cyclooxygenase-2 overexpression enhances lymphatic invasion and metastasis in human gastric carcinoma. Am J Gastroenterol 1999;94:451-455.

15. Lacko M, Roelofs HM, Te Morsche RH, et al. Microsomal epoxide hydrolase genotypes and the risk for head and neck cancer. Head Neck 2008;30:836-844.

16. Peters WH, Lacko M, Te Morsche RH, Voogd AC, Oude Ophuis MB, Manni JJ. COX-2 polymorphisms and the risk for head and neck cancer in white patients. Head Neck 2009;31:938-943.

17. Tukey RH, Strassburg CP. Human UDP-glucuronosyltransferases: metabolism, expression, and disease. Annu Rev Pharmacol Toxicol 2000;40:581-616.

18. Zheng Z, Fang JL, Lazarus P. Glucuronidation: an important mechanism for detoxification of benzo[a]pyrene metabolites in aerodigestive tract tissues. Drug Metab Dispos 2002;30:397-403.

19. Benhamou S, Reinikainen M, Bouchardy $C$, Dayer $P$, Hirvonen A. Association between lung cancer and microsomal epoxide hydrolase genotypes. Cancer Res 1998;58:5291-5293.

20. Zhang X, Miao X, Tan W, et al. Identification of functional genetic variants in cyclooxygenase-2 and their association with risk of esophageal cancer. Gastroenterology 2005;129:565-576.

21. Papafili A, Hill MR, Brull DJ, et al. Common promoter variant in cyclooxygenase-2 represses gene expression: evidence of role in acute-phase inflammatory response. Arterioscler Thromb Vasc Biol 2002;22:1631-1636.

22. Raijmakers MT, Jansen PL, Steegers EA, Peters WH. Association of human liver bilirubin UDPglucuronyltransferase activity with a polymorphism in the promoter region of the UGT1A1 gene. J Hepatol 2000;33:348-351.

23. Nagar S, Remmel RP. Uridine diphosphoglucuronosyltransferase pharmacogenetics and cancer. Oncogene 2006;25:1659-1672.

24. Butler LM, Duguay Y, Millikan RC, et al. Joint effects between UDP-glucuronosyltransferase $1 \mathrm{~A} 7$ genotype and dietary carcinogen exposure on risk of colon cancer. Cancer Epidemiol Biomarkers Prev 2005;14:1626-1632.

25. Huang $\mathrm{YH}$, Galijatovic A, Nguyen N, et al. Identification and functional characterization of UDPglucuronosyltransferases UGT1A8*1, UGT1A8*2 and UGT1A8*3. Pharmacogenetics 2002;12:287-97.

26. Ginsberg G, Guyton K, Johns D, Schimek J, Angle K, Sonawane B. Genetic polymorphism in metabolism and host defense enzymes: implications for human health risk assessment. Crit Rev Toxicol;40:575-619.

27. Lazarus $P$, Zheng Y, Aaron Runkle E, Muscat JE, Wiener D. Genotype-phenotype correlation between the polymorphic UGT2B17 gene deletion and NNAL glucuronidation activities in human liver microsomes. Pharmacogenet Genomics 2005;15:769-778.

28. Benhamou S, Benhamou E, Flamant R. Lung cancer risk associated with cigar and pipe smoking. Int J Cancer 1986;37:825-829.

29. Elahi A, Bendaly J, Zheng Z, et al. Detection of UGT1A10 polymorphisms and their association with orolaryngeal carcinoma risk. Cancer 2003;98:872-880.

30. Lacko M, Roelofs HM, Te Morsche RH, et al. Genetic polymorphism in the conjugating enzyme UGT1A1 and the risk of head and neck cancer. Int J Cancer 2010;127: 2815-2821.

31. Lampe JW, Bigler J, Horner NK, Potter JD. UDP-glucuronosyltransferase (UGT1A1*28 and UGT1A6*2) polymorphisms in Caucasians and Asians: relationships to serum bilirubin concentrations. Pharmacogenetics 1999;9:341-349.

32. Lacko M, Roelofs HM, te Morsche RH, et al. Genetic polymorphisms in the tobacco smoke carcinogens detoxifying enzyme UGT1A7 and the risk of head and neck cancer. Head Neck 2009;31:12741281.

33. Berkhout $\mathrm{M}$, Roelofs $\mathrm{HM}$, te Morsche $\mathrm{RH}$, et al. Detoxification enzyme polymorphisms are not involved in duodenal adenomatosis in familial adenomatous polyposis. Br J Surg 2008;95:499-505.

34. van der Logt EM, te Morsche $\mathrm{RH}$, Groenendaal N, et al. Genetic polymorphism in UDPglucuronosyltransferase 2B7 and colorectal cancer risk. Oncol Res 2009;17:323-329. 
35. Wilson W, 3rd, Pardo-Manuel de Villena F, Lyn-Cook BD, et al. Characterization of a common deletion polymorphism of the UGT2B17 gene linked to UGT2B15. Genomics 2004;84:707-714.

36. McCarty MF. "latrogenic Gilbert syndrome"-a strategy for reducing vascular and cancer risk by increasing plasma unconjugated bilirubin. Med Hypotheses 2007;69:974-994.

37. Zucker SD, Horn PS, Sherman KE. Serum bilirubin levels in the U.S. population: gender effect and inverse correlation with colorectal cancer. Hepatology 2004;40:827-835.

38. Keshavan P, Schwemberger SJ, Smith DL, Babcock GF, Zucker SD. Unconjugated bilirubin induces apoptosis in colon cancer cells by triggering mitochondrial depolarization. Int J Cancer 2004;112:433-445.

39. Lin JP, Vitek L, Schwertner HA. Serum bilirubin and genes controlling bilirubin concentrations as biomarkers for cardiovascular disease. Clin Chem;56:1535-1543.

40. Schwertner HA, Vitek L. Gilbert syndrome, UGT1A1*28 allele, and cardiovascular disease risk: possible protective effects and therapeutic applications of bilirubin. Atherosclerosis 2008;198:1-11.

41. Vitek L, Schwertner HA. Protective effects of serum bilirubin on peripheral vascular disease. Ann Hepatol 2008;7:94-95.

42. Lin JP, Schwaiger JP, Cupples LA, et al. Conditional linkage and genome-wide association studies identify UGT1A1 as a major gene for anti-atherogenic serum bilirubin levels--the Framingham Heart Study. Atherosclerosis 2009;206:228-233.

43. Kohle C, Mohrle B, Munzel PA, et al. Frequent co-occurrence of the TATA box mutation associated with Gilbert's syndrome (UGT1A1*28) with other polymorphisms of the UDP-glucuronosyltransferase-1 locus (UGT1A6*2 and UGT1A7*3) in Caucasians and Egyptians. Biochem Pharmacol 2003;65:1521-1527. 


\section{Chapter 7}

Summary, future implications and perspectives of this research

Samenvatting, toekomstige implicaties en perspectieven van dit onderzoek

Súhrn, možnosti budúceho uplatnenia a perspektívy tohto výskumu 



\section{Summary}

Tobacco and alcohol use and/or infection with oncogenic HVP are the most important etiological factors in head and neck carcinogenesis. However, little is known about the fact why some of the individuals exposed to tobacco (smoke) and alcohol do develop head and neck cancer, whereas others do not. Individual genetic predispositions based on polymorphisms in the genes coding for enzymes involved in biotransformation and detoxification of the (pro)carcinogens present in tobacco smoke and alcohol as well as genetic polymorphisms in other enzymes involved in the process of carcinogenesis might explain these inter-individual differences in head and neck cancer susceptibility .

Chapter 1 is an introductory chapter which describes the role of phase I and II biotransformation enzymes in biotransformation and detoxification of (pro)carcinogens present in tobacco smoke. Polymorphisms in the genes coding for these enzymes may alter activity of these enzymes and influence biotransformation and elimination of (pro)carcinogens. Therefore not only the amount of (pro)carcinogens to which the mucosa of the UADT is exposed, but also the genetically determinated capability to detoxify and eliminate these (pro)carcinogens might be an important risk modifying factor in head and neck carcinogenesis. A literature review of the genetic polymorphisms in phase I biotransformation enzymes $\mathrm{mEH}$ and COX-2 and the phase II biotransformation enzymes GSTM1, GSTT1, GSTP1, UGT1A7 and UGT1A10 with respect to their impact on head and neck cancer risk is given in this chapter.

Chapter 2 describes the results of our case-control study on head and neck cancer risk in relation to genetic polymorphisms in the phase I biotransformation enzyme $\mathrm{mEH}$. This enzyme is involved in detoxification of several intermediate metabolites, but $\mathrm{mEH}$ also activates some compounds like the procarcinogen $\mathrm{BaP} 7,8$ oxide, present in tobacco smoke, which is transformed into an ultimate carcinogen. Two polymorphisms in the gene coding for $\mathrm{mEH}$ (EPHX1) are described. One of them (exon 3 variant at position 113 ) is associated with a $40 \%$ to $50 \%$ decreased enzyme activity, whereas the second polymorphism (exon 4 variant at position 139) increases enzyme activity with approximately $25 \%$. According to different combinations of these genetic polymorphisms, the $\mathrm{mEH}$ activity can be predicted as low, intermediate or high. One would expect a reduced SCCHN risk in individuals with a 
low or intermediate $\mathrm{mEH}$ activity (low concentration of carcinogens) when compared to a high $\mathrm{mEH}$ activity. In our study population consisting of 429 patients with cancer of oral cavity, pharynx or larynx and 419 healthy controls, either smokers or ex-smokers, we found no statistically significant differences in distribution of the polymorphisms with different predicted $\mathrm{mEH}$ activities between patients and controls. Non-significant differences in the distribution of these polymorphisms between patients and controls were also observed when stratified analysis with regard to smoking habits (moderate versus heavy smokers) and gender was performed. Although the homozygote variant of the exon 4 polymorphism was significantly more often found in patients with hypopharynx carcinoma when compared to the control group, no significant differences in the distribution of EPHX1 polymorphisms according to predicted enzyme activities were discovered when analysed with respect to tumor site (larynx, oral cavity/oropharynx, hypopharynx). Our study, which is the largest on this topic so far, therefore does not demonstrate a risk-modifying effect of predicted altered $\mathrm{mEH}$ activity (due to genetic polymorphisms in EPHX1) in head and neck carcinogenesis.

Chapter 3 presents the results of our study on COX-2 polymorphisms and susceptibility to head and neck cancer. COX-2 is a phase I enzyme catalyzing the conversion of arachidonic acid into prostaglandins, which are mediators of processes like cell proliferation, transformation, invasion, angiogenesis and others, which play an important role in carcinogenesis. Expression of the COX-2 gene is inducible by proinflammatory and mitogenic stimuli. COX-2 is present in head and neck cancer tissue and there is some evidence, that this enzyme might be also involved in head and neck carcinogenesis. Two of the three SNPs present in the COX-2 promoter as described so far, (replacement of Guanine by Cytosine on base position -765 and replacement of Adenine by Guanine on base position -1195) significantly reduce the expression of this gene. In this chapter, we describe the results of our study on the relation between these functional polymorphisms in the COX-2 promoter and risk for SCCHN. In total 431 patients with carcinoma of the oral cavity, pharynx or larynx and 438 healthy controls were investigated for the COX-2 promoter polymorphisms. Statistical analysis showed no significant difference in the distribution of the COX-2 gene promoter polymorphisms between patients and controls. The stratified analyses according to tumor site, age, smoking habits and alcohol consumption also showed no significant differences in the investigated COX-2 polymorphisms between patients and controls. We can conclude that the above mentioned COX-2 
promoter polymorphisms have no risk-modifying effect in head and neck carcinogenesis.

UGT1A7 is a phase II biotransformation enzyme involved in the conjugation and elimination of environmental toxins and (pro)carcinogens present in tobacco smoke. So far 11 different allelic variants of the gene coding for this enzyme have been found (UGT1A7*1, *2, *3, *4,*5, *6, *7, *8, *9, *10, *11). Some of these UGT1A7 variants showed a decreased catalytic activity to tobacco smoke (pro)carcinogens when compared to the enzyme coded by the wild type UGT1A7*1 allele. Chapter 4 deals with the genetic polymorphisms in UGT1A7 in relation to head and neck cancer risk. We investigated 427 patients with carcinomas of the oral cavity, oropharynx, hypopharynx or larynx and 420 healthy controls, smokers or ex-smokers, on the presence of UGT1A7 genetic polymorphisms. Significant differences in the distribution of UGT1A7 polymorphisms between patients and controls were observed. Surprisingly, polymorphisms coding for the high-activity UGT1A7 enzyme were more frequently present among patients than among controls. The stratified analyses showed, that these high activity polymorphisms were found significantly more often in patients with laryngeal carcinoma when compared to controls. The same trend, although not significant, was found for patients with carcinomas of the pharynx or oral cavity. Stratified analyses according to age, gender, smoking and alcohol consumption showed a higher prevalence of the predicted high-activity UGT1A7 polymorphisms in the group of older patients ( $>60$ years) heavy smokers ( $\geq 40$ packyears), or heavy drinkers ( $>4$ units/day), when compared to the corresponding control subjects. In our study population therefore high activity UGT1A7 polymorphisms were associated with an increased risk for SCCHN; and more especially in patients with laryngeal carcinoma, in older patients, in heavy smoking patients and in excessive alcohol drinkers. We also discussed possible explanations why highinstead of the expected low-activity UGT1A7 polymorphisms are associated with an increased risk for SCCHN.

In Chapter 5 we describe the relation between genetic polymorphisms in UGT1A1 and the risk of head and neck cancer. UGT1A1 is another phase II biotransformation enzyme belonging to the UGT family. Although UGT1A1 is involved in biotransformation and detoxification of some tobacco smoke carcinogens, this enzyme is probably not expressed in the mucosa of the Upper AreoDigestive Tract. However, UGT1A1 is the only enzyme which catalyses the glucuronidation of bilirubin and 
therefore it is essential for the excretion of bilirubin. The serum concentration of bilirubin is inversely related to the activity of UGT1A1. Until recently, bilirubin was considered to be only a waste product of hemoglobin degradation. Recent research has shown however, that bilirubin may have an important anti-oxidant and anticarcinogenic effect. High levels of bilirubin therefore may have a protective effect against cardiovascular diseases and probably also against cancer. Genetic polymorphisms in the TATA region of the UGT1A1 promoter exist, which influence the transcriptional activity of this gene and subsequently also the UGT1A1 enzyme activity. In our study population of 421 patients with cancer of the oral cavity, pharynx and larynx and 417 healthy controls we found, that high activity UGT1A1 polymorphisms (leading to low serum concentrations of bilirubin), are indeed associated with an increased risk for SCCHN. Stratified analysis has shown, that this high activity UGT1A1 polymorphisms were more common in patients with laryngeal carcinoma, males, heavy smokers and excessive alcohol drinkers. The high activity UGT1A1 polymorphisms were also more often present in patients with oral or pharyngeal cancer when compared to controls, but these associations were not statistically significant. We also found a linkage between the genetic polymorphisms in UGT1A1 and UGT1A7 in our study population, which may explain the dominating effect of the UGT1A1 polymorphism, overruling the effects of the UGT1A7 polymorphisms, as discussed in Chapter 4.

Chapter 6 In contrast to diseases caused by an allelic variation or mutation of a single gene, many types of cancer including SCCHN can be considered from an etiological point of view as a complex disease, where the risk of disease development depends on external factors (exposure to carcinogens), together with the simultaneous presence of inconvenient variations in several genes involved in carcinogesis. In this chapter we therefore evaluated the risk-modifying effect of different genetic polymorphisms of phase I biotransformation enzymes ( $\mathrm{mEH}, \mathrm{COX}-2)$ in combination with genetic polymorphisms of several phase II enzymes from the UGT family (UGT1A1, UGT1A6, UGT1A7, UGT1A8, UGT2B4, UGT2B7, UGT2B17). These are all enzymes involved in biotransformation and elimination of (pro)carcinogens (mEH, UGTs), or in other carcinogenesis related reactions (COX-2). We investigated whether the combination of different genetic polymorphisms in the genes coding for the above mentioned enzymes might have more impact on the risk of SCCHN when compared to the impact of each of these genes evaluated separately. Blood samples from 432 patients with cancer of the oral cavity, pharynx and larynx and 
439 healthy controls were investigated for polymorphisms in genes coding for the above mentioned enzymes. In our study population, we could not find an additional effect on head and neck carcinogenesis for the investigated combinations of polymorphisms in the phase I and phase II biotransformation enzymes. In addition, no risk-modifying effect was found for the polymorphisms in UGT1A8, UGT2B4, $U G T 2 B 7$ or UGT2B17 separately, which was not described before. However, we observed a risk-modifying effect on head and neck carcinogenesis for polymorphisms in UGT1A6; again the predicted high activity genotype was more common in cancer patients. We presumed, that this might be due to linkage disequilibrium between the UGT1A6, UGT1A1 and UGT1A7 polymorphisms, where the UGT1A1*28 polymorphism represents the true risk-modifying factor (associated with low bilirubin levels) overruling the UGT1A6 and UGT1A7 polymorphisms. The UGT1A6 and UGT1A7 polymorphisms are probably only markers of this risk-modification.

\section{Future implications and perspectives of this research}

The main target of this research was to find the specific genetic polymorphisms in biotransformation enzymes as modulating factors in susceptibility to SCCHN. The possibility to recognize genetic predisposition and to identify individuals with increased risk for SCCHN, can contribute to the establishment of better prevention programs for this disease. Moreover, several biotransformation c.q. detoxification enzymes like UGT1A1 potentially involved in carcinogenesis, are also involved in biotransformation and elimination of (chemo)therapeutics and other drugs, used in cancer treatment. Genetic polymorphisms in these enzymes (e.g. UGT1A1*28) might influence treatment results as well as adverse effects of these drugs, which can differ between patients. Knowledge about polymorphisms in the genes coding for biotransformation enzymes as well as for other enzymes and proteins involved in carcinogenesis, might therefore be used in future, not only for identification of susceptible individuals, but also in decisions about the treatment of choice in patients with SCCHN and other malignancies.

Besides the above-mentioned implications, the results of this research may also help us to discover and elucidate new carcinogenic and anti-carcinogenic pathways involved in head and neck carcinogenesis. Such pathways might offer additional possibilities in the prevention and treatment of SCCHN. For example, we showed 
that genetic polymorphisms in the UGT1A1 enzyme, important for conjugation and excretion of the strong anti-oxidant and anti-carcinogen bilirubin, might influence the risk for head and neck cancer, especially in heavy smokers and for laryngeal cancer. Further identification of this potential "bilirubin induced anti-carcinogenic effect" may offer therapeutic possibilities in primary and secondary prevention of head and neck cancer. Identification of new genetic polymorphisms in other genes involved in head and neck carcinogenesis, such as the genes involved in DNA-repair or apoptosis as well as identification of high-risk combinations of these genetic polymorphisms, may offer new perspectives for the patients.

Recent achievements in the Human Genome project with an increasing amount of newly identified SNPs and other genetic variations, together with the application of Genome Wide Association (GWA) studies to discover the relationship between genetic variations and susceptibility to diseases like cancer, will accelerate identification of new genetic factors involved in the etiology of many diseases including SCCHN. This will improve our knowledge about inter-individual differences in relation to SCCHN risk and will probably also lead to a more tailored individual approach, when dealing with the prevention and treatment of this disease. Hopefully, this new approach will lead to a decrease of the disease related mortality rates in patients with SCCHN.

On the other hand, broad implementation of genetic screening tests for multifactorial diseases such as SCCHN, will probably confront us also with new ethical questions and dilemmas: does the information about a high-risk genetic profile of an individual help in taking preventive measures and changing the unhealthy lifestyle? And what if not? Would the result of such genetic susceptibility testing for SCCHN influence medical insurance policy for high-risk individuals? Can everyone deal with "bad news" about his/her high-risk genetic profile? Might individuals who did not show a high-risk genetic profile be more inclined in participating in harmful behaviour (smoking, alcohol drinking) and therefore increase their risk for SCCHN? These and other issues, like the reliability and correct interpretation of the rapidly increasing numbers of commercial genetic screening tests, will become a challenge for both physicians as well as patients, in the near future. 


\section{Samenvatting}

Blootstelling aan tabak en tabaksrook is, samen met de consumptie van alcohol en infectie door oncogene HPV virussen, de meest belangrijke oorzaak van het ontstaan van een plaveiselcelcarcinoom in het hoofd-halsgebied (SCCHN). Weinig is echter bekent over het feit, waarom expositie aan een bepaalde hoeveelheid alcohol/tabaks-carcinogenen bij een deel van de blootgestelde populatie leidt tot ontwikkeling van SCCHN en bij een ander deel niet.

Een van de mogelijke verklaringen is de individuele genetische predispositie, gebaseerd op de aanwezigheid van polymorfismen (variaties) in de genen die coderen voor enzymen betrokken bij biotransformatie en detoxificatie van (pro)carcinogenen aanwezig in tabaksrook en alcohol, of op genetische polymorphsismen in enzymen die op een andere manier betrokken zijn bij carcinogenese.

Hoofdstuk 1 is een introductie van dit proefschrift en beschrijft de rol van fase I en II biotransformatie enzymen bij de detoxificatie van (pro)carcinogenen aanwezig in tabaksrook. Polymorfismen in de genen die coderen voor enzymen betrokken bij biotransformatie van (pro)carcinogenen beïnvloeden de activiteit van deze enzymen en als zodanig ook de detoxificatie en eliminatie van (pro)carcinogenen. Dat betekent dat niet alleen de hoeveelheid carcinogenen waaraan het slijmvlies van het hoofd-hals gebied is blootgesteld, maar ook dat er een genetisch invloed is op de capaciteit van detoxificatie en eliminatie van (pro)carcinogenen, die waarschijnlijk een belangrijke risico-modulerende rol speelt in de hoofd-hals carcinogenese. Dit hoofdstuk geeft een overzicht van de literatuur over de genetische polymorfismen in fase I (mEH, COX-2) and fase II (GSTM1, GSTT1, GSTP1, UGT1A7 en UGT1A10) biotransformatie enzymen en hun invloed op het risico voor hoofd-halskanker.

Hoofdstuk 2 beschrijft de resultaten van onze "case-control " studie naar het risico op hoofd-halskanker in relatie tot genetische polymorfismen in het fase I biotransformatie enzym epoxide hydrolase $(\mathrm{mEH})$. Dit enzym is betrokken bij detoxificatie van intermediaire metabolieten, maar activeert ook enkele, in tabaksrook aanwezige chemische procarcinogenen, zoals BaP 7,8 oxide, dat wordt getransformeerd tot een carcinogeen. In de literatuur zijn twee polymorfismen beschreven in het gen van $\mathrm{mEH}(E P H X 1)$. Eén daarvan (exon 3 variant op positie 113) is geassocieerd met een 40 tot $50 \%$ verlaging van de enzymactiviteit, terwijl het tweede polymorfisme (exon 4 variant op positie 139) de enzymactiviteit met ongeveer $25 \%$ verhoogt. 
Afhankelijk van de verschillende combinaties van deze polymorfismen kan per persoon een lage, intermediaire of hoge enzymactiviteit worden voorspeld. Bij personen met lage of intermediaire enzymactiviteit (lage concentratie van carcinogenen) zou men een verlaagd risico op hoofd-halskanker, ten opzichte van de personen met een hoge enzymactiviteit, kunnen verwachten. In onze studie populatie bestaande uit 429 patiënten met mondholte- keelholte-, of strottenhoofdkanker en bij een controle groep van 438 gezonde individuen, hebben we geen statistisch significant verschil in de distributie van de genetische polymorfismen tussen de patiënten en de controle groep kunnen vinden. Hetzelfde geldt ook voor de analyse met stratificatie voor rookgedrag, alcoholgebruik en geslacht. Hoewel de homozygote variant van het exon 4 polymorfisme significant vaker aanwezig was bij de patiënten met hypofarynxcarcinoom ten opzichte van de controle groep, zijn er met betrekking tot de verwachte enzymactiviteit geen significante verschillen gevonden tussen de patiënten (apart geanalyseerd per tumorlocatie) ten opzichte van de controle groep. In onze, tot nu toe de grootste studie gepubliceerd over dit onderwerp, hebben we dus geen risicomodulerend effect van het EPHX1 polymorfisme op hoofdhalskanker kunnen aantonen.

Hoofdstuk 3 behandelt de resultaten van onze studie naar genetische polymorfismen in COX-2 gen en het risico op hoofd-halskanker. COX-2 is een fase I enzym dat de omzetting katalyseert van arachidonzuur naar prostaglandinen. Prostaglandinen zijn mediatoren betrokken bij de regulatie van belangrijke bioprocessen zoals proliferatie en transformatie van cellen, maar ook angiogenese (vorming van nieuwe bloedvaten), invasie en andere processen betrokken bij het ontstaan van kanker. Expressie van het COX-2 enzym wordt gestimuleerd door pro-inflammatoire (ontsteking stimulerende) en mitogene (celdeling veroorzakende) stimuli. COX-2 is aanwezig in het weefsel van hoofd-hals tumoren en er zijn aanwijzingen dat dit enzym betrokken zou kunnen zijn bij het ontstaan van hoofd-halskanker. Twee van de drie tot nu toe beschreven "single nucleotide polymorphisms" (SNPs) aanwezig in de COX-2 promotor (vervanging van guanine door cytosine op positie -765 en adenine door guanine op positie -1195) reduceren de expressie van het COX-2 gen aanzienlijk. Deze twee COX-2 polymorfismen werden bepaald bij in totaal 431 patiënten met mondholte- keelholte-, of strottenhoofdkanker en bij een controle groep van 438 gezonde individuen (rokers of voormalige rokers). Statistische analyse liet geen significant verschil in de distributie van de onderzochte COX-2 polymorfismen tussen de patiënten en controle groep zien. Hetzelfde geldt ook voor de analyse gestra- 
tificeerd voor tumorlokalisatie, leeftijd, rookgedrag en alcoholconsumptie. We concluderen, dat de door ons onderzochte polymorfismen in het COX-2 gen geen risicomodulerend effect hebben op het ontstaan van hoofd-halskanker.

UGT1A7 is een fase II biotransformatie enzym betrokken bij de conjugatie en eliminatie van toxinen aanwezig in ons milieu maar ook van (pro)carcinogenen uit tabaksrook. Tot nu toe zijn er 11 verschillende varianten beschreven van het gen dat codeert voor dit enzym (UGT1A7*1, *2, *3, *4, *5, *6, *7, *8, *9, *10, *11). Enkele van deze varianten vertonen een verlaagde katalytische activiteit voor carcinogenen uit tabaksrook ten opzichte van het meest voorkomende ("wild type") UGT1A7*1 allele. Zoals in Hoofdstuk 4 beschreven werd bij 427 patiënten met mondholtekeelholte-, of strottenhoofdkanker en bij een controle groep bestaande uit 420 gezonde individuen (rokers of voormalige rokers) het UGT1A7 polymorfisme bepaald. Verrassenderwijs waren juist de polymorfismen die coderen voor hoge UGT1A7 enzymactiviteit (hoge detoxificatie van carcinogenen) statistisch significant vaker aanwezig in de patiënten groep in vergelijking met de controle groep. Gestratificeerde analyse liet zien dat dit verschil nog meer significant was in de subgroep patiënten met strottenhoofdkanker ten opzichte van de controle groep. Hetzelfde geldt ook voor de subgroep van oudere patiënten ( $>60$ jaar), zware rokers ( $\geq 40$ "pack-years") en bovenmatige alcohol drinkers ( $>4$ alcoholische eenheden per dag) in vergelijking met de bijbehorende controle subgroep. Concluderend kunnen we zeggen dat in onze studiepopulatie genetische polymorfismen die coderen voor de hoge UGT1A7 enzymactiviteit geassocieerd zijn met een verhoogd risico op hoofdhalskanker. Een mogelijke verklaring voor het feit dat juist de polymorfismen die geassocieerd zijn met een hoge enzymactiviteit vaker voorkomen bij patiënten met hoofd-halskanker, wordt besproken in de discussie van dit hoofdstuk.

In hoofdstuk 5 beschrijven we de relatie tussen genetische polymorfismen in UGT1A1 en het risico op hoofd-halskanker. UGT1A1 is een andere fase II enzym dat behoort tot de UGT familie. Hoewel het enzym UGT1A1 betrokken is bij biotransformatie en detoxificatie van enkele carcinogenen uit tabaksrook, komt dit enzym waarschijnlijk niet tot expressie in het slijmvlies van het hoofd-hals gebied. UGT1A1 is echter het enige enzym dat de conjugatie van bilirubine katalyseert en is daardoor essentieel voor de excretie van bilirubine uit het lichaam. De serumconcentratie van bilirubine is omgekeerd evenredig aan de UGT1A1 activiteit. Tot voor kort werd bilirubine slechts als een afvalproduct van de heem (hemoglobine) afbraak be- 
schouwd. Recent onderzoek heeft echter aangetoond, dat bilirubine waarschijnlijk ook een belangrijke antioxidant is en mogelijk over anti-carcinogene werking beschikt. Een hoge serumspiegel van bilirubine kan daarom mogelijk beschermen tegen cardiovasculaire ziektes en misschien zelfs tegen kanker. Genetische polymorfismen in de TATA regio van de UGT1A1 promotor (UGT1A1*28 polymorfisme) beinvloedt de transcriptie activiteit van het gen (het proces waarbij het gen wordt gekopieerd naar mRNA) en daardoor wordt ook de UGT1A1 enzymactiviteit beïnvloed. In onze studie populatie, bestaande uit 421 patiënten met mondholte-, keelholte- en strottenhoofdkanker en uit 417 gezonde controle individuen, konden we aantonen dat UGT1A1 polymorfismen gepaard gaande met een hoge UGT1A1 activiteit (met een verwachte lage serum spiegel van bilirubine) inderdaad geassocieerd zijn met een verhoogd risico op hoofd-halskanker. Gestratificeerde analyse liet zien dat polymorfismen die leiden tot hoge UGT1A1 activiteit vaker vertegenwoordigd waren in de subgroep patiënten met strottenhoofdkanker, mannen, zware rokers ( $\geq$ 40 "pack-years") en bovenmatig alcohol drinkers (>4 alcoholische eenheden per dag). Ook hebben we in onze studie populatie een verband aangetoond tussen de genetische polymorfismen in UGT1A1 en UGT1A7. Het UGT1A1 polymorfisme speelt in de hoofd-hals carcinogenese waarschijnlijk een dominante rol ten opzichte van het UGT1A7 polymorfisme, hetgeen de resultaten vermeld in hoofdstuk 4 kunnen verklaren.

In contrast tot de ziekten die veroorzaakt zijn door een allelische variatie of de mutatie van een enkel gen, kunnen we verschillende typen kanker, inclusief hoofd-hals kanker, beschouwen als een complexe ziekte, waar het risico op het ontstaan afhankelijk is van externe factoren (expositie aan carninogenen), in combinatie met de simultane aanwezigheid van "ongunstige" varianten in meerdere genen betrokken bij de carcinogenese. In hoofdstuk 6 evalueren we het risico modificerend effect van fase I biotransformatie enzymen ( $\mathrm{mEH}, \mathrm{COX}-2)$ in combinatie met enkele fase II biotransformatie enzymen van de UGT familie (UGT1A1, UGT1A6, UGT1A7, UGT1A8, UGT2B4, UGT2B7, UGT2B17). Deze enzymen zijn betrokken in biotransformatie en eliminatie van (pro)carcinogenen ( $\mathrm{mEH}$, UGTs) of in andere voor carcinogenese belangrijke processen (COX-2). Wij hebben onderzocht of een combinatie van verschillende genetische polymorfismen in de genen die coderen voor de bovenvermelde enzymen meer impact op het hoofd-halskanker risico heeft, in vergelijking met een impact geanalyseerd per individueel gen. Hiervoor hebben wij bloedmonsters van 432 patiënten met mondholte-, keelholte- en strottenhoofdkan- 
ker en van 439 gezonde controle individuen onderzocht op polymorfismen in genen die coderen voor de bovengenoemde enzymen. In onze studie populatie konden wij geen extra risico-modulerend effect vinden voor de combinatie van genetische polymorfismen in fase I en fase II biotransformatie enzymen. Ook hebben we geen risico-modulerend effect gevonden voor de onderzochte polymorfismen in UGT1A8, UGT2B4, UGT2B7 en UGT2B17 apart, wat niet eerder beschreven was. Wij hebben wel een correlatie gevonden tussen het onderzochte polymorfisme in UGT1A6 en het hoofd-halskanker risico, waarbij de polymorfismen geassocieerd met verwachte hoge enzymactiviteit vaker aanwezig waren in de patiënten groep dan in de controle groep. Wij veronderstellen dat dit waarschijnlijk het gevolg is van het verband dat er bestaat tussen de polymorfismen in UGT1A1, UGT1A6 and UGT1A7, waarbij het UGT1A1 (UGT1A1*28) polymorfisme de ware risico-modulerende factor vertegenwoordigt (gekoppeld aan de serum bilirubine waarde), die het effect van de UGT1A6 en UGT1A7 polymorfismen aan zich ondergeschikt maakt.

\section{Toekomstige implicaties en perspectieven van dit onderzoek}

Het belangrijkste doel van dit onderzoek was om te onderzoeken of specifieke genetische polymorfismen in biotransformatie enzymen een modulerende rol spelen bij het ontstaan van hoofd-halskanker. De mogelijkheid om genetische predispositie te herkennen en het identificeren van personen met een verhoogd risico op hoofdhalskanker, kan bijdragen aan het ontstaan van betere preventie programma's voor deze ziekte.

Bovendien zijn meerdere biotransformatie/detoxificatie enzymen zoals UGT1A1, die mogelijk betrokken zijn bij de carcinogenese, ook betrokken bij de biotransformatie en eliminatie van chemotherapeutica- en andere medicijnen die gebruikt worden in de behandeling van kanker. Genetische polymorfismen in deze enzymen (zoals UGT1A1*28) zouden de behandel resultaten zowel als de neveneffecten van deze medicijnen, die per patiënt verschillen, kunnen beïnvloeden. In de toekomst kan kennis over polymorfismen in genen die coderen voor zowel biotransformatie enzymen, als voor andere enzymen of proteïnen betrokken bij de carcinogenese, gebruikt worden voor de identificatie van individuen met verhoogd risico, maar ook in beslissingen over de behandelingskeuze bij patiënten met hoofd-halskanker of andere maligniteiten. 
Naast de hierboven genoemde implicaties, zullen de resultaten van dit onderzoek ons helpen bij de ontdekking en opheldering van nieuwe "pathways" in carcinogenese en anti-carcinogenese met betrekking tot hoofd-halskanker. Dit kan ons extra mogelijkheden voor preventie en behandeling van deze ziekte verschaffen. We hebben bijvoorbeeld aangetoond dat het genetische polymorfisme in UGT1A1 (UGT1A1*28), dat belangrijk is voor de conjugatie en uitscheiding van het antioxidant en anti-carcinogeen bilirubine, het risico op hoofd-hals kanker zou kunnen beïnvloeden, in het bijzonder bij zware rokers en bij het voorkomen van strottenhoofdkanker. Nadere analyse van dit mogelijk "bilirubine geïnduceerde anticarcinogeen effect" zou ons therapeutische mogelijkheden kunnen bieden in primaire en secundaire preventie van hoofd-halskanker. Identificatie van nieuwe polymorfismen in andere genen betrokken bij de carcinogenese van hoofd-halskanker, zoals in genen betrokken bij DNA-herstel of cel apoptose en de identificatie van risico verhogende combinaties van deze polymorfismen, zullen hopelijk voor onze patiënten nieuwe perspectieven bieden.

Recente successen bereikt in het Menselijk Genoom Project met een toenemend aantal nieuw geïdentificeerde genetische varianten, in combinatie met GenoomBrede Associatie studies waarbij de relatie tussen de genetische variaties en vatbaarheid voor ziektes zoals kanker in kaart worden gebracht, zal de identificatie van genetische factoren die een rol spelen bij het ontstaan van veel ziektes, inclusief hoofd-halskanker, versnellen. Dit zal onze kennis over inter-individuele verschillen in het risico op hoofd-halskanker verbeteren en zal waarschijnlijk resulteren in een betere individuele benadering van preventie en behandeling van deze ziekte. Hopelijk zal deze nieuwe benadering leiden tot een daling van het aantal sterftegevallen door hoofd-halskanker.

Aan de andere kant zal het breed inzetten van genetische screeningstesten voor multifactoriële ziekten zoals hoofd-halskanker, ons confronteren met nieuwe ethische vragen en dilemma's. Helpt de informatie over een hoog risico genetisch profiel in het nemen van preventieve maatregelen en bij het veranderen van de ongezonde levensstijl? En zo niet, wat dan? Zullen de resultaten van zulke genetische vatbaarheids tests voor hoofd-halskanker de zorgverzekeraars beïnvloeden in hun beleidskeuzes voor individuen met een verhoogd risico? Kan iedereen omgaan met slecht nieuws over zijn of haar ongunstig genetisch profiel? Zullen individuen die geen hoog risico profiel hebben juist meer geneigd zijn om ongezond gedrag te 
vertonen (zoals roken en alcohol drinken) en daarmee hun risico op hoofdhalskanker vergroten?

Deze en andere onderwerpen, zoals de betrouwbaarheid en de correcte interpretatie van een snel toenemend aantal commerciële genetische screeningstesten, zullen in de nabije toekomst steeds meer een uitdaging vormen voor zowel de arts als voor de patiënten. 



\section{Súhrn}

Expozícia karcinogénnym (nádorotvorným) splodinám prítomným v tabakovom dyme a v metabolitoch alkoholu, je spolu s infekciou spôsobenou nádorotvornými sérotypmi HPV vírusov najčastejšou a najdôležitejšou príčinou vzniku zhubných nádorov horných dýchacích a prehĺtacích orgánov (tiež nazývaných zhubnými nádormi hlavy a krku). Doteraz neobjasneným však zostáva fakt, prečo u niektorých jedincov vystavených nádorotvorným vplyvom tabaku a alkoholu dochádza k vzniku maligného nádoru, kým u iných jedincov vystavených tým istým škodlivým vplyvom ku vzniku nádoru nedochádza. Pravdepodobne tu zohráva dôležitú úlohu individuálna genetická predispozícia podmienená polymorfizmami (variáciami) v génoch kódujúcich tvorbu enzýmov potrebných na biologickú premenu (biotransformáciu) a zneškodnenie (detoxifikáciu) prekarcinogénov a karcinogénov prítomných $v$ tabaku a $v$ alkohole. Taktiež polymorfizmy $v$ iných génoch zodpovedných za tvorbu enzýmov a ostatných bielkovín podielajúcich sa na karcinogenéze (alebo na ochrannom účinku proti vzniku nádorov) zohrávajú pravdepodobne dôležitú úlohu $v$ individuálnych rozdieloch $v$ predispozicii $k$ zhubným nádorovým ochoreniam v oblasti hlavy a krku.

V prvej časti tejto knihy opisujeme úlohu ktorú zohrávajú enzýmy 1. a 2. biotransformačnej fázy $v$ biologickej premene a zneškodňovaní (pre)karcinogénov prítomných $v$ tabaku a tabakovom dyme. Vrodené polymorfizmy $v$ štruktúre génov kódujúcich pre tieto enzýmy môžu ovplyvňovat' aktivitu detoxifikačných enzýmov voči (pre)karcinogénom a môžu viest' k významnému zníženiu ich enzymatickej účinnosti, či dokonca $\mathrm{k}$ ich úplnej afunkčnosti a tým aj k neschopnosti zneškodnit' karcinogénnu látku. To znamená, že nielen rozdiely v expozícii slizničných povrchov horných dýchacích a prehítacích orgánov na určité množstvo nádorotvorných splodín, ale aj individuálne geneticky podmienené odlišnosti v schopnosti zneškodnenia a eliminovania týchto látok môžu zohrávat' dôležitú úlohu $v$ individuálnych rozdieloch v predispozícii ku vzniku zhubných nádorov hlavy a krku. $\checkmark$ tejto časti podávame taktiež súhrnný popis dostupnej literatúry o genetických polymorfizmoch $v$ biotransformačných enzýmoch 1 . fázy akými sú mikrozomálna epoxid-hydroláza (mEH) a cyclooxygenáza-2 (COX-2) ako aj v biotransformačných enzýmoch 2. fázy patriacich do rodiny glutathion S-transferáz (GST): GSTT1, GSTP1 a do rodiny uridin 5'-difosfo-glucuronozyltransferáz (UGT): UGT1A7, UGT1A10 a ich vplyvu na riziko vzniku zhubných nádorov v oblasti hlavy a krku. 
Druhá čast' knihy je venovaná opisu výsledkov našej (case-control) štúdie zameranej na riziko vzniku zhubných nádorov v oblasti hlavy a krku vo vztahu ku geneticky podmieneným polymorfizmom $v$ biotransformačnom enzyme 1 . fázy, $m E H$. Tento enzým sa podiel'a na zneškodnení niekol'kých intermediárnych metabolitov, ale $\mathrm{mEH}$ taktiež aktivuje niektoré zlúčeniny ako napríklad potenciálne karcinogénny BaP 7,8 oxid prítomný $v$ tabakovom dyme, ktorý je reakciou katalyzovanou mEH premenený na definitívny, silno nádorotvorný metabolit. $V$ géne kódujúcom syntézu $\mathrm{mEH}$ (EPHX1) existujú dve varianty ovplyvňujúce funkciu vytvoreného enzýmu. Jeden z týchto variantov (exon 3 variant na 113 pozícii génu) je spojený so $40-50 \%$ znížením funkcie enzýmu, kým druhý variant (exon 4 variant na 139 pozícii génu) zvyšuje enzymatickú aktivitu o približne $25 \%$. Kombinácia výskytu týchto dvoch genetických polymorfizmov u jedného jedinca určuje celkovú enzýmovú aktivitu, ktorá môže byt' bud' znížená, stredná, či zvýšená. Na základe horeuvedeného je možné predpokladat', že jedinci so strednou či nízkou aktivitou $\mathrm{mEH}$ (spojenou $\mathrm{s}$ nižšou koncentráciou karcinogénnych matabolitov) majú nižšiu šancu na získanie zhubného nádoru v oblasti hlavy a krku v porovnaní s jedincami s vysokou aktivitou tohto enzýmu. V našom súbore pozostávajúcom zo 429 pacientov so zhubnými nádoromi ústnej dutiny, hltana alebo hrtana a z kontrolnej skupiny pozostávajúcej zo 419 zdravých jedincov (fajčiarov a bývalých fajčiarov) sme však nezistili žiadne štatisticky signifikantné rozdiely $v$ distribúcii genetických polymorfizmov $s$ predpokladanou rozdielnou aktivitou $\mathrm{mEH}$ enzýmu medzi pacientmi a kontrolnou skupinou. Taktiež neboli zistené žiadne rozdiely medzi týmito dvomi skupinami po vykonaní stratifikovanej analýzy $v$ závislosti od intenzity fajčenia (silní fajčiari v porovnaní sostatnými jedincami) a $\mathrm{v}$ závislosti od pohlavia. $\mathrm{V}$ analýze podla lokalizácie zhubného nádoru sme zistili, že homozygotný výskyt polymorfizmu na 4 exone sa vyskytuje štatisticky signifikantne častejšie v skupine pacientov s nádorom lokalizovanom $v$ hrtanovej časti hltana (hypopharynx) v porovnaní s kontrolnou skupinou. Avšak distribúcia genetických variantov EPHX1 génu vzhl'adom na predpokladanú hodnotu enzymatickej aktivity sa medzi jednotlivými lokalizáciami zhubných nádorov (ústna dutina, hltan, hrtan) nelíšila. V našej, doteraz najväčšej, štúdii publikovanej na túto tému sme teda nepreukázali žiadny signifikantný riziko modulujúci vplyv mEH aktivity (podmienenej horeuvedenými genetickými polymorfizmami) na vznik zhubných nádorov v oblasti hlavy a krku.

$\checkmark$ tretej časti tejto knihy prezentujeme výsledky nášho výskumu zameraného na polymorfizmy v COX-2 géne a ich vztahu k prípadnej zvýšenej predispozícii na tvorbu 
zhubných nádorov v oblasti hlavy a krku. COX-2 je biotransformačný enzým 1. fázy, ktorý katalyzuje premenu kyseliny arachidónovej na prostaglandíny. Prostaglandíny su mediátormi procesov súvisiacich s proliferáciou, transformáciou a invazívnou aktivitou buniek, ale aj s angiogenézou (novotvorbou ciev) a d'alšími procesmi hrajúcimi dôležitú úlohu pri vzniku zhubných nádorov. Expresia COX-2 génu (proces aktivácie COX-2 génu vedúci ku tvorbu COX-2 enzýmu) je indukovaná zápalovými a delenie buniek podporujúcimi podnetmi. COX-2 enzým je prítomný v zhubných nádoroch hlavy a krku a existujú dôkazy na to, že tento enzým sa môže aktívne podiel'at' na vzniku týchto nádorov. Dva z troch doteraz známych polymorfizmov jednotlivých nukleotidov (nukleotid je základná stavebná čast' genetického materiálu) v promótore COX-2 génu (zámena bázy guanín za cytozín na pozícií -765 a zámena bázy adenín za guanín na pozícii -1195) signifikantne znižujú expresiu tohto génu. $V$ tejto časti opisujeme výsledky našej štúdie na riziko vzniku zhubných nádorov v oblasti hlavy a krku vo vztahu k vyššie uvedeným polymorfizmom v COX-2 géne. $V$ súbore pozostávajúcom zo 431 pacientov so zhubnými nádormi dutiny ústnej, hltana alebo hrtana a 438 zdravých kontrolných jedincov (fajčiarov a bývalých fajčiarov) sme zistovali výskyt polymorfizmov v promótore COX-2 génu. Štatistická analýza nevykázala žiadne rozdiely v distribúcii týchto polymorfizmov medzi pacientami a kontrolným súborom. Taktiež $v$ stratifikovanej analýze $v$ závislosti od lokalizácie tumoru, veku, pohlavia, intenzity fajčenia a konzumácie alkoholu, neboli zistené žiadne rozdiely vo výskyte COX-2 polymorfizmov medzi pacientami a kontrolným súborom zdravých jedincov. Na základe týchto výsledkov sme dospeli k záveru, že vyššie uvedené polymorfizmy v promótore COX-2 génu nemajú žiadny riziko ovplyvňujúci vplyv na vzniku zhubných nádorov hlavy a krku.

UGT1A7 je biotransformačný a detoxifikačný enzým 2. fazy podielajúci sa na konjugácii a eliminácii environmentálnych toxínov a (pre)karcinogénov prítomných v tabakovom dyme. Doteraz bolo zistených 11 rozličných polymorfných variantov $v$ géne kódujúcom tvorbu tohto enzýmu (UGT1A7 *1, *2*3*4, *5, *6, *7, *8, *9, *10, *11). Niektoré z týchto genetických variantov vykazujú v porovnaní s najčastejšie sa vyskytujúcim základným typom génu (UGT1A7*1) výrazne zníženú katalytickú aktivitu voči (pre)karcinogénom $v$ tabakovom dyme. Vo štvrtej časti knihy sa zaoberáme genetickými polymorfizmami v UGT1A7 géne a ich vplyvu na vznik zhubných nádorov $v$ oblasti hlavy a krku. $V$ našom súbore pozostávajúcom zo 427 pacientov s nádormi dutiny ústnej, hltana, alebo hrtana a kontrolnou skupinou zdravých jedincov (fajčiarov a bývalých fajčiarov) sme zist'ovali výskyt genetických 
polymorfizmov v UGT1A7 géne. Ukázalo sa, že distribúcia týchto polymorfizmov je štatisticky signifikantne rozdielna medzi skupinou pacientov a kontrolnou skupinou. Polymorfizmy kódujúce tvorbu UGT1A7 enzýmu s vysokou aktivitou a tým aj s vysokou schopnost'ou zneškodnit škodlivé karcinogénne látky, boli prekvapivo častejšie prítomné $u$ pacientov $v$ porovnaní s kontrolnou skupinou. Stratifikovaná štatistická analýza $v$ závislosti od lokalizácie nádoru ukázala, že polymorfizmy $s$ predpokladanou vysokou aktivitou boli ešte signifikantnejšie prítomné v podskupine pacientov so zhubným nádorom hrtana. Stratifikácia podla veku, pohlavia, intenzity fajčenia a intenzity konzumácie alkoholu ukázala signifikantne zvýšený výskyt polymorfizmov s vysokou aktivitou enzýmu UGT1A7 v podskupine starších pacientov (>60 rokov), silných fajčiarov (1 balíček cigariet denne počas viac ako 40 rokov) a nadmerných užívatel'ov alkoholu (>4 alkoholické jednotky za deň) v porovnaní s korešpondujúcou podskupinou kontrolného súboru. To znamená, že zvýšená aktivita UGT1A7 enzýmu bola v našom súbore neočakávane spojená so štatisticky signifikantne zvýšeným rizikom tvorby zhubných nádorov $v$ horných dýchacích a prehltacích orgánoch; a to hlavne u pacientov s nádormi hrtana, u starších pacientov, silných fajčiarov a u jedincov s nadmerným užívaním alkoholu. $v$ tejto kapitole predkladáme taktiež možné vysvetlenie prečo práve polymorfizmy so zvýšenou (namiesto s predpokladanou zníženou) enzymatickou aktivitou sú spojené s väčším rizikom tvorby zhubných nádorov v horných dýchacích a prehĺtacích orgánoch.

$\checkmark$ piatej časti tejto publikácie opisujeme vztáah medzi polymorfizmami $v$ géne kódujúcom tvorbu UGT1A1 enzýmu. Tento enzým je d’alším biotransformačným a detoxifikačným enzýmom 2. biotransformačnej fázy patriacim do rodiny UGT. Aj napriek tomu že tento enzým zasahuje do biotransformácie a detoxifikácie niektorých karcinogénov prítomných $v$ tabakovom dyme, tento enzým sa $s$ najväčšou pravdepodobnost'ou nevyskytuje $v$ sliznici horných dýchacích a prehítacích orgánov. Na druhej strane je ale UGT1A1 jediným enzýmom katalyzujúcim glukuronizáciu bilirubínu a je preto nesmierne dôležitý pri jeho vylučovaní z tela. Až donedávna bol bilirubin považovaný len za odpadový produkt vznikajúci pri rozklade krvného farbiva hemoglobínu. Najnovšie výskumy však odhalili, že bilirubin má pravdepodobne tiež dôležité antioxidačné účinky a môže zabraňovat' tvorbe zhubných nádorov. Zvýšená hladina bilirubínu môže teda poskytovat' ochranný efekt proti kardiovaskulárnym a nádorovým ochoreniam. Geneticky polymorfizmus $v$ takzvanom TATA (Timín, Adenín) bloku prítomnom $v$ 
promotore UGT1A1 génu (tento polymorfizmus sa označuje aj ako UGT1A1*28) ovplyvňuje transkripčnú aktivitu tohto génu a tým následne aj aktivitu UGT1A1 enzýmu. $V$ našej populácii pozostávajúcej zo 421 pacientov so zhubnými nádormi v dutine ústnej, v hltane alebo v hrtane a 417 zdravými jedincami (fajčiarmi alebo bývalými fajčiarmi) sme zistili, že polymorfizmy spojené so zvýšenou aktivitou UGT1A1 enzýmu (a tým vedúce k zníženej koncentrácii bilirubínu v krvnom sére), sú skutočne štatisticky signifikantne spojené so zvýšeným rizikom tvorby zhubných nádorov v oblasti horných dýchacích a prehltacích orgánov. Stratifikovaná štatistická analýza vykázala, že polymorfizmy so zvýšenou UGT1A1 aktivitou sú ešte signifikantnejšie prítomné u pacientov so zhubnými nádormi hrtana, u mužov, silných fajčiarov a nadmerných užívatel'ov alkoholu. Zvýšený výskyt týchto polymorfizmov sme pozorovali aj u pacientov s malignými nádormi ústnej dutiny a hltana, avšak v porovnaní s kontrolnou skupinou nebola tato asociácia štatisticky dostatočne signifikantná. $V$ našej populácii pacientov a kontrolných zdravých jedincov sme taktiež odhalili vzájomnú väzbu medzi polymorfizmami UGT1A1 génu a v predchádzajúcej časti popisovanými polymorfizmami v UGT1A7 géne. UGT1A1 polymorfizmy zohrávajú pravdepodobne dominantnú (ochrannú) úlohu v procese tvorby nádorov v oblasti hlavy a krku, v porovnaní s polymorfizmami UGT1A7 génu, čo može vysvetlitt výsledky opísané vo štvrtej časti tejto knihy.

Na rozdiel od ochorení ktoré sú spôsobené alelickymi variantmi alebo mutáciami jedného samostatného génu zodpovedného za vznik ochorenia, väčšina zhubných nádorov, vrátane tých lokalizovaných $v$ oblasti horných dýchacích a prehĺtacích orgánov, je z etiologického hladiska považovaných za komplexné ochorenie. To znamená, že riziko získania takého zhubného nádoru je závislé na simultánnej prítomnosti viacerých rizikových génov podielajúcich sa na vzniku nádoru a zároveň na externých faktoroch, akými sú napríklad expozícia na karcinogénne metabolity prítomné $v$ tabakovom dyme a $v$ alkohole. $v$ šiestej časti knihy sa zaoberáme riziko modulujúcim efektom genetických polymorfizmov v enzýmoch 1. biotransformačnej a detoxifikačnej fázy $(\mathrm{mEH}, \mathrm{COX}-2)$ v kombinácii s genetickými polymorfizmami enzýmov 2. biotransformačnej a detoxifikačnej fázy patriacich do rodiny UGT (UGT1A1, UGT1A6, UGT1A7, UGT1A8, UGT2B4, UGT2B7, UGT2B17) a ich spoločným vplyvom na vznik zhubných nádorov $v$ oblasti hlavy a krku. Tieto enzýmy sa podielajú na biotransformácii a eliminácii (pre)karcinogénov ( $\mathrm{mEH}$, rodina UGT enzýmov), alebo na iných reakciách dôležitých v procese vzniku zhubného nádoru (COX-2). Zistóvali sme, či vzájomná a súčasne prítomná kombinácia rôznych 
genetických polymorfizmov $v$ génoch kódujúcich tvorbu týchto enzýmov bude viac vplývat' na riziko získania zhubného nádoru v oblasti hlavy a krku, v porovnaní s polymorfizmami v týchto génoch vyhodnocovaných pre každý gén samostatne. Vo vzorkách krvi odobraných 432 pacientom so zhubným nádorom dutiny ústnej, hltana, alebo hrtana a 439 kontrolným zdravým jedincom (fajčiarom alebo bývalým fajčiarom) bola stanovená prítomnost' polymorfizmov $v$ génoch kódujúcich tvorbu vyššie uvedených enzýmov. V našom súbore pacientov a kontrolných jedincov sme nezistili žiadny extra zvýšený nádorotvorný efekt kombinovaného účinku genetických polymorfizmov v enzýmoch 1. a 2. biotransformačnej fázy, v porovnaní $s$ efektom jednotlivých polymorfizmov vyhodnocovaných osobitne. Taktiež sme nezistili žiadny samostatný riziko ovplyvňujúci efekt genetických polymorfizmov kódujúcich tvorbu enzýmov UGT1A8, UGT2B4, UGT2B7 a UGT2B17, čo doteraz ešte nebolo publikované. Na druhej strane sme zistili koreláciu medzi genetickými polymorfizmami v UGT1A6 géne a zvýšeným rizikom vzniku zhubného nádoru $v$ oblasti hlavy a krku. Aj $v$ tomto prípade, podobne ako pri UGT1A7 géne boli polymorfizmy spojené so zvýšenou aktivitou génu štatisticky signifikantne častejšie prítomné v skupine pacientov v porovnaní so zdravými jedincami. Na základe našich výsledkov predpokladáme, že vysvetlením tohto faktu je vzájomná väzba medzi genetickými polymorfizmami $v$ génoch kódujúcich enzýmy UGT1A1, UGT1A6 a UGT1A7. Polymorfizmus v géne UGT1A1 (UGT1A1*28) opísaný v predchádzajúcej časti predstavuje pravdepodobne pravý a podstatný faktor ovplyvňujúci riziko vzniku nádoru (účinok tohto faktoru je sprostredkovaný pravdepodobne zmenami hladiny sérového bilirubinu) ktorý prevláda nad vplyvom detoxifikačného efektu enzýmov kódovaných UGT1A6 a UGT1A7 génmi. Polymorfizmy v týchto dvoch posledne zmienených génoch môžeme pravdepodobne považovat' iba za "markery" tohto riziko ovplyvňujúceho efektu.

\section{Možnosti budúceho uplatnenia a perspektívy tohto výskumu}

Hlavným ciel'om tohto výskumu bolo nájdenie špecifických genetických polymorfizmov $v$ biotransformačných/detoxifikačných enzýmoch ktoré by mohli vysvetlit' rozdielnosti $v$ individuálnej predispozicii ku vzniku zhubných nádorov v oblasti hlavy a krku. Možnost' odhalenia genetickej predispozície a identifikácie jedincov so zvýšeným rizikom, môže prispiet' k zlepšeniu prevenčných programov zameraných na zníženie výskytu zhubných nádorov v tejto oblasti. Okrem toho, 
viacero biotransformačných a detoxifikačných enzýmov ako napríklad UGT1A1, ktoré sa potenciálne podielajú na (ochrane proti) vzniku týchto nádorov, sú tiež zapojené do biotransformácie a eliminácie chemoterapeutík a iných liečebných preparátov používaných v liečbe zhubných nádorov. Genetické polymorfizmy v týchto enzýmoch (napríklad UGT1A1*28) môžu ovplyvňovat́ výsledky liečby ako aj nežiaduce účinky používaných liekov, ktoré sa môžu medzi jednotlivými pacientmi výrazne odlišovat'. Znalost' polymorfizmov $v$ génoch kódujúcich tvorbu biotransformačných enzýmov ako aj iných enzýmov a bielkovín podielajúcich sa na tvorbe zhubných nádorov môžeme $v$ budúcnosti využit' nielen na identifikáciu genetickej predispozície, ale aj za účelom optimálnej vol'by liečby pre pacientov so zhubnými nádormi $v$ oblasti horných dýchacích a prehltacích orgánov a iných nádorových ochorení.

Okrem vyššie uvedeného využitia nám môžu výsledky podobne zameraného genetického výskumu pomôct' odhalit' a objasnit' nové biologické pochody vedúce ku vzniku zhubných nádorov $v$ oblasti hlavy a krku, ako aj biologické pochody smerujúce $k$ ochrane proti týmto nádorom. Tieto poznatky môžu poskytnút d'alšie možnosti $v$ prevencii a $v$ liečbe nádorov $v$ tejto lokalite. My sme napríklad našim výskumom preukázali, že geneticky polymorfizmus v UGT1A1 enzýme (UGT1A1*28), ktorý je dôležitý pre konjugáciu a vylučovanie bilirubinu, môže ovplyvnit riziko vzniku zhubného nádoru $v$ oblasti hlavy a krku (prevažne nádorov hrtana) a to hlavne u silných fajčiarov. Následné objasnenie tohto potenciálneho "bilirubinom ovplyvneného proti-nádorového efektu“ nám môže ponúknut' d’alšie možnosti v primárnej a sekundárnej prevencii nádorov v tejto lokalizácii. Identifikácia nových polymorfizmov $v$ génoch zapojených do tvorby zhubných nádorov $v$ oblasti hlavy a krku, [akými sú gény podiel'ajúce sa na obnove nádorotvornými látkami poškodenej bunkovej DNA (DNA-repair) a gény vedúce $k$ naprogramovanému odumretiu rakovinotvorným procesom poškodených buniek (apoptoza)] a odhalenie vysokorizikových kombinácií týchto polymorfizmov, môže ponúknut' nové perspektívy pre našich pacientov.

Nedávno boli dosiahnuté výrazné úspechy v rámci Ĺudského Génového Projektu (Human Genom project), zavŕšeného kompletnou identifikáciou l'udského genetického materiálu, ktorá umožňuje odhalit' stále vzrastajúci počet nových genetických variácií akými sú napríklad jednotlivé nukleotidové polymorfizmy (Single nucleotide polymorphisms-SNPs), tvoriace takmer $80 \%$ medziludských genetických variácií. Tieto poznatky spolu s aplikáciou rozsiahlych výskumov zameraných na zistenie genetických variantov v kompletnom genetickom materiáli 
jednotlivca a vplyv týchto variantov na predispozíciu k zhubným nádorom, (tzv. Genome Wide Association-GWA štúdie) sa budú podiel'at' na urýchlenej identifikácii nových genetických faktorov zasahujúcich do vzniku mnohých ochorení vrátane zhubných nádoroví horných dýchacích a prehĺtacích orgánov. Toto prispeje $\mathrm{k}$ zlepšeniu našich terajších znalostí o individuálnych rozdieloch $v$ predispozicii a zvýšenému riziku vzniku týchto nádorov, čo vyústi pravdepodobne k viac "na mieru šitému“ individuálnemu prístupu v prevencii a liečbe. Dúfajme, že tento nový prístup bude viest' $\mathrm{k}$ zníženiu úmrtnosti pacientov so zhubnými nádormi horných dýchacích a prehĺtacích orgánov, ktorá napriek medicínskym výdobytkom uplynulých desatročí zostáva stále relatívne vysoká.

$\mathrm{Na}$ druhej strane, obsiahla implementácia genetických skríningových testov $v$ multifaktorialne podmienených ochoreniach akými sú aj zhubné nádory v oblasti hlavy a krku, nás bude konfrontovat' s novými etickými otázkami a dilemami: Môže informovanost' o individuálnom vysokorizikovom genetickom profile pomôct' pri uplatnení preventívnych opatrení a zmenit životný štýl jednotlivcov s takýmto rizikovým genetickým profilom? A čo ak nie? Bude znalost' výsledkov skríningových genetických testov ovplyvňovat' politiku zdravotných poistovní voči poistencom $s$ vysokým rizikom k nádorovým ochoreniam a prípadným iným chorobám? Budeme pripravení na prijatie eventuálnej zlej správy o svojom prípadnom vysokorizikovom genetickom profile a dokážeme sa s tým vysporiadat'? Môže sa stat', že jedinci ktorých testy nevykážu vysokorizikový genetický profil budú na základe tejto informácie viac inklinovat' ku škodlivému životnému štýlu (fajčenie, konzumácia alkoholu) a tým práve zvyšovat' svoje riziko vzniku zhubného nádoru v oblasti hlavy a krku? Odpoved' na tieto a d'alšie sporné otázky akými sú spol'ahlivost' a správna interpretácia rýchlo vzrastajúceho počtu komerčne dostupných genetických skríningových testov, bude v dohladnej budúcnosti tvorit' „ výzvu“ pre nás lekárov, ako aj pre našich pacientov. 


\section{Acknowledgment}

I would like to express my gratitude to everyone who contributed to this research project or lent me their support. Without all the people who have helped me, I would not have been able to accomplish this work.

To my promoter, Prof. J.J. Manni, MD, PhD. Dear Hans, it was your brilliant idea born many years ago, to investigate the genetic polymorphisms as a risk modulating factor in head and neck carcinogenesis, which initiated this research. I remember the moment very well in which you asked me, if I was interested in researching the genetic polymorphisms in relation to head and neck cancer susceptibility. Something that, as you optimistically said, could be completed within 2 or 3 years. My answer was yes, and I am happy that we now, (seven years later!) can present our results in this thesis. Thank you very much for all of your effort and for your dedicated coaching on this scientific project. I am also thankful for your devoted and remarkable teaching and coaching at the beginning of my carrier as a head and neck oncologist.

To my co-promoter W.H. Peters PhD: Dear Wilbert, if I could compare our team to a car, you would be the steering wheel, the engine and also, very often, the technician, all embodied in one person. Besides that, you managed to get us the gasoline for free. Thank you very much for everything you did to help this "car" successfully cross the finish line.

To my second promoter, Prof. B. Kremer, MD, PhD: Dear Bernd, as my promoter and the head of our department, you facilitated my research whenever it was possible. By doing so, you created appropriate working conditions for me; for that, I am very grateful.

To A.C. Voogd, PhD: Dear Adri, thank you very much for all your time and effort you spent on the statistical analysis and support of this research. Statistics were not my strong point, but you patiently explained it every time, making it understandable for me. I appreciate it greatly 
To M.B. Oude Ophuis, MD, PhD: Dear Michel, you were my predecessor from whom I took the baton of relay that is research on the genetic predisposition to head and neck cancer. Thank you very much for your support, your wise advice and your involvement in this project.

Dear Hans, Wilbert, Adri and Michel, once again, I will miss the evenings we have spent together in the last years: eating, drinking, discussing and brainstorming about the plans and ideas related to our research, but also just talking about (our) everyday life. Those moments have been inspiring to me.

To H.M. Roelofs, BSc and R.H te Morsche, BSc: Dear Hennie and Rene, you were the brains behind the laboratory work of this project. Thank you both for all your effort related to laboratory analysis of the genetic polymorphisms described in our research. Hennie, thank you also for explaining it to me whenever it was necessary. You did it so well, that even an otorhinolaryngologist could understand it.

My acknowledgment goes to all patients and blood donors giving their permission to be included in this research. Without their willingness to contribute, it would not have been possible for us to perform this research.

Thanks to employees of the Blood bank of the South-East Netherlands and to the employees of the Hematology laboratory at Maastricht University Medical Centre, for your contribution to the logistical support of this project.

I am very thankful to all residents and former residents from our department of Otorhinolaryngology and Head and Neck surgery, for their contribution to include the patients with head and neck cancer in this research.

Thanks to the manuscript and promotional commission for your willingness to critically read the manuscript, for your approval of this thesis and your presence during the defense.

To my colleagues, the medical staff of our department: Dear Bernd, Janny, Jan Wouter, Kenneth, Laura and Robert, thank you very much for your direct and indirect support of my scientific work and your willingness to help whenever it was necessary, but above all, for your understanding and your patience during those 
moments when I was more of a researcher than a clinician. Some of you might find certain recognition in the lasts statement belonging to this thesis.

I am very obliged and thankful to all other colleagues from our department: nonmedical staff (Herman, Jan, Lucien), all co-workers of our out-patients department and related sub-departments, as well as the staff of our office-administration for their support and interest in my work on this thesis.

To my friend and "paranymph" H.P.M. Kunst MD, PhD: Dear Dirk, during our time together as the residents in Nijmegen, I asked you if you would accept my request to be my "paranymph" if I ever had to defend my PhD thesis. The time has come. Thank you for being there for me.

To my younger brother and "paranymph": Dear Marek, I am so happy to have a brother like you. Although you had no idea what it meant to be a "paranymph", and knowing only that it ment supporting and helping your older brother, you did not hesitate to accept the role immediately.

To my parents: Mom and dad, (mami a oci) thanks to your upbringing I had enough endurance and probably also discipline to finish this task. You provide a home for us every time I come back with my family to my fatherland to visit you. I wish this could last forever.

To my younger sister Karolina, other members of my family and my friends in the Netherlands and in Slovakia: thank you very much for your encouragement, interest in my work and all those moments together that make life pleasurable. My highest gratitude goes to my uncle Gabriel, for his support and for being there every time I needed him. I am grateful to my parents in law Mieke and Gert, for taking some of the weight off my shoulders and, in doing so, lowering the pressure of my busy life.

To my wife: Dear Esther, I thought, I would be able to work on my thesis without sacrificing the time I would otherwise spend with my family. As you noticed, I did not succeed. Without your immense support and ability to take care of us, despite to your own busy career, I would not be able to accomplish this work. Thank you for being both my loving partner and my best friend. 
Acknowledgment

To my children: Dear Lukas, Nicolai and Lara, the last page of the book is almost finished; I promise: I will be there more often for you. I am looking forward to do so. 


\section{Curriculum Vitae}

Martin Lacko was born on April 18, 1966 in Banska Bystrica, in central Slovakia. Upon completion of secondary school in 1984 at J.G.Tajovsky Gymnazium, he entered the Jessenius Medical School (a branch of Comenius University in Bratislava) in the city of Martin, in northern Slovakia. He graduated as a Medical University Doctor (MUDr.) in 1990. After serving his military duty as a general practitioner at the Military Academy and Training Centre in Zilina, in 1991, he returned to the University Hospital in Martin. He worked there for a period of almost a year as a physician in the internal medicine, anesthesiology, and general surgery departments, as a part of an obligatory rotation training required from the residents in surgical disciplines. He began his residency in Otolaryngology and Head and Neck Surgery in the same hospital in 1992. In 1995, shortly after he finished his (first degree) specialization training and participated in several international post-residential fellowship programs in Otorhinolaryngology and Head and Neck Surgery, he moved to the Netherlands to join his Dutch wife (then girlfriend) Esther. After obtaining recognition of his medical degree in the Netherlands, he began working as a resident at the department of Otorhinolaryngology in a hospital in Assen (for a short time also in Stadskanaal) in the northern part of the Netherlands. In 1999, he became a resident-in-training at the Department of Otorhinolaryngology and Head and Neck Surgery in St. Radboud University Nijmegen Medical Center (under the supervision of prof. P. van den Broek, prof. C.W.R.J. Cremers and prof. K. Graamans). For the final months of his residency, he moved to Maastricht, where he got the opportunity to broaden his skills in Head and Neck Surgery and Oncology, under the supervision of prof. J.J. Manni at the Department of the Otorhinolaryngology and Head and Neck Surgery of the Maastricht University Medical Centre (MUMC). In this period, he also commenced work on a research project, the results of which are described in this book. After finishing his training in Otorhinolaryngology and Head and Neck Surgery in 2004, he did a 2-year fellowship in Head and Neck Surgery and Oncology at the same department (supervised by prof. J.J. Manni and prof. B. Kremer). Part of this fellowship was also done at the Netherlands Cancer Institute in Amsterdam. Since completing his residency in 2004, he became a staff member of the Department of Otorhinolaryngology and Head and Neck Surgery at the MUMC, with a primary focus on Head and Neck Surgery and Oncology.

Martin is married to Esther and he has three children: Lukas, Nicolai and Lara. 